\title{
ANÁLISE DE FATORES ("FACTOR ANALYSIS") PELO MÉTODO DA MÁXIMA VEROSSIMILHANÇA: aplicação ao estudo da estrutura de florestas tropicais
}

\author{
WALDENEI TRAVASSOS DE QUEIROZ \\ Engo-Flor. - FCAP/MEC
}

Orientador : Dr. CÁSSIO ROBERTO DE MELO GODOI

Tese apresentada à Escola Superior de Agricultura "Luiz de Queiroz", da Universidade de São Paulo, para obtenção do título de Doutor em Agronomia. Área de Concentração: Estatística e Experimentação Agronômica.

\footnotetext{
$P|R A C| C A B A$

Estado de São Paulo - Brasil

Fevereiro - 1984
} 


\section{A Deus}

\section{OFERECO}

\section{A minha esposa Izabel $e$ aos meus bilhos Anderson e Alex.}

Ao meu pai e irmãos 


\section{AGRADECIMENTOS}

- Ā Faculdade de Ciências Agrārias do Pará (FCAP/MEC) e à Escola Superior de Agricultura "Luiz de Queiroz" (ESALQ/USP), pela concessão da o portunidade para realização do curso.

- Ao Dr. Cássio Roberto de Melo Godoi, de um modo especial, pelo incenti vo, amizade e dedicação na orientação deste trabalho.

- Ao Dr. Humberto de Campos, coordenador do curso de Estatística e Expe rimentação Agronômica da ESALQ/USP, por sua acolhida e amizade.

- Aos Professores do Departamento de Matemática e Estatística da ESALQ/ USP, pelos ensinamentos recebidos.

- Ao Dr. Vivaldo Francisco da Cruz e ao Engenheiro Florestal Valter João Diehl, pela.: disposição. na elucidação das dūvidas na elaboração dos programas computacionais.

- Ao Dr. Hilton Thadeu Zarate do Couto, pelas sugestões e amizade.

- Aos companheiros de Curso de Pós-Graduação, pelo Convívio. 
- À CAPES - Coordenação de Aperfeiçoamento do Pessoal de Nível Superior, pela bolsa concedida que proporcionou a realização do curso.

- Ao Extinto Projeto de Desenvolvimento e Pesquisa Florestal (PNUD/FAo/ IBDF/BR-45), pelo suporte financeiro alocado para os trabalhos de cole ta de informações de campo no ano de 1975.

- Aos funcionārios do Departamento de Matemática e Estatística da ESALQ/ USP, pelas disponibilidades e amizade.

- A Srta. Rosa Maria Alves pelo excelente trabalho de datilografia, e aos colegas e amigos que de alguma forma contribuiram para o exito deste trabalho.

- À minha família e à cunhada Lindalva pelo amor, paciência e dedicação. 
LISTA DE TABELAS $\ldots \ldots \ldots \ldots \ldots \ldots \ldots \ldots \ldots \ldots \ldots \ldots \ldots \ldots \ldots \ldots \ldots \ldots$

LISTA DE FIGURAS $\ldots \ldots \ldots \ldots \ldots \ldots \ldots \ldots \ldots \ldots \ldots \ldots \ldots \ldots \ldots \ldots \ldots \ldots$

CURRICULUM VITAE $\ldots \ldots \ldots \ldots \ldots \ldots \ldots \ldots \ldots \ldots \ldots \ldots \ldots \ldots \ldots \ldots$

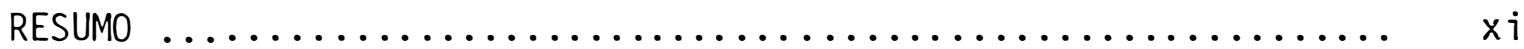

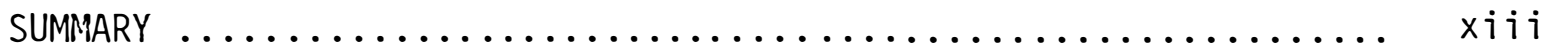

1. INTRODUÇÃO $\ldots \ldots \ldots \ldots \ldots \ldots \ldots \ldots \ldots \ldots \ldots \ldots \ldots \ldots \ldots \ldots \ldots \ldots \ldots \ldots$

1.1. Natureza e importāncia do problema ................ 1

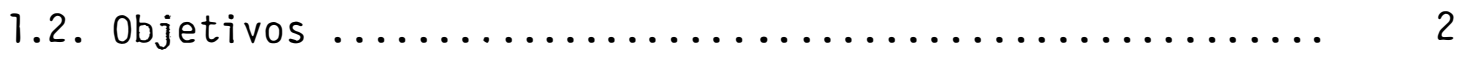

2. REVISÃO DE LITERATURA $\ldots \ldots \ldots \ldots \ldots \ldots \ldots \ldots \ldots \ldots \ldots \ldots \ldots \ldots \ldots \ldots \ldots \ldots \ldots \ldots$

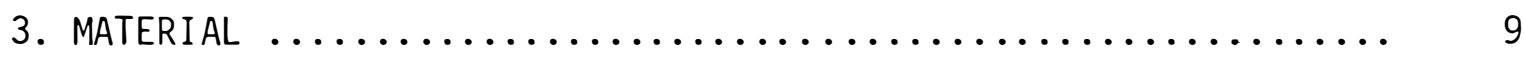

3.1. Caracteristicas do povoamento florestal ............ 9

3.1.1. Localização ........................ 9

3.1.2. Clima, solo e topografia ................ 9

3.1.3. Características da floresta ............... 10

3.1.4. Estrutura de amostragem ................ 11

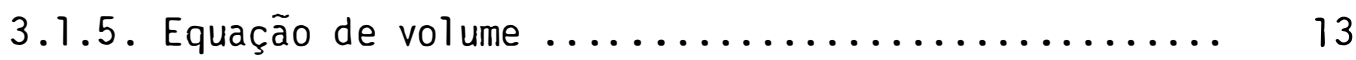

3.1.6. Definição do vetor $\underset{\sim}{x}$ (variāveis respostas) ...... 14

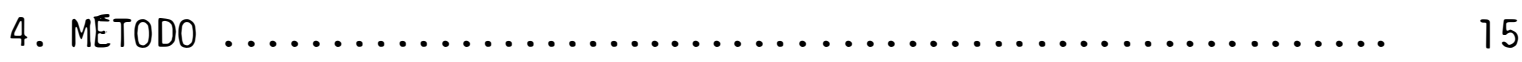

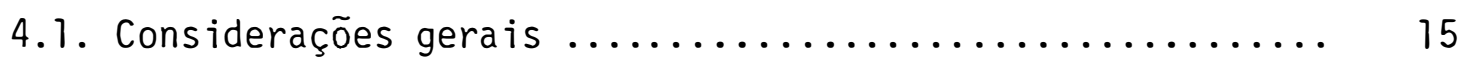

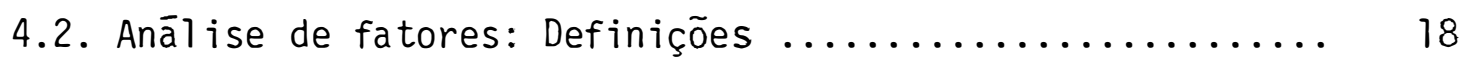

4.3. Método da máxima verossimilhança ............... 22 
4.3.1. Desenvolvimento teōrico ................. 22

4.3.2. Procedimento iterativo para obter as estimativas dos pesos fatoriais $(\bar{A})$ e variāncias espe-

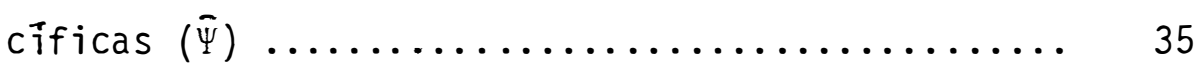

4.3.3. Caso de variāveis sem componente residual ....... 41

4.3.4. Teste de hipōtese .................... 43

4.3.5. Estimação dos escores fatoriais ............ 46

4.3.6. Metodologia dos indices normalizados ......... 48

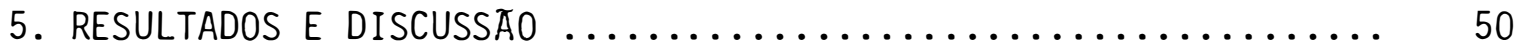

5.1. Matriz das correlações das variāveis respostas ........ 50

5.2. Estimativas de māxima verossimilhança dos pesos fatoriais $\bar{A}$ e variāncias especitficas $\bar{\Psi} \ldots \ldots \ldots \ldots \ldots \ldots$

5.3. Estimativas dos escores dos fatores .............. 52

5.4. Interpretação dos fatores .................... 53

5.5. Mapeamento com respeito aos indices normalizados ...... 56

5.6. Experiéncias com outros procedimentos iterativos ...... 58

6. CONCLUSÖES .............................. 60

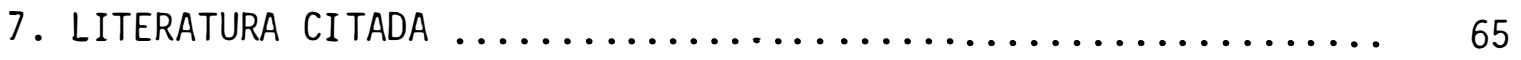

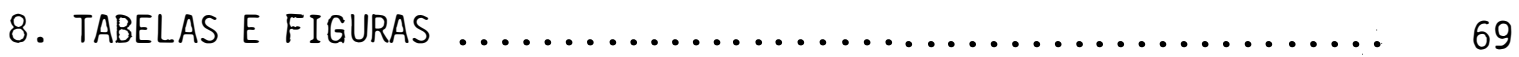

9. APENDICE I - Códigos, classes de importāncia, nomes vulga res e científicos, famîlia botānica das espécies.encontradas . 81 10. APENDICE I I - Matriz dos dados ....................... 91

11. APENDICE III - Valores dos escores fatoriais ........... 94 
vii.

Pāg.

12. APENDICE IV - Valores dos indices normalizados condensando todos os fatores $\ldots \ldots \ldots \ldots \ldots \ldots \ldots \ldots \ldots \ldots \ldots \ldots \ldots$

13. APENDICE V - Listagens do programa principal e subrotinas

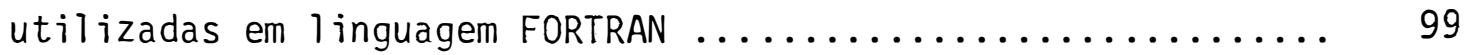

14. APENDICE VI - Diferenciação de matrizes ................. 107 
viji.

\section{LISTA DE TABELAS}

Tabela nọ

Pāg.

1 Matriz de correlação das variāveis respostas........... 70

2 Estimativas de māxima verossimilhança dos pesos fạ toriais $\bar{A}=\left[\hat{a}_{\sim}^{j}\right]$ e variāncias especificas $\bar{\Psi}$ (so luções imprōprias) 70

3 Valores das derivadas parciais de primeira ordem e da função $f_{m}(\Psi)$ apōs 30 iterações .............. 71

4 Estimativas de máxima verossimilhança dos pesos dos fatores $\quad \widehat{A}=\left[\hat{a}_{j}\right]$ e variāncias especîficas $\bar{\Psi}$ (so lução final)

5 Coeficientes dos escores fatoriais $\left(\widehat{A} \bar{A}^{\prime}+\bar{\Psi}\right)^{-1} \widehat{A} \ldots \ldots .72$

6 Estimativas das médias (estratificação pelo fator 1) ... 72

7 Estimativas das médias (estratificação pelo fator 2) ... 73

8 Estimativas das médias (estratificação pelo fator 3 ) ... 73

9 Estimativas das médias (estratificação pelo fator 4 ) .. 74

10 Estimativas das médias (estratificação pelos indices normalizados considerando todos os fatores) . . . . 74

11 Estimativas das médias (estratificação pelos inndices normalizados considerando os fatores 2,3

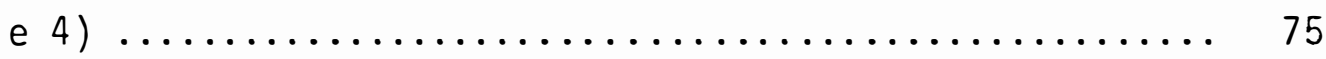




\section{LISTA DE FIGURAS}

Figura nọ

Pāg.

1 Posição geogrāfica da floresta estudada $\ldots \ldots \ldots \ldots \ldots$

2 Caracterização espacial da unidade amostral :con-

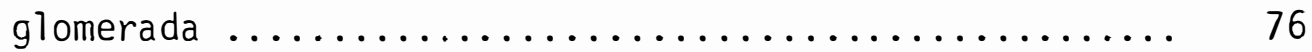

3 Croqui da ārea florestal inventariada ............. 77

4 Mapa caracterizando a estratificação pelo fator $1 \ldots . .78$

5 Mapa caracterizando a estratificação pelo fator $2 \ldots . .78$

6 Mapa mostrando a estratificação pelo fator $3 \ldots \ldots . . .79$

7 Mapa evidenciando a estratificação pelo fator $4 \ldots . . . \quad 79$

8 Mapa evidenciando a estratificação pelos indices

normalizados considerando todos os fatores ......... 80 


\section{CURRICULUM VITAE}

WALDENEI TRAVASSOS DE QUEIROZ, filho de wagner Marques de Queiroz e Erecina Travassos de Queiroz, nasceu a 26 de fevereiro de 1950 em Belém, Pará. Em 1973 concluiu o Curso de Graduação em Engenharia Florestal pela Universidade Federal do Paraná (U.F.P.). Em fevereiro de 1974 foi contratado pelo Projeto RADAMBRASIL para exercer atividades téc nicas em inventários florestais. Em 1975 foi contratado pelo Projeto de Desenvolvimento e Pesquisa Florestal (PNUD/FAO/IBDF/BR-45) para exercer função de Contraparte Nacional de Inventário Florestal. Em 1977 concluiu - Curso de Mestrado em Manejo Florestal pela Universidade Federal do Pa raná, apresentando o trabalho de Dissertação de título: Efeitos da Varia ção Estrutural em Unidades Amostrais na Aplicação do Processo de Amostra gem em Conglomerados nas Florestas do Planalto do Tapajós. Em 1977 foi contratado pela Faculdade de Ciências Agrárias do Pará (FCAP) como Professor do Curso de Engenharia Florestal para ministrar as disciplinas de Biometria e Inventário Florestal. Nessa FCAP, exerceu os cargos de Chefe do Departamento Florestal e Coordenações dos Cursos de Graduação em Enge nharia Florestal e Pós-Graduação a nível de Especialização em Silvicultụ ra e Exploração de Florestas Tropicais. Desde 1979 pertence à Comissão encarregada de traçar diretrizes básicas para o estabelecimento de um Sis tema Nacional de Avaliação dos Recursos Florestais do País - Inventário Florestal - IBDF. Em março de 1981 iniciou o curso de Doutorado em Estatística e Experimentação Agronômica na ESALQ/USP. Possui vārios trabalhos publicados no setor de inventário aplicado ao estudo de florestas naturais. 


\section{ANALISE DE FATORES ("FACTOR ANALYSIS") PELO METODO DA MAXIMA VEROSSIMILHANÇA: ApT icação ao Estudo da Estrutura de Florestas Tropicais}

Autor: WALDENEI TRAVASSOS DE QUEIROZ

Orientador: Dr. CASSIO ROBERTO DE MELO GODOI

RESUMO

Estudou-se a operacionalidade do estabelecimento do método da máxima verossimilhança na análise de fatores, direcionando-o com o fim de caracterizar em detalhes a estrutura de um povoamento florestal tropical de 5.324,04 hectares, localizado na Floresta Nacional do Tapajōs.

A floresta foi dividida em 51 subpopulações de 104,04 hectares cada uma, nas quais implantou-se uma unidade conglomerada composta de quatro subunidades de 1 (um) hectare cada. Mediu-se nas subunidades as seguintes características:
ALT : altura comercial média (m)
VOLT: volume total sem casca $\left(\mathrm{m}^{3} / \mathrm{ha}\right)$
DAP : diâmetro a $1,30 \mathrm{~m}$ do solo 
xii.

VOLl: volume sem casca $\left(\mathrm{m}^{3} / \mathrm{ha}\right)$ das espécies com mercado de exporta ção definido.

VOL2: volume sem casca $\left(\mathrm{m}^{3} / \mathrm{ha}\right)$ das espécies estabelecidas no merca do nacional.

VOL3: volume sem casca $\left(\mathrm{m}^{3} / \mathrm{ha}\right)$ das espécies ocasionalmente emprega das no mercado local e as de valor potencial.

A partir das interpretações dos pesos dos fatores ortogonais relativos à matriz de correlações, concluiu-se sobre os efeitos das características envolvidas e suas interrelaçōes. Outrossim, com base no significado florestal dos fatores produziu-se mapas, os quais, trazem informações importantes que poderão orientar o planejamento de diversas atividades florestais, principalmente no que concerne à elaboração de planos de explorações madeireiras.

No referente à obtenção de mapas construídos a partir de uma pós-estratificação multidimensional, através da aplicação da meto dologia dos índices normalizados definidos como o módulo da resultante da soma vetorial dos escores dos fatores ponderados pela contribuição de cada fator à comunalidade total, mostrou-se consistente, eficiente e ope racional.

Aspéctos relevantes sobre amostragens são abordados no sentido de atender aos objetivos de caracterizar realmente a estrutura da floresta tropical.

Em face da inexistência de "pacotes" do método da máxi ma verossimilhança da análise de fatores nestes estudos, apresentou-se o desenvolvimento teórico e um programa em FORTRAN operacionalmente precí so e otimizado quanto ao tempo de execução. 


\section{FACTOR ANALYSIS BY MAXIMUM LIKELIHOOD ESTIMATION \\ METHOD: An Application on the Study of the Struc ture of a Tropical Forest}

Author: WALDENEI TRAVASSOS DE QUEIROZ

Adviser: Dr. Cássio Roberto de Melo Godoi

SUMMARY

An algorithm for maximum likelihood estimation method was impplemented based on Newton-Raphson numerical method in Factor Ana lysis directed to characterize in detail the structure of a tropical fo rest of $5.324,04$ ha, located at Tapajós National Forest.

The forest wasdivided in 51 subpopulations of 104,04 ha each, where clustered samples were stablished composed of four subunits of 1 ha each. The following data were collected:
ALT : averaged commercial height $\left(\mathrm{m}^{3} / \mathrm{ha}\right)$
VOLT: total barkless volume $\left(\mathrm{m}^{3} / \mathrm{ha}\right)$
DAP : $1,30 \mathrm{~m}$ from ground diameter
VOL1: barkless volume of export comercial class $\left(\mathrm{m}^{3} / \mathrm{ha}\right)$
VOL2: barkless volume of national commercial class $\left(\mathrm{m}^{3} / \mathrm{ha}\right)$
VOL3: barkless volume of local and potentialy valueble class $\left(m^{3} / h a\right)$ 
xiv.

From the orthogonal factor weights with respect to the correlations matrix, conclusions were obtained about the importan ce of the observable variables and their interelations. Furthermore, based on the forest interpretations of the factors, charts were designed to classify the subunits in view of the planning of forest manegement, specially with respect to those activities related to wood exploitation.

In designing the charts the multimendional normalized index was used as a criterio of unit classification, defined as the norm of the vector resultant of the individual factor scores, weighted by the corresponding part of the total communality.

Relevant aspects about sampling are treated with the scope of a real characterization of the tropical forest structure.

In view of the inexistence of confiable "packages" with detailed description of the calculation programs of the maximum likeli hood method in factor analysis, the theoretical methodology and FORTRAN programs are included with complete data description and detailed examples exhxibitted. 
1. INTRODUÇAOO

1.1. Natureza e importāncia do problema.

Os inventários florestais efetuados na região Amazônica geralmente produzem mapas tipológicos alicerçados sob uma estratificação estabelecida mediante pré interpretação de foto-coberturas, as quais, mui tas vezes, não correspondem aos tipos florestais existentes. Esta situação se verifica particularmente no uso de imagens radar ou satélite.

As fotos radar e satélite, muitas vezes, geram interpretações que conduzem a definição de estratos que abrangem mais de um tipo florestal e normalmente nem permitem distinguir e definir os limites es paciais entre tipos florestais diferentes. Seguramente, essas imagens não oferecem subsídios suficientes para atingir-se uma estratificação ótima em função da complexidade da tipologia florestal tropical.

Entrementes, a obtenção de mapas tipológicos através de fotografias aéreas em escala ideal ( 1 : 10.000 a 1 : 5000) seria extrema mente oneroso . 
E notório que até o momento não se verificou na Amazônia brasileira, nenhuma aplicação a nível operacional de sistemas de ma nejo auto-sustentado, dirigida para comprovação da viabilidade econômica e ein consequência, pode-se afirmar que não existem inventários florestais que atendam objetivamente esse propósito.

Inventārios florestais delineados a atender à planifica ção de técnicas de manejo florestal de rendimento auto-sustentado, obrigatoriamente devem sintetizar e explicar todas as variāveis que compõem a estrutura florestal, e concluir sobre as suas interrelações. Assim, de vem ser considerados na anālise os segmentos fito-sociológicos, as dinâa micas de crescimento das espécies e a associação entre os aspectos ecoló gicos e econômicos.

Do exposto, surge a necessidade do estabelecimento de me todologias eficientes e não onerosas visando caracterizar em detalhes a estrutura das florestas tropicais, instrumento obrigatório para o planeja mento de qualquer projeto de manejo auto-sustentado.

\subsection{Objetivos}

Devido ao nümero de variāveis requeridas para tornar pos sível caracterizar a estrutura das florestas tropicais, as quais estão interrelacionadas, depreende-se que conclusões adequadas só serão factîveis se essas informações multidimensionais forem investigadas sob os a pectos da anālise estatística multivariada. 
Preocupou-se em desenvolver um trabalho operacionalmente dirigido para ser entendido e utilizado por especialistas em manejo de florestas tropicais. Assim, os objetivos primordiais a serem desenvolvidos nesta pesquisa são:

1.2.1. Apresentar os fundamentos teóricos do método da máxima ve rossimilhança da análise de fatores, tornando-o viável computacionalmente.

1.2.2. Estabelecer metodologia de pós-estratificação multidimensional fundamentada na análise de fatores (método da máxima verossimilhan ça) para um conjunto de características florestais, visando a obter mapas tipológicos para um povoamento de 5.324,04 hectares, localizado na região do planalto da Floresta Nacional do Tapajós.

1.2.3. Apresentar recomendações sobre técnicas de amostragem ade quadas e propor próximas pesquisas para solucionar satisfatoriamente os problemas centrais expostos. 


\section{REVISÃO DE BIBLIOGRAFIA}

SPEARMAN (1904) apresenta pela prrmerra vez uma teoria sobre anālise de fatores. O autor obtém um fator "g". A variável hipotéti ca "g" explicaria as interrelações de uma série de características congenitivas.

BARTLETT (1962) observa que a fatoração da matriz de dis persao proposta por SPEARMAN (1904) apresenta-se inadequada, pois, confi gura somente um fator comum, quando na realidade deveriam ser introduzidos mais fatores comuns no modelo.

LAWLEY (1940) aborda originalmente o problema da estimaçao na anālise de fatores, tornando-a um método estatístico propriamente dito. O autor emprega o método da máxima verossimilhança para estimar os parâmetros do modelo fatorial $\underset{\sim}{x}=A \underset{\sim}{f}+e$, mostrando que as estimativas dos pesos fatoriais $(\widehat{A})$ e as estimativas das variâncias específicas $\widehat{\Psi}$ onde,

$$
\underset{\sim}{E}\left(e_{\sim} e^{\prime}\right)=\Psi
$$


são soluções das seguintes equações matriciais implícitas:

$$
\begin{aligned}
& \widehat{\Psi}=\operatorname{diag}\left(S-\widehat{\mathrm{A}} \hat{A}^{\prime}\right) \text { e } S \widehat{\Psi}^{-1} \widehat{A}=\widehat{A}\left(I+\widehat{A}^{\prime} \hat{\Psi}^{-1} \widehat{A}\right) \\
& S={ }_{p}\left[s_{i j}\right]_{P}: \text { matriz de covariâncias amostrais de } \underset{\sim}{x} .
\end{aligned}
$$

Demonstra também que

$$
\log _{e} \frac{\left|\Psi+A A^{\prime}\right|}{|S|}
$$

é aproximadamente a soma de quadrados dos seguintes resíduos:

$$
\sum_{i<J} \frac{\left(s_{i j}-\sigma_{i j}\right)^{2}}{\Psi_{i} \Psi_{j}}
$$

onde:

$$
\begin{aligned}
\sigma_{i j} & =\sum_{h=1}^{m} a_{i h} a_{j h} \quad(i \neq j) \\
A & ={ }_{p}\left[a_{i j}\right]_{m}
\end{aligned}
$$

$s_{i j}$ : é a covariância ou correlação entre as variáveis respostas $x_{i} \quad$ e $x_{j}$ 
O teste estatístico aproximado obtido pelo autor para ve vificar se o número de fatores m está adequado para o modelo fatorial é:

$$
X^{2}=\left[N-1-\frac{1}{6}(2 p+5)-\frac{2}{3} m\right] \sum_{i<j} \sum_{j} \frac{\left(s_{i j}-\sigma_{i j}\right)^{2}}{\Psi_{i} \Psi_{j}}
$$

A referida estatística possui distribuição assintótica $\underline{i}$

dêntica a:

$$
x^{2}=\left[N-1-\frac{1}{6}(2 p+5)-\frac{2}{3} m\right] \log _{e} \frac{\left|\Psi+A A^{\prime}\right|}{|S|}
$$

$\mathrm{N}$ : nümero de observações.

LAWLEY (1942, 1943) apresenta um método iterativo para resolução das equações matriciais implícitas de máxima verossimilhança. Tal procedimento, contudo possui fraca convergência e pouca precisão. 0 método proposto é inicializado a partir de pesos fatoriais arbitrários e caso sejam mal escolhidos comprometem a eficiência do procedimento.

HARMAN (1976) indica que os pesos fatoriais computados pe lo método matemático de "MINRES" poderão ser bons iniciadores para o método de LAWLEY (1942, 1943).

Tambēm introduz uma modificação no método de LAWLEY (1942). O autor não descarta meramente os elementos fora da diagonal da matriz $\Delta=\mathrm{A}^{\prime} \Psi^{-1} \mathrm{~A}$, mas a diagonaliza.

RAO (1955) e MAXWELL (1964) adotam um procedimento para a resolução numérica das equações matriciais de máxima verossimilhança com boa propriedade de convergência. O procedimento está descrito em detalhes em MORRISON (1976). 
JÖRESKOG (1963) justifica, e a prática tem demonstrado, que a utilização nos processos iterativos das variâncias específicas in ciais calculadas pela expressão abaixo, reduzem o nümero de iterações ne cessārias para atingir-se a convergência.

$$
\Psi_{i}=\frac{1}{s^{i i}}\left(1-\frac{m}{2 p}\right)
$$

onde:

$\mathrm{S}^{\mathrm{i} i}$ : í-ésimo elemento diagonal da matriz $\mathrm{s}^{-1} \cdot(i=1, \ldots, \mathrm{p})$

$\mathrm{m}$ : nümero de fatores.

$\mathrm{p}$ : nümero de variāveis.

JÖRESKOG (1966) desenvolve um método computacional itera tivo com boa convergência para resolução das equações matriciais implícitas de máxima verossimilhança.

BARTLETT (1937, 1938) apresenta um método para avaliação dos escores fatoriais através da minimização da soma de quadrados dos re síduos padronizados com respeito aos elementos de $\underset{\sim}{f}$. Ou seja,

$$
\sum_{i=1}^{p} \frac{e_{i}}{\Psi_{i}}=\stackrel{e}{\prime}^{\prime} \Psi^{-1} \underset{\sim}{e}=(\underset{\sim}{x}-\underset{\sim}{A f})^{\prime} \Psi^{-1}(\underset{\sim}{x}-A f)
$$

onde, diferenciando com respeito a $\underset{\sim}{f}$ e igualando a zero, resulta:

$$
\underset{\sim}{\underline{f}}=\Delta^{-1} A^{\prime} \Psi^{-1} \underset{\sim}{x} \quad \Delta=A^{\prime} \Psi^{-1} A
$$


FACHEL (1976) cita um estudo de autoria do Eng? Nicolas Botto Corrêa, da SERETE ENGENHARIA, SP, o qual utiliza com pleno éxito o método do fator principal de análise de fatores na hierarquização de 98 municípios do Estado de Minas Gerais, visando estabelecer as regiões prioritárias em termos de investimento em saneamento básico.

o critério de classificação dos municípios ficou estabelecido através da construção de um índice definido como o módulo da resul tante da soma vetorial dos escores fatoriais em cada município, pondera dos pela contribuição dos respectivos fatores à comunalidade total. 


\section{MATERIAL}

\subsection{Caracteristicas do povoamento florestal.}

\subsubsection{Localização}

Conforme mostra a figura 1 o povoamento florestal, objeto desta pesquisa, localiza-se na Floresta Nacional do Tapajós, no Municí. pio de Santarém, Estado do Pará. Inicia-se a 1500 metros do km 62 da rodo via BR-165 no sentido leste-oeste, estendendo-se no sentido norte-sul até o ponto localizado a $3,3 \mathrm{~km}$ no sentido 1 este-oeste do $\mathrm{km} 73$ aproximadamen te, abrangendo uma área de 5.324,04 ha.

3.1.2. Clima, solo e topografia

Segundo LIMA e SANTOS (1976), o clima da região, de acor do com a classificação de Köppen, insere-se no grupo A englobando os tipos climáticos Afi, Ami e Awi. Esse grupo é caracterizado por climas tro 
picais úmidos, sem estação fria e com temperatura quente de baixa amplitu彑 de anual, onde a mínima média mensal anual é $16^{\circ} \mathrm{C}$ e a máxima média mensal anual é $34^{\circ} \mathrm{C}$. A umidade relativa média gira em torno de $31 \%$ e o indice pluviométrico varia entre $1000 \mathrm{~mm}$ a $3600 \mathrm{~mm}$.

De acordo com BRASIL (1977), o solo é do tipo latossolo amarelo distrófico com mais de $70 \%$ de argila no horizonte B. O relêvo na maior parte da área é predominantemente plano.

\subsubsection{Características da floresta}

Trata-se basicamente de uma floresta alta e relativamente aberta, apresentando poucas árvores com grandes diâmetros e distribuí das aleatoriamente. Encontram-se, contudo, manchas com estrutura mais fe chada e apresentando maior adensamento de ärvores pertencentes às classes superiores de diâmetros.

A variação interna do conjunto florestal abrange áreas que fisionomicamente se aproximam estruturalmente às matas com árvores $\underline{e}$ mergentes. Há ocorrências de pequenas manchas de matas cipoálicas que pro vavelmente são representativas de estāgios dinâmicos.

CARVALHO (1982) afirma que na área foram processadas ex plorações seletivas, resultando na extração de espécies de alto valor co mercial, tais como o pau rosa (Aniba duckei, Kostermans), o cedro verme1ho (Cedrela odorata, L.), a maçaranduba (Manilkara huberi, Standley), em pobrecendo a composição florística. 
o povoamento florestal congrega ärvores com diâmetros (DAP) de até $180 \mathrm{~cm}$ e considerando-se ārvores com DAP maior ou igual a $30 \mathrm{~cm}$ abrange mais de 170 espécies.

As seis espécies que apresentaram os maiores volumes sem casca foram:

ESPECIE

Erisma uncinatum, Warm.

Holopyxidium jarana, Ducke

Manilkara huberi, Ducke

Berthollettia excelsa, HBK

Espécie não identificada (cōdigo 84)

Hyminea courbaril, L.
VOLUME $\mathrm{EM} \mathrm{m} \mathrm{m}^{3} / \mathrm{ha}$

$$
10,449
$$

9,342

6,676

$6,57 c$

6,295

6,040

No apêndice I estão descritos os códigos, classes de im portância, nomes vulgares e científicos, família botânica das espécies en contradas.

3.1.4. Estrutura de amostragem

As informações a serem analisadas nesta pesquisa, foram inventariadas pelo autor, quando desenvolvia atividades científicas no Pro jeto de Desenvolvimento e Pesquisa Florestal (PNUD/FAO/IBDF/BR-45), atual mente vinculado à EMBRAPA. 
O povoamento florestal de 5.324,04 hectares foi dividido em 51 subpopulações formando quadrados de 104,04 hectares (unidades primá rias). Implantou-se sistematicamente em cada unidade primária uma unidade amostral conglomerada de quatro hectares, agregando quatro subunidades re tangulares orientadas na forma de cruz para os sentidos norte-sul e leste-oeste (unidades secundārias). As unidades secundárias apresentam as se guintes dimensões: largura de 20 metros e 500 metros de comprimento. A fi gura 2 mostra a caracterização espacial da unidade amostral conglomerada. Para facilitar a visualização mostra-se na figura 3 um croqui da ārea florestal definindo a localização das subunidades amostrais no conjunto do plano de amostragem. Codificou-se as subunidades por uma numeração em que o primeiro dígito associa-se ao eixo $\mathrm{Y}$, os dois dígi tos intermediários relacionam-se ao eixo $\mathrm{X}$, o quarto dígito caracteriza a orientação geográfica da subunidade definidas como: oeste: 1, norte: 2 , leste: 3 e sul: 4 .

Identificou-se e mensurou-se em todas as subunidades as seguintes características por ärvore:

- identificação botânica

- diâmetro a 1,30 m do solo (DAP)

- altura comercial até a primeira bifurcação ou até o diâmetro mínimo de $7 \mathrm{~cm}$. 


\subsubsection{Equação de volume}

As estimativas dos volumes individuais por ārvore foram calculadas pela análise de regressão. A equação volumétrica baseou-se na coleta aleatória de 110 ārvores, contudo, distribuídas de forma balancea da nas diversas classes de diâmetros de $10 \mathrm{em} 10 \mathrm{~cm}$.

Para calcular o volume real sem casca mediu-se os diâme tros com casca de 2 em 2 metros de fuste e, conjuntamente, as respectivas espessuras duplas de casca, DAF com casca e altura comercial. 0 volume real sem casca, a partir desses dados, foi calculado pelo Método de SMALIAN .

Definindo o volume sem casca como variävel dependente V e o DAP com casca ao quadrado multiplicado pela altura comercial como a variāvel independente, calculou-se a regressão linear simples

$$
\widehat{\mathrm{V}}=\hat{\mathrm{a}}+\overline{\mathrm{b}}\left(\mathrm{DAP}^{2} \mathrm{H}\right)
$$

Os resultados pelo processo dos mínimos quadrados foram:

$$
\begin{aligned}
& \hat{a}=0,0774759688 \\
& \hat{b}=0,517896768 \\
& \mathrm{R}^{2}=0,9652 \text { (coeficiente de determinação) } \\
& \mathrm{F}=2994,78 \text { (teste } \mathrm{F} \text { da regressão linear). }
\end{aligned}
$$




\subsubsection{Definição do vetor $\underset{\sim}{x}$ (variāveis respostas)}

A partir das informações coletadas no campo e da equação de volume sem casca por árvore, determinaram-se os valores das seguintes variāveis respostas, por subunidade conglomerada:

ALT : altura comercial média, por subunidade.

VOLT: volume total sem casca, por subunidade.

DAP: diâmetro médio com casca, por subunidade.

VOL 1: volume sem casca, por subunidade das espécies pertencentes à classe I, ou sejam, as espécies com mercado de exportạ ção definido segundo QUEIROZ (1977).

VOL 2: volume sem casca por subunidade das espécies pertencentes à classe II, ou sejam, as espécies estabelecidas no merca do nacional segundo QUEIROZ (1977).

VOL 3 : volume sem casca por subunidade das espécies pertencentes à classe III, ou sejam, as espécies ocasionalmente empregadas no mercado local e as de valor potencial segundo QUEIROZ (1977).

No apêndice I, apresentam-se as espécies pertencentes às classes I, II e III.

No apêndice II, incluem-se os respectivos valores dessas variāveis (Matriz dos dados). 
15.

4. METODO

\subsection{Considerações gerais}

Comumente ocorrem nos levantamentos e experimentos, mensurações compostas de várias características obtidas em uma mesma unidade amostral, dificultando a interpretação da pesquisa. Assim, è recomendāvel uma exploração dos dados visando simplificá-los, porém, conservando ao máximo as informações inerentes às variáveis respostas originais.

Para tratar do problema da diminuição da dimensão do vetor de dados na estatística multivariada, normalmente utilizam-se as técnicas de componentes principais e análise de fatores. Esses métodos vi sam gerar um nümero menor de variāveis hipotéticas, combinações lineares das variáveis originais, tal que, mesmo em menor número expliquem adequadamente a interdependência do conjunto original multidimensional dos da dos. 
Consiste a análise dos componentes principais em: dado um conjunto de variáveis aleatórias obter por transformação linear um nú mero igual de novas variáveis não correlacionadas (componentes principais), tal que a soma das variâncias seja invariante.

Por outro lado, no caso dos primeiros componentes princi pais explicarem parte significativa da variância total, pode-se então ava liá-los para cada indivíduo ("score") ou unidade de amostra e processā-los nas anālises em substituição às variáveis originais.

A anālise de fatores estuda as relações internas de um conjunto de variáveis aleatórias, substituindo-as por um número menor de variāveis hipotéticas denominadas fatores, que podem ser correlacionados (fatores oblíquos) ou não correlacionados (fatores ortogonais). Esses fatores devem explicar parte significativa da variância do conjunto das: va riāveis originais.

Existem algumas similaridades entre as análises de fato res e de componentes principais. Ambas iniciam-se com um modelo linear e encerram-se com a fatoração da matriz de covariâncias ou correlações. Con tudo, na análise dos componentes principais a fatoração da matriz é ünica se todos os componentes de variância são diferentes. Entretanto, na a nálise de fatores a fatoração da matriz não seră única, pois, por transformação ortogonal (rotação) um número infinito de matrizes de pesos fa toriais podem ser obtidas para reproduzir a matriz de covariancias ou correlações das variáveis respostas. 
A equação básica do modelo linear dos componentes princí pais não possui componente residual, propriedade essa que a diferencia mar cantemente da análise de fatores.

Uma grande desvantagem da anālise dos componentes principais é que os componentes oriundos da matriz de correlações não são os mesmos computados sob a matriz de covariâncias. Entrementes, as estimativas de máxima verossimilhança dos parâmetros da análise de fatores gozem da importantíssima propriedade: mudança nas escalas das variāveis originais somente implicam modificação na escala dos pesos fatoriais. Particularmente, os valores dos pesos obtidos da matriz de correlações diferem dos pesos computados da matriz de covariâncias pelo fator

$$
\begin{aligned}
& I_{i} \quad(i=1, \ldots, p) \\
& s_{i}: \quad \text { desvio padrão da variável resposta } x_{i},
\end{aligned}
$$

onde $\mathrm{p}$ é o número de variáveis originais, propriedade não apresentada pelos componentes principais.

$\mathrm{Na}$ anālise de fatores existem outros métodos de estimação além da máxima verossimilhança, entretanto, são essencialmente não es tatísticos e consequentemente sem as características probabilísticas dese jāveis. Destacam-se entre esses métodos os seguintes: solução bi-fatorial, solução do fator principal e o método dos centróides. HARMAN (1976) e MULAIK (1972) descrevem em detalhes os princípios e procedimentos operacionais para a obtenção dos pesos fatoriais e variâncias específicas para es ses métodos. 


\subsection{Anālise de fatores: definições}

Seja o modelo m-dimensional linear

$$
x_{i}=\sum_{j=1}^{m} a_{i j} F_{j}+e_{i}(i=1, \ldots, p)
$$

escrito na forma matricial:

$$
\underset{\sim}{x}=\underset{\sim}{A f}+\underline{e}
$$

$\underset{\sim}{x^{\prime}}=\left(x_{1}, x_{2}, \ldots, x_{p}\right):$ vetor correspondente às variáveis respostas observadas.

$\underline{\sim}^{\prime}=\left(F_{1}, \ldots, F_{m}\right)$ : vetor correspondente aos fatores comuns (variáveis hipotéticas) aleatōrios, independentes e de variâncias iguais a um.

$\mathrm{e}^{\prime}=\left(\mathrm{e}_{1}, \mathrm{e}_{2}, \ldots, \mathrm{e}_{\mathrm{p}}\right)$ : vetor correspondente aos resíduos específicos aleatórios de média zero.

$A=\left[a_{i 1}, a_{i 2}, \ldots, a_{i m}\right]:$ é a matriz dos pesos correspondentes à i-ésima variāvel resposta e ao j-ésimo fator, sendo m o nư mero de fatores do modelo. $(m \leq p)$. 
Seja a matriz $Z=\left[\sigma_{i j}\right]$ definida positiva de ordem $p$ das covariâncias de $\underset{x}{x}$

Suponham-se as seguintes pressuposições:

$$
\begin{aligned}
& E\left(\sim_{\sim}^{f} \underline{e}^{\prime}\right)=\phi \\
& E\left(\underset{\sim}{f} \underline{\sim}^{\prime}\right)=m^{I} m \\
& E\left(\underline{\sim}_{\mathrm{e}^{\prime}}\right)=\mathrm{p}_{\mathrm{p}}^{\Psi^{\prime}}=\operatorname{diag}\left(\Psi_{1}, \Psi_{2}, \ldots, \Psi_{\mathrm{p}}\right)
\end{aligned}
$$

Do exposto, pelas pressuposições acima,

$$
\begin{aligned}
& Z=E\left(\underset{\sim}{x} \underline{\sim}^{\prime}\right)=E\left[(\underbrace{f}_{\sim}+e)(A \underset{\sim}{f}+\underset{\sim}{e})^{\prime}\right] \\
& =E\left[(A \underset{\sim}{f}+e)\left(f_{\sim}^{\prime} A^{\prime}+e^{\prime}\right)\right] \\
& =A E\left(\underset{\sim}{f} \underline{\sim}^{\prime}\right) A^{\prime}+E\left(\underset{\sim}{e} \underline{\sim}^{\prime}\right) \\
& =\mathrm{AA}^{\prime}+4
\end{aligned}
$$

Conclue-se que a matriz de covariância de $\underset{\sim}{x}$ sob o mode 1o fatorial $\underset{\sim}{x}=\underset{\sim}{A f}+\underset{\sim}{e}$ :

$$
\Sigma=\mathrm{AA}^{\top}+\Psi
$$

onde 


$$
\begin{aligned}
& v\left(x_{i}\right)=\sigma_{i i}=a_{i_{1}}^{2}+a_{i_{2}}^{2}+\ldots+a_{i m}^{2}+\Psi_{i} \\
& \operatorname{cov}\left(x_{i}, x_{j}\right)=\sigma_{i j}=a_{i_{1}} a_{j 1}+a_{i_{2}} a_{j 2}+\ldots+a_{i m} a_{j m}
\end{aligned}
$$

Denominam-se comunalidades das variáveis $x_{i}(i=1, \ldots, p)$ os elementos diagonais da matriz $\mathrm{AA}^{\prime}$ :

$$
\sum_{j=1}^{m} a_{i j}^{2}=\sigma_{i i}-\Psi_{i}
$$

Denota-se que, se obedecidas as pressuposições definidas anteriormente, tem-se que os parâmetros $a_{i j}$ corresponderão às covariâncias entre $X_{i}$ e $F_{j}$. Em consequência, se $Z$ exprimir a matriz das cor relações entre as variáveis observáveis, os $a_{i j}^{\prime} s$ expressarão os coeficientes de correlação entre $X_{i}$ e $F_{j}$, pois,

$$
\begin{aligned}
\operatorname{COV}\left(\underset{\sim}{x}, \underset{\sim}{f^{\prime}}\right) & =E\left[\left({\underset{\sim}{f}}^{f} \underset{\sim}{e}\right) f^{\prime}\right] \\
& =A E\left(\underset{\sim}{f}{\underset{\sim}{f}}^{\prime}\right)+E\left(\underset{\sim}{e}{\underset{\sim}{f}}^{\prime}\right) \\
& =A
\end{aligned}
$$

No caso dos fatores comuns serem correlacionados (fatores oblíquos) ou apresentarem variâncias não unitárias, a matriz de covariâncias de $\underset{\sim}{x}$ sob o modelo fatorial m-dimensional $\underset{\sim}{x}=\underset{\sim}{A f}+\underset{\sim}{e} \operatorname{será}$ da do por:

$$
Z=\mathrm{A} \Gamma \mathrm{A}+\Psi \quad \text { onde: } \Gamma=E\left(\underset{\sim}{\mathrm{f}} \underline{\sim}^{\prime}\right) \quad 4.2 .3
$$


Observe-se que as equações $4.2 .1,4.2 .2$ e 4.2 .3 são in variantes sob transformações ortogonais não singulares dos fatores. Essas expressões não são alteradas quando das substituições de $\underset{\sim}{f}$ por $\underset{\sim}{\underset{\sim}{f}}$ A por $A M^{\prime}$ e $\Gamma$ por $M \Gamma M^{\prime}$, onde $M$ é uma matriz ortogonal de ordem cor respondente ao número de fatores, pois,

a)

$$
\begin{aligned}
\underset{\sim}{\mathrm{x}} & =\mathrm{AM}^{\prime}(\underset{\sim}{\mathrm{M}})+\underset{\sim}{\mathrm{e}} \\
& =\mathrm{A}\left(\mathrm{M}^{\prime} \mathrm{M}\right) \underset{\sim}{\mathrm{f}}+\underset{\sim}{\mathrm{e}} \\
& =\mathrm{Af}+\underline{\sim}
\end{aligned}
$$

b) $\quad Z=\left(A M^{\prime}\right)\left(M A^{\prime}\right)+\Psi$

$$
=\mathrm{AA}^{\prime}+\Psi
$$

c) $\quad Z=A M^{\prime}\left(M \Gamma M^{\prime}\right) M A^{\prime}+\Psi$

$$
\begin{aligned}
& =A^{\prime}\left(M^{\prime} M\right) \Gamma\left(M^{\prime} M\right) A^{\prime}+\Psi \\
& =A \Gamma A^{\prime}+\Psi
\end{aligned}
$$


4.3. Método da máxima verossimilhança

\subsubsection{Desenvolvimento teórico}

Considera-se na aplicação do método da máxima verossimilhança em análise de fatores que $\underset{\sim}{f}$ (vetor dos fatores comuns) e e (ve tor dos resíduos específicos) são independentes e multinormalmente distri buídos com vetor de médias nulas (sem perda de generalidade) e respectiva mente com matrizes de covariâncias $\mathrm{m}^{\mathrm{I}} \mathrm{m}$ e $\mathrm{p}_{\mathrm{p}}^{\Psi}$.

Não obstante, sendo $\underset{\sim}{x}$ formado por funções lineares de $\underset{\sim}{\mathrm{f}} \mathrm{e} \underset{\sim}{\mathrm{e}}$, então $\underset{\sim}{\mathrm{x}}$ é multinormalmente distribuído com matriz de covariân cia $Z=\mathrm{AA}^{\prime}+\Psi$ e, sem perda de generalidade, com vetor de médias nulas.

Seja $S=\left[s_{i j}\right]$ a matriz usual de covariância amostral, tal que $E(S)=Z$ e computada de uma amostra aleatória de $N(>p)$ observações de $\underset{\sim}{x}$. Então, os elementos de $\mathrm{S}$ ou de n S seguem a distribuição de Wishart (ANDERSON, 1958) com $\mathrm{n}=\mathrm{N}-1$ graus de liberdade.

$$
f(s)=c|s|^{\frac{1}{2}(n-p-1)}|z|^{-\frac{1}{2} n} \text { exp }\left(-\frac{1}{2} n \operatorname{tr} s z^{-1}\right) \quad 4.3 .1
$$

Seja o logarítmo neperiano da função de verossimilhança de $\mathrm{S}$, omitindo-se os termos independentes de $\mathrm{A}$ e $\Psi$. 


$$
\log _{e} L(A, \Psi)=-\frac{1}{2} n\left[\log _{e}|Z|+\operatorname{tr}\left(S Z^{-1}\right)\right]
$$

Por razões que se tornarão evidentes posteriormente, è conveniente minimizar a função:

$$
F_{m}=\log _{e}|z|+\operatorname{tr}\left(S z^{-1}\right)-\log |s|-p
$$

Tal procedimento é equivalente a maximizar a expressão 4.3.2, desde que $\log _{e} L(A, \Psi) \quad \bar{e}-\frac{1}{2} n$ vezes $F_{m}$ mais uma função (constante) das observações. O indice m indica o número de fatores.

Quanto às operações matriciais de diferenciação, conforme o apêndice VI, obtēm-se:

$$
\begin{aligned}
& \frac{\partial \mathrm{F}_{\mathrm{m}}}{\partial Z_{i i}^{-1}}-\left(Z^{-1} \mathrm{~S} Z^{-1}\right)_{i i}=\left[Z^{-1}(Z-S) Z^{-1}\right]_{i i} \\
& \partial \sigma_{i i} \\
& \frac{\partial F_{m}}{\partial \sigma_{i j}}=2 Z_{i j}^{-1}-2\left(Z^{-1} s Z^{-1}\right)_{i j}=2\left[Z^{-1}(Z-s) Z^{-1}\right]_{i j} i \neq j
\end{aligned}
$$

Por outro lado, sendo

$$
\sigma_{i .}=\sum_{k=1}^{m} a_{i k}^{2}+\Psi_{i} \quad \text { e } \quad \sigma_{i j}=\sum_{k=1}^{m} a_{i k} a_{j k} \text {, }
$$




$$
\begin{aligned}
& \frac{\partial \sigma_{i i}}{\partial a_{i r}}=2 a_{i r} \\
& \frac{\partial \sigma_{i j}}{\partial a_{i r}}=a_{j r} \\
& \frac{\partial \sigma_{i i}}{\partial \Psi_{i}}=1
\end{aligned}
$$$$
\mathrm{r}=1, \ldots, \mathrm{m}
$$

Pela derivação de funções compostas, obtém-se

$$
\begin{aligned}
& \frac{\partial F_{m}}{\partial a_{i r}}=\sum_{j=1}^{p}\left[\left(\begin{array}{llll}
\partial F_{m} & \partial \sigma_{i j} \\
\partial \sigma_{i j} & \partial a_{i r}
\end{array}\right]\right. \\
& =2 \sum_{j=1}^{p}\left[z^{-1}(z-s) z^{-1}\right]_{i j} a_{j r} \\
& =2\left[Z^{-1}(Z-S) Z^{-1} A\right]_{i r}
\end{aligned}
$$

$\underline{\partial \mathrm{F}_{\mathrm{m}}}=\left(\stackrel{\partial \mathrm{F}_{\mathrm{m}}}{\longrightarrow}\right)\left(\stackrel{\partial \sigma_{\mathrm{i} . \mathrm{i}}}{\longrightarrow}\right)$

$\partial \Psi_{i} \quad \partial \sigma_{i i} \quad \partial \Psi_{i}$

$$
=\left[Z^{-1}(Z-S) Z^{-1}\right]_{i i}
$$


$\mathrm{Na}$ notação matricial:

$$
\begin{array}{ll}
\frac{\partial \mathrm{F}_{\mathrm{m}}}{\partial \mathrm{A}}=2 Z^{-1}(Z-S) Z^{-1} \mathrm{~A} & 4.3 .5 \\
\frac{\partial \mathrm{F}_{\mathrm{m}}}{\partial \Psi}=\operatorname{diag}\left[Z^{-1}(Z-S) Z^{-1}\right] & 4.3 .6
\end{array}
$$

LAWLEY e MAXWELL (1971) recomendam a utilização de um procedimento em duas etapas para a determinação do mínimo da função $\mathrm{F}_{\mathrm{m}}$. A primeira etapa consiste em calcular o mínimo condicional para $F_{m}(\Psi)$, onde $\Psi$ é uma matriz fixa e sob a condição de que $\Delta=A^{\prime} \psi^{-1} A$ seja dia gonal.

Igualando-se a zero a expressão 4.3 .5 e pré-multiplicando-a pela matriz $\mathbb{Z}$,

$$
\begin{aligned}
& \begin{array}{ll}
(Z-S) Z^{-1} A=\phi & 4.3 .7
\end{array} \\
& \text { Lema: } Z^{-1}=\Psi^{-1}-\Psi^{-1} \mathrm{~A}(I+\Delta)^{-1} \mathrm{~A}^{\top} \Psi^{-1} \quad 4.3 .8 \\
& \text { onde } \Delta=\mathrm{A}^{\prime} \Psi^{-1} \mathrm{~A}
\end{aligned}
$$

Prova:

Pós-multiplicando 4.3 .8 pela matriz $\mathrm{AA}^{\prime}+\Psi$, tem-se: 


$$
\begin{aligned}
& {\left[\Psi^{-1}-\Psi^{-1} A(I+\Delta)^{-1} A^{\prime} \Psi^{-1}\right]\left(A^{\prime}+\Psi\right)} \\
& \Psi^{-1} \mathrm{AA} A^{\prime}-\Psi^{-1} \mathrm{~A}(I+\Delta)^{-1} \mathrm{~A}^{\prime} \Psi^{-1} \mathrm{AA}^{\prime}+I-\Psi^{-1} \mathrm{~A}(I+\Delta)^{-1} \mathrm{~A}^{\prime} \\
& \Psi^{-1} \mathrm{AA}^{\prime}-\Psi^{-1} \mathrm{~A}(I+\Delta)^{-1}(\Delta+I) \mathrm{A}^{\prime}+\mathrm{I} \\
& \Psi^{-1} \mathrm{AA}^{\prime}-\Psi^{-1} \mathrm{AA}^{\prime}+\mathrm{I} \\
& =I \quad \text { C.Q.D. }
\end{aligned}
$$

Pós-multiplicando-se 4.3 .8 pela matriz A, resulta:

$$
\begin{aligned}
& Z^{-1} \mathrm{~A}=\Psi^{-1} \mathrm{~A}-\Psi^{-1} \mathrm{~A}(I+\Delta)^{-1} \mathrm{~A}^{\prime} \Psi^{-1} \mathrm{~A} \\
& Z^{-1} \mathrm{~A}=\Psi^{-1} \mathrm{~A}\left[I-(I+\Delta)^{-1} \Delta\right] \\
& Z^{-1} \mathrm{~A}=\Psi^{-1} \mathrm{~A}(I+\Delta)^{-1}[(I+\Delta)-\Delta] \\
& Z^{-1} \mathrm{~A}=\Psi^{-1} \mathrm{~A}(I+\Delta)^{-1}
\end{aligned}
$$

Assim, pode-se reescrever 4.3 .7 da seguinte forma:

$$
(Z-S) \Psi^{-1} A(I+\Delta)^{-1}=\phi
$$


Pós-multiplicando 4.3.10 pela matriz $(I+\Delta)$ e substi tuindo a matriz $Z$ por $\mathrm{AA}^{\prime}+\Psi^{\prime}$, tem-se:

$$
\left(\mathrm{AA}^{\prime}+\Psi-\mathrm{S}\right) \Psi^{-1} \mathrm{~A}=\phi
$$

ou seja:

$$
\begin{aligned}
& \mathrm{S} \Psi^{-1} \mathrm{~A}=\left(\mathrm{AA}^{\prime}+\Psi\right) \Psi^{-1} \mathrm{~A} \\
& \mathrm{~S} \Psi^{-1} \mathrm{~A}=\mathrm{A} \triangle+\mathrm{A} \\
& \mathrm{S} \Psi^{-1} \mathrm{~A}=\mathrm{A}(\Delta+\mathrm{I})
\end{aligned}
$$

Finalmente, pré-multiplicando-se 4.3 .11 por $\Psi^{-1 / 2}$, re sulta:

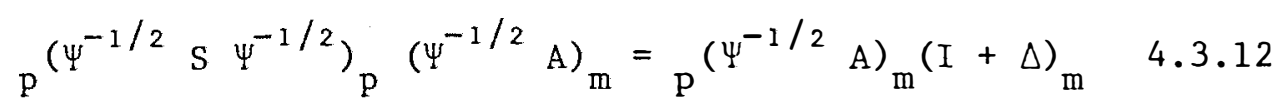

Impondo-se a condição de que $\Delta=A^{\prime} \Psi^{-1} A$ seja diagonal então a expressão 4.3 .12 é um sistema de equações onde $\Psi^{-1 / 2} \mathrm{~A}$ é uma ma triz com colunas iguais aos vetores próprios de $S^{*}=\Psi^{-1 / 2} S \Psi^{-1 / 2}$ e $(I+\Delta)$ matriz diagonal dos seus maiores valores próprios como mostrado adiante. 
Justifica-se a imposição da matriz $\Delta=A^{\prime} \Psi^{-1} A$ ser dia gonal pela necessidade de remoção da indeterminação de A com relação a transformações ortogonais de $\underset{\sim}{x}$. De fato, seja

$$
A_{1}=A U, \quad \operatorname{com} \quad U^{\prime}=U^{\prime} U=I
$$

então tem-se:

$$
\begin{aligned}
& \left.\underset{\sim}{x}=\mathrm{A}_{1} \underset{\sim}{\mathrm{f}}+\underset{\sim}{\mathrm{e}} \quad \mathrm{D} \underset{\sim}{\mathrm{x}}\right)=\mathrm{A}_{1} \mathrm{~A}_{1}^{\prime}+\Psi \\
& \begin{aligned}
\mathrm{D}(\underset{\sim}{\mathrm{x}}) & =\left(\begin{array}{ll}
\mathrm{A} & \mathrm{U}
\end{array}\right)\left(\mathrm{A} \mathrm{U}^{\prime}+\Psi\right. \\
& =\mathrm{A}\left(\mathrm{U}^{\prime} \mathrm{U}^{\prime}\right) \mathrm{A}^{\prime}+\Psi \\
& =\mathrm{A} \mathrm{A}^{\prime}+\Psi
\end{aligned}
\end{aligned}
$$

Obtendo-se o mesmo modelo.

Seja $\quad \theta=\operatorname{diag}\left(\theta_{1}, \theta_{2}, \ldots, \theta_{\mathrm{m}}\right)$ a matriz das $m$ maio res raízes características de $S^{*}=\Psi^{-1 / 2} \mathrm{~S} \Psi^{-1 / 2}$, supondo-as distintas e maiores que a unidade, arranjadas na ordem decrescente e associadas res pectivamente à matriz de vetores característicos $W=\left({\underset{\sim}{w}}_{1}, \underset{\sim}{w}, \ldots, \underset{\sim m}{w}\right)$ na forma normalizada $\left(W^{\prime} W=I\right)$ e satisfazendo à expressão

$$
S^{*} W=W \Theta
$$


Fazendo-se:

$$
\Psi^{-1 / 2} A_{0}=W(\theta-I)^{1 / 2} \text { e } \quad \Delta=A_{0}^{1} \Psi^{-1} A_{0}
$$

Obtém-se de 4.3 .12

$$
\operatorname{S*W}(\theta-I)^{1 / 2}=W(\theta-I)^{1 / 2} \theta
$$

Pós-multiplicando-se por $(\Theta-I)^{-1 / 2}$ e pelo fato de $(\Theta-I)^{1 / 2}$ ser diagonal, tem-se

$$
S * W=W \Theta
$$

Pode-se, portanto escrever que

$$
A_{0}=\Psi^{1 / 2} W(\theta-I)^{1 / 2}
$$

Essa conceituação não é válida quando pelo menos dois vetores próprios são iguais, pois os correspondentes vetores próprios são indeterminados e também quando pelo menos uma das raízes é menor do que a unidade, o que corresponderia a ter-se elementos imaginārios na matriz $A_{0}$. Entretanto, tais fatos são raros na prática.

No caso de ocorrerem raízes características menores que a unidade, pode-se em programas computacionais substituí-las pela unidade, onde a correspondente coluna da matriz $A_{0}$ tornar-se-á nula. 
Teorema: $A_{0}=\Psi^{1 / 2} W(\Theta-I)^{1 / 2}$ minimiza a função $F_{m}(\Psi)$.

\section{Prova:}

Seja a função 4.3.3 escrita da seguinte forma:

$$
f_{m}(\Psi)=\log _{e}\left|Z_{o}\right|+\operatorname{tr}\left(S Z_{o}^{-1}\right)-\log _{e}|s|-p
$$

onde $\quad Z_{0}=A_{0} A_{0}^{\prime}+\Psi \cdot$ Assim,

$$
\begin{aligned}
\Psi^{-1 / 2} Z_{0} \Psi^{-1 / 2} & =\Psi^{-1 / 2}\left(A_{0} A_{0}^{1}+\Psi\right) \Psi^{-1 / 2} \\
& =I+\Psi^{-1 / 2} A_{0} A_{0}^{1} \Psi^{-1 / 2} \\
& =I+\Psi^{-1 / 2} \Psi^{1 / 2} W(\Theta-I)^{1 / 2}(\Theta-I)^{1 / 2} W^{r} \Psi^{1 / 2} \Psi^{-1 / 2} \\
& =I+W(\Theta-I) W^{\prime}
\end{aligned}
$$

$\operatorname{Sejam} \quad[\underset{\sim 1}{w}, \underset{\sim 2}{w}, \ldots, \underset{\sim m}{w}, \underset{\sim m+1}{\mathrm{w}}, \ldots, \underset{\sim \mathrm{p}}{\mathrm{u}}]=[\mathrm{w}, \mathrm{U}]$ um con junto ortonormal de vetores. Então:

$$
\begin{aligned}
{\left[I+W(\Theta-I) W^{\prime}\right] W } & =W+W \Theta-W \\
& =W \theta
\end{aligned}
$$

mostrando que $\theta_{1}, \theta_{2}, \ldots, \theta_{\mathrm{m}}$ são autovalores de $\Psi^{-1 / 2} Z_{0} \Psi^{-1 / 2}$. Ademais como, por construção $W^{\prime} U=\phi$, tem-se:

$$
\left[I+W(\Theta-I) W^{\prime}\right] U=U+\phi=U
$$

mostrando que os restantes $\mathrm{p}$-m autovalores de $\Psi^{-1 / 2} Z_{0} \Psi^{-1 / 2}$ são iguais a unidade. Então: 


$$
\left|\mathbb{Z}_{\mathrm{o}}\right| /|\Psi|=\theta_{1} \ldots \theta_{\mathrm{m}}
$$

e

$$
\left|Z_{0}\right|=\left(\theta_{1}, \ldots \theta_{\text {m }}\right)|\Psi|
$$

Como $S^{*}=\Psi^{-1 / 2} S \Psi^{-1 / 2}$, então

$$
|S|=\left|\Psi^{1 / 2} S^{*} \Psi^{1 / 2}\right|=\left|S^{*}\right| \cdot|\Psi|=\left(\theta_{1} \ldots \theta_{\mathrm{P}}\right)|\Psi|
$$

Seja a expressão 4.3.7 descrita da seguinte forma:

$$
\left(z_{0}-S\right) Z_{0}^{-1} A=\phi
$$

Então,

$$
\begin{aligned}
& A_{0}-S Z_{0}^{-1} A_{0}=\phi \\
& S Z_{0}^{-1} A_{0}=A_{0}
\end{aligned}
$$

\section{Pode-se escrever}

$$
\begin{aligned}
S Z_{0}^{-1} & =S Z_{0}^{-1} \Psi \Psi^{-1} \\
& =S Z_{0}^{-1}\left(Z_{0}-A_{0} A_{0}^{1}\right) \Psi^{-1} \\
& =S \Psi^{-1}-\left(S Z_{0}^{-1} A_{0}\right) A_{0}^{1} \Psi^{-1}
\end{aligned}
$$


32.

Usando 4.3 .16

$$
S Z_{0}^{-1}=S \Psi^{-1}-A_{0} A_{0}^{\prime} \Psi^{-1}
$$

Daí

$$
\begin{aligned}
\operatorname{tr}\left(S Z_{0}^{-1}\right) & =\operatorname{tr}\left(S \Psi^{-1}\right)-\operatorname{tr}\left(A_{0} A_{0}^{\prime} \Psi^{-1}\right) \\
& =\operatorname{tr}\left(\Psi^{-1 / 2} S \Psi^{-1 / 2}\right)-\operatorname{tr}\left(A_{0}^{\prime} \Psi^{-1} A_{0}\right) \\
& =\operatorname{tr}\left(S^{*}\right)-\operatorname{tr}(\theta-I) \\
& =\left(\theta_{1}+\ldots+\theta_{p}\right)-\left[\left(\theta_{1}-1\right)+\ldots+\left(\theta_{m}-1\right)\right] \\
& =\sum_{k=m}^{p} \theta_{k}+\mathrm{m}
\end{aligned}
$$

Substituindo-se $\left|z_{0}\right|$, is $\mid$ e $\operatorname{tr}\left(s z_{0}^{-1}\right)$ na expressão 4.3.15, resulta

$$
\begin{aligned}
f_{m}(\Psi)= & \log _{e}\left(\theta_{1}, \theta_{2} \ldots \theta_{m}\right)+\log _{e}\left(\Psi_{1} \Psi_{2} \ldots \Psi_{p}\right)+\sum_{k=m+1}^{p} \theta_{k}+m- \\
& -\log _{e}\left(\theta_{1} \theta_{2} \ldots \theta_{p}\right)-\log _{e}\left(\Psi_{1} \Psi_{2} \ldots \Psi_{p}\right)-p \\
f_{m}(\Psi)= & \sum_{k=m+1}^{p} \theta_{k}+m-\sum_{k=m+1}^{p} \log _{e} \theta_{k}-p \\
f_{m}(\Psi)= & \sum_{k=m+1}^{p}\left(\theta_{k}-\log _{e} \theta_{k}\right)-(p-m)
\end{aligned}
$$


Demonstrando que $\Theta$ deve corresponder na expressão 4.3.14 às $m$ maiores raizes características da matriz $S^{*}=\Psi^{-1 / 2} S^{-1 / 2}$, pois, caso $\Theta$ seja definido por outro conjunto de autovalores que não os maiores, todas as passagens seriam vālidas, mas ter-se-ia um valor de $\mathrm{f}_{\mathrm{m}}(\Psi)$ maior, devido $\theta-\log _{e} \theta$ ser uma função crescente em relação a $\theta>1$. (C.Q.D)

Alternativamente a partir de $\left|\Sigma_{0}\right|$ e $\operatorname{tr}\left(S \mathbb{Z}_{0}^{-1}\right)$, pode-se escrever a expressão 4.3.15 em função das $m$ maiores raizes caracteristicas da matriz $\mathrm{S}^{*}=\Psi^{-{ }_{1} / 2} \mathrm{~S}^{-{ }_{1} / 2}$ :

$$
\begin{aligned}
f_{m}(\Psi)= & \log _{e}\left(\theta_{1} \cdot \theta_{2} \ldots \theta_{m}\right)-\left(\theta_{1}+\ldots+\theta_{m}\right)-\log _{e}|S|+ \\
& +\log _{e}\left(\Psi_{1} \cdot \Psi_{2} \ldots \Psi_{p}^{\prime}\right)+\operatorname{tr}\left(S^{*}\right)-(p-m) \quad 4.3 .17
\end{aligned}
$$

A segunda etapa na minimização de $F_{m}$ consiste em deter minar $\hat{\Psi}$ que minimize $\mathrm{F}_{\mathrm{m}}\left(\Psi^{\prime}\right)$.

Igualando a zero a expressão 4.3 .6 definida por

$$
\operatorname{diag}\left[Z_{0}^{-1}\left(Z_{0}-S\right) Z_{0}^{-1}\right]=\phi
$$

Utilizando a identidade 4.3 .8

$$
\begin{aligned}
Z_{0}^{-1}\left(Z_{0}-S\right) Z_{0}^{-1}= & {\left[\Psi^{-1}-\Psi^{-1} A_{0}\left(I+\Delta_{0}\right)^{-1} A_{0}^{\prime} \Psi^{-1}\right]\left(Z_{0}-S\right) . } \\
& \cdot\left[\Psi^{-1}-\Psi^{-1} A_{0}\left(I+\Delta_{0}\right)^{-1} A_{0}^{\prime} \Psi^{-1}\right]
\end{aligned}
$$




$$
\begin{aligned}
= & \Psi^{-1}\left(Z_{0}-S\right) \Psi^{-1}-\Psi^{-1}\left(Z_{0}-S\right) \Psi^{-1} A_{0}\left(I+\Delta_{0}\right)^{-1} A_{0}^{\prime} \Psi^{-1}- \\
& -\Psi^{-1} A_{0}\left(I+\Delta_{0}\right)^{-1} A_{0} \Psi^{-1}\left(Z_{0}-S\right) \Psi^{-1}+ \\
& +\Psi^{-1} A_{0}\left(I+\Delta_{0}^{-}\right)^{-1} A_{0}^{\prime} \Psi^{-1}\left(Z_{0}-S\right) \Psi^{-1} A_{0}\left(I+\Delta_{0}\right)^{-1} A_{0}^{\prime} \Psi^{-1}
\end{aligned}
$$

Usando a expressão $4 \cdot 3 \cdot 10$

$$
z_{0}^{-1}\left(z_{0}-s\right) Z_{0}^{-1}=\Psi^{-1}\left(Z_{0}-s\right) \Psi^{-1}
$$

donde, igualando-se a zero a derivada em relação a $\psi$ tem-se:

$$
\begin{aligned}
\operatorname{diag}\left[Z_{0}^{-1}\left(Z_{0}-S\right) Z_{0}^{-1}\right] & =\operatorname{diag}\left[\hat{\Psi}^{-1}\left(Z_{0}-S\right) \hat{\Psi}^{-1}\right]=\phi \\
& =\operatorname{diag}((t-S)=\phi \\
& =\operatorname{diag}\left(A_{0} A_{0}^{\prime}+\hat{\Psi}-S\right)=\phi
\end{aligned}
$$

e finalmente

$$
\widehat{\Psi}=\operatorname{diag}\left(S-A_{0} A_{O}^{\prime}\right)
$$

Resume-se que o método da máxima verossimilhança da anälise de fatores consiste em calcular

$$
\widehat{A}=\widehat{\Psi}^{1 / 2} W(\Theta-I)^{1 / 2} \text { e } \hat{\Psi}=\operatorname{diag}\left(S-\widehat{A} \widehat{A}^{\prime}\right) \text {, }
$$


tal que $\mathrm{F}_{\mathrm{m}}(\Psi)$ seja mínimo. Os procedimentos e demonstrações nas obtenções de $\widehat{A}$ e $\widehat{\Psi}$ mostram que é operacionalmente mais fácil minimizar a expressão 4.3.3 em vez de maximizar a 4.3.2.

Do ponto de vista computacional as estimativas $\widehat{A}$ e $\widehat{\Psi}$ somente são obtidas por procedimentos iterativos, ressaltando-se que nem sempre verificam-se convergências.

4.3.2. Procedimento para obter as estimativas dos pesos fatoriais $(\bar{A})$ e variāncias específicas $(\bar{\Psi})$

A função 4.3 .3 posta em função das $m$ maiores raizes características da matriz $\mathrm{S}^{*}=\Psi^{-1 / 2} \mathrm{~S}^{-1 / 2} \quad(4.3 .17)$ e minimizada nes ta pesquisa pelo processo de minimização de NEWTON-RAPHSON.

Não utiliza-se diretamente a expressão

$$
\Psi=\operatorname{diag}\left(S-A A^{\prime}\right)
$$

mas calcula-se os valores da função $f_{m}(\Psi)$ e de suas derivadas parciais de primeira ordem em cada iteração. Uma sequência de matrizes $\Psi^{(1)}, \Psi^{(2)}$, $\ldots, \Psi^{(s)}, \ldots$ serā obtida, tal que, $\mathrm{f}_{\mathrm{m}}[\Psi(s+1)]<\mathrm{f}_{\mathrm{m}}\left[\Psi^{(s)}\right]$ até atingir-se a convergência para $\widehat{\Psi}$. Em cada iteração calcula-se pela expressão 4.3.14. os pesos fatoriais $A_{0}^{(s)}$, os quais, em sequência deverão conver gir para $\widehat{A}$, obtendo-se assim o valor mínimo para $f_{m}(\Psi)$. 
Seja a expressão (4.3.6) das derivadas parciais de pri meira ordem em relação a $\Psi$, assim definida:

$\frac{\partial F_{m}}{\partial \Psi}=\operatorname{diag}\left[L_{0}^{-1}\left(Z_{0}-S\right) L_{0}^{-1}\right]$

Como visto anteriormente:

$$
\begin{aligned}
& Z_{0}^{-1}\left(Z_{0}-S\right) Z_{0}^{-1}=\Psi^{-1}\left(Z_{0}-S\right) \Psi^{-1} \\
& \frac{\partial F_{m}}{\partial \Psi}=\operatorname{diag}\left[\Psi^{-1}\left(Z_{0}-S\right) \Psi^{-1}\right] \\
& \quad=\operatorname{diag}\left[\Psi^{-1} Z_{0} \Psi^{-1}-\Psi^{-1} \mathrm{~S} \Psi^{-1}\right] \\
& \quad=\operatorname{diag}\left[\Psi^{-1 / 2} \Psi^{-1 / 2} Z_{0} \Psi^{-1 / 2} \Psi^{-1 / 2}-\Psi^{-1} S \Psi^{-1}\right]
\end{aligned}
$$

De resultados anteriores:

$$
\begin{aligned}
& \Psi^{-1 / 2} Z_{c} \Psi^{-1 / 2}=I+W(\Theta-I) W^{\prime} \\
& \frac{\partial F_{m}}{\partial \Psi}=\operatorname{diag}\left\{\Psi^{-1 / 2}\left[I+W(\Theta-I) W^{\prime}\right] \Psi^{-1 / 2}-\Psi^{-1} S \Psi^{-1}\right\} \\
&=\operatorname{diag}\left[\Psi^{-1} W(\Theta-I) W^{\prime}+\Psi^{-1}-\Psi^{-1} S \Psi^{-1}\right]
\end{aligned}
$$


Então:

$$
g_{i}=\frac{\partial F_{m}}{\partial \Psi_{i}}=\frac{1}{\Psi_{i}}\left[\sum_{r=1}^{m}\left(\theta_{r}-1\right) w_{i r}^{2}+1-s_{i i} / \Psi_{i}\right] \quad 4.3 \cdot 19
$$

onde:

$$
\begin{aligned}
w_{i r}: & \text { é o i-ésimo elemento do vetor característico } \underset{\sim}{w_{r}} \text { associado } \\
& \text { à r-ésima raiz característica } \theta_{\mathrm{r}} \text { da matriz } \mathrm{S}^{*}=\Psi^{-{ }_{1} /{ }^{2}} \mathrm{~S}^{-{ }^{1} / 2} .
\end{aligned}
$$

LAWLEY e MAXWELL (1971) mostram que a matriz $G=t_{i j}^{2}$ $(i, j=1, \ldots, p)$ tal que, os $t_{i j}^{\prime} s$ são elementos da matriz

$$
\Psi^{-1 / 2}\left(I-W W^{1}\right) \Psi^{-1 / 2}
$$

converge assintoticamente para a matriz Hessiana, ou seja,

$$
\frac{\partial^{2} f_{m}(\Psi)}{\partial \Psi_{i} \partial \Psi_{j}}=E\left(\frac{\partial^{2} f_{m}(\Psi)}{\partial \Psi_{i} \partial \Psi_{j}}\right)=t_{i j}^{2}
$$

Suponha-se que $\underset{\sim}{\Psi}(\mathrm{s})$ pertença à vizinhança de $\hat{\Psi}^{\prime}=$ $=\left(\Psi_{1}, \ldots, \Psi_{\mathrm{p}}\right)$ dentro da qual $\mathrm{f}_{\mathrm{m}}(\underset{\sim}{\Psi})$ é aproximadamente uma função quadrātica dos parâmetros e $G$ uma matriz definida positiva. Então, se

$$
\underset{\sim}{g}=\left[g_{i}\right]=\frac{\left.\partial \mathrm{f}_{\mathrm{m}} \underset{\sim}{\sim}\right)}{\partial \underset{\sim}{\Psi}}=\phi \quad \text { para } \quad \underset{\sim}{\Psi}=\underset{\sim}{\hat{\Psi}}
$$

tem-se pelo método de minimização de funções de Newton-Raphson, aproximadamente: 


$$
-\underline{\sim}^{(s)}=G^{(s)}[\underset{\sim}{\underline{\Psi}}-\underset{\sim}{\Psi}(s)]
$$

onde ${\underset{\sim}{g}}^{(s)}$ e $G^{(s)}$ são avaliadas para $\underset{\sim}{\Psi}={\underset{\sim}{\Psi}}^{(s)}$.

Resultando:

$\underset{\sim}{\Psi} \cong \underline{\sim}^{(s)}-E^{(s)} g^{(s)} \cdot$ onde $\quad E=G^{-1}$

Tal aproximação sugere definir $\Psi^{\left(s^{\prime}+1\right)}$ como:

$$
{\underset{\sim}{\Psi}}^{(s+1)}=\underset{\sim}{\Psi}(s)-E^{\left(s^{\prime}\right)} \underline{g}^{\left(s^{\prime}\right)}
$$

Apresentam-se os passos básicos que nortearam a elabora ção do programa computacional em linguagem FORTRAN, visando obterem-se as estimativas de máxima verossimilhança dos pesos fatoriais ( $\widehat{A})$ e variân cias específicas $(\widehat{\Psi})$.

Primeiro passo: definição das seguintes variâncias específicas iniciais.

$\Psi \underset{i}{(1)}=\frac{2 p-m}{2 p}\left(1 / S^{i i}\right) \quad i=1, \ldots, p$

$$
\mathrm{S}^{\mathrm{i} i}=\overrightarrow{\mathrm{e}} \text { o } \mathrm{i} \text {-ésimo elemento diagonal da matriz } \mathrm{S}^{-1} \text {. }
$$


Segundo passo: cálculo do valor da função $\mathrm{f}_{\mathrm{m}}^{(\mathrm{s})}(\Psi)$ pela expressão 4.3.17.

Terceiro passo: obtenção da matriz dos pesos fatoriais $A_{0}^{(s)}$ corresponden te a $\Psi^{(\mathrm{s})}$, através da expressão 4.3 .14 .

Quarto passo: computação da matriz $E^{(s)}=\left[G^{(s)}\right]^{-1}$ conforme exposto an teriormente.

Quinto passo: obtenção do vetor das derivadas parciais de primeira ordem $g^{(s)}$ pela expressão 4.3 .19 .

Sexto passo: cálculo do vetor gradiente $\stackrel{\sim}{d}^{(s)}=E^{(s)}{\underset{\sim}{g}}^{(s)}$.

Sétimo passo: obtenção das novas aproximações para as variâncias especí ficas pela expressão $\underset{\sim}{\Psi}(\mathrm{s}+1)=\underline{\sim}^{(\mathrm{s})}-\underline{\sim}^{(\mathrm{s})}$ e retornar ao segundo passo, prosseguindo-se até o atingimento das con vergências desejadas.

Inclui-se no Apêndice III, o programa computacional elaborado segundo os passos expostos. O programa em linguagem FORTRAN atende os requisitos requeridos pelo computador IBM-1130.

Objetivando oferecer flexibilidades operacionais na uti lização do programa, optou-se pela apresentação de um exemplo explanando os sete passos descritos e aplicado para o caso de uma matriz de correlação que resulte na obtenção de soluções prōprias. (definidas no item seguinte). 
No entanto, em face da ocorrência neste trabalho de solu ções impróprias (definidas no item seguinte), processou-se a matriz da Ta bela 4.1. da página 43 do livro de LAWLEY e MAXWELL (1971), mostrando-se os resultados concernentes às interações 1, 2, 3, 28, 29 e 30 .

Por outro lado, ressaltam-se que foram utilizadas as se guintes subrotinas: MINV (S1U, P, DD, L , M) da biblioteca científica IBM-1130 e AUVAL (A,AA, C, NR, N) desenvolvida por DEPIZZOLATTI (1983).

- Subrotina MINV: inverte e calcula determinante de matrizes.

S1U: matriz de entrada (correlações), destruída durante a computação; na saída expressa a matriz inversa resultante.

P : ordem da matriz (definido inteiro no programa).

DD : determinante resultante.

L e M: vetor de comprimento $\mathrm{p}$ para uso interno da subrotina.

- Subrotina AUVAL: Calcula valores próprios e vetores próprios de matrizes simétricas pelo método de Jacobi, con forme exposto em NOBLE (1969).

A : matriz de entrada, destruída durante a computação; na saída ex pressa na diagonal os valores próprios na ordem decrescente de magnitude.

AA : expressa os vetores próprios associados aos valores próprios correspondentes.

C : na saída expressa a matriz de entrada.

NR : nümero de rotações realizadas (método de Jacobi).

$\mathrm{N}$ : ordem da matriz. 
Destaca-se que a subrotina original AUVAL não ordena os valores próprios na ordem decrescente de magnitude, assim teve-se que adaptar tal requisito.

\subsubsection{Caso de variāveis sem componente residual}

O modelo fatorial representado pelas equações $\underset{\sim}{x}=\operatorname{Af}+e$ e $\mathbb{Z}=\mathrm{AA}^{\prime}+\Psi$, pode ser generalizado para o caso de existirem $\mathrm{k}<\mathrm{m}$ variáveis que possuem variâncias específicas nulas, isto é, essas k variāveis são combinações lineares exclusivamente dos fatores comuns. Entre tanto, o valor $k$ não poderá exceder ao número $m$ de fatores, pois, ex cedendo-o torna a matriz $\mathbb{Z}$ singular.

Geometricamente, significa dizer que essas k variāveis estão totalmente inseridas no espaço vetorial gerado pelos fatores.

Por outro lado, esse fato acarreta dificuldades na aplicação do método da máxima verossimilhança, pois a função de verossimilhan ça não possuirá ponto de máximo no sentido de anular as derivadas parciais de primeira ordem dentro da região em que todos os elementos de $\Psi$ são positivos. As variâncias específicas nos procedimentos iterativos podem tornar-se negativas.

Entretanto, contorna-se esse problema obtendo-se o mínimo da função $f_{m}(\Psi)$ dentro da região $R_{\varepsilon}$ tal que $\Psi_{i} \geq \varepsilon$ para todo $i$, onde $\varepsilon$ é um valor positivo. Em aplicações práticas utiliza-se $\varepsilon=0,005$ no caso de variáveis estandartizadas. 
Denominam-se soluções próprias às estimativas de máxima verossimilhança obtidas quando o mínimo da função $\mathrm{f}_{\mathrm{m}}(\Psi)$ ocorre no interior da região $R_{\varepsilon}$, enquanto que, são chamadas soluções imprōprias aque las originadas quando o mínimo se situa na fronteira de $R_{\varepsilon}$.

Na literatura sobre anālise de fatores as soluções impró prias são conhecidas como "casos de Heiwood".

Do exposto, se soluções imprōprias são ocorrentes, então as hipóteses sobre o modelo deverão ser redefinidas, ou seja, o procedimento iterativo deverá prosseguir utilizando-se a matriz de dispersão con dicional: $\mathrm{S}_{22 \cdot 1}=\mathrm{S}_{22}-\mathrm{S}_{21} \mathrm{~S}_{11}^{-1} \mathrm{~S}_{12}$. Onde:

$$
S=\left[\begin{array}{ll}
S_{11} & S_{12} \\
S_{21} & S_{22}
\end{array}\right]
$$

tal que $\underset{\sim}{x^{\prime}}=(\underset{\sim 1}{x}, \underset{\sim 2}{x}): \underset{\sim_{1}}{x}=\left(x_{1}, x_{2}, \ldots, x_{k}\right)$

$$
\underset{\sim 2}{x}=\left(x_{k+1}, x_{k+2}, \ldots, x_{p}\right)
$$

resultando

$$
A=\left[\begin{array}{ll}
A_{11} & \phi \\
A_{12} & A_{22}
\end{array}\right]
$$




\subsubsection{Teste de hipótese}

A maıs importante vantagem do método da máxima verossima 1hança resume-se na possibilidade de verificar se um determinado numero de fatores $m$ está adequado para reproduzir o modelo. No presente traba1ho, consideram-se que os fatores são não correlacionados.

O teste estatístico baseia-se no critério da razáo de má xima verossimilhança, onde o negativo do dobro do logaritmo da razão de verossimilhança distribui-se aproximadamente como um qui-quadrado quando o número de observações $\mathrm{N}$ e $\geq 50+\mathrm{p}$. ANDERSON e RUBIN (1956) exprá mem a estatística da seguinte forma:

$$
-2 \log _{e} \lambda=N \log _{e} \frac{|\hat{z}|}{|z|}
$$

A razão de verossimilhança $\lambda$ é definida como o quocien te da função de verossimilhança com respeito aos parâmetros em um subconjunto especificado $\omega$ e a função de verossimilhança considerando o con junto total $\Omega$.

Do exposto, seja $\Omega$ o conjunto formado por todas as ma trizes simétricas, definidas positivas de ordem $p$ e $\omega$ um subconjunto de $\Omega$, formado pelas matrizes $\hat{z}=\mathrm{AA}^{\prime}+\Psi$ originadas do modelo fatorial m-dimensional.

Seja a função de verossimilhança 4.3.2, escrita com:zelação somente aos elementos de $\mathcal{Z}$. 


$$
\log _{e} L=-\frac{1}{2} n\left[\log _{e}|Z|+\operatorname{tr}\left(Z^{-1} s\right)\right] \quad 4 \cdot 3 \cdot 4 \cdot 1
$$

De acordo com a análise estatística multivariada, a função 4.3.4.1 atingirá o māximo em $\Omega$ quando $z=S$.

Sejam $L_{\Omega}$ e $L_{\omega}$ os máximos respectivamente das funções de verossimilhança em $\Omega$ e $\omega$. Então:

$$
\log _{e} L_{\Omega}=-\frac{1}{2} n\left(\log _{e}|s|+p\right)
$$

$$
\log _{e} L_{\omega}=-\frac{I}{2} n\left[\log \hat{\mathbb{Z}}+\operatorname{tr}\left(\hat{\mathbb{Z}}^{-1} \mathrm{~S}\right)\right] \quad \text { onde } \hat{\mathbb{Z}}=A A^{\prime}+\Psi
$$

$+2 \log _{\mathrm{e}} \mathrm{L}_{\Omega} \cdot$ Logo:

$$
\text { Assim, se } \lambda=\frac{\mathrm{L}_{\omega}}{\mathrm{L}_{\Omega}} \text {, implica }-2 \log _{\mathrm{e}} \lambda=-2 \log _{\mathrm{e}} \mathrm{L}_{\omega}+
$$

$$
U_{m}=-2 \log _{e} \lambda=n\left[\log _{e}|\hat{\mathbb{Z}}|+\operatorname{tr}\left(S \hat{\mathbb{Z}}^{-1}\right)-\log |s|-p\right] \quad 4.3 .4 .2
$$

Contudo, se $\widehat{\mathbb{Z}}$ é obtido com boa precisão pode-se consi derar que $\operatorname{tr}\left(S \hat{\mathbb{Z}}^{-1}\right)=p \cdot$ Então:

$$
\mathrm{U}_{\mathrm{m}}=\mathrm{n}[\log |\widehat{\mathrm{Z}}|-\log |\mathrm{s}|]
$$


Por outro lado, BARTLETT (1954) introduz uma modificação visando aumentar a convergência para a distribuição de $\chi^{2}$. 0 autor sugere usar o fator multiplicativo $\left(n-\frac{2 p+5}{6}-\frac{2}{3} m\right)$ em vez de $n$.

O nūmero de graus de liberdades associados à distribui ção de $\chi^{2}$ é a diferença entre a dimensionalidade do conjunto total $\Omega$, definido por $\mathrm{p}(\mathrm{p}+1) / 2$ parâmetros gerado pelas $\mathrm{p}$ variáveis e a dimensionalidade do subconjunto $\omega$ com $\mathrm{pm}+\mathrm{p}-\mathrm{m}(\mathrm{m}-1) / 2$ parâmetros. Assim, o nümerode graus de liberdade $v$ sob a hipótese da nulidade $H_{0}$ para o modelo fato rial m-dimensional, ê:

$$
v=\frac{1}{2}\left[(p-m)^{2}-p-m\right] \quad 4.3 \cdot 4.4 .
$$

Rejeita-se $\mathrm{H}_{\mathrm{O}}$ para um determinado número de fatores se ocorrer do valor de $U_{\mathrm{m}}$ exceder ao valor do $\chi^{2}$ a um nível de signifi cância estipulado, resultando que outro modelo com maior número de fato res deve ser assumido para explanar as covariâncias ou correlações observadas.

Devido à propriedade de invariância na estimação dos fatores e variâncias específicas, decorre que o valor do teste estatístico é o mesmo para as matrizes de covariâncias e correlações. 


\subsubsection{Estimação dos escores fatoriais}

Empregando-se a anālise de fatores preliminarmente à outra técnica de anālise estatística multivariada, ou se existir interesse em calcular índices que caracterize a importância da unidade amostral, então, além de estimar os parâmetros A e $\Psi$, determinam-se os valores dos fatores em função das variáveis respostas.

E óbvio que, os escores fatoriais não são estimados no sentido estatístico usual, pois, não são parâmetros do modelo fatorial, mas valores atribuídos às variāveis hipotéticas. Assim, hâ a necessidade de introduzir um princípio de quadrados mínimos para predizer os escores fatoriais. Na linguagem estatística dir-se-á que os escores fatoriais são preditores dos fatores.

Neste trabalho, aplicar-se-á o método de regressão devido a THOMSON (1951) para predizer os escores fatoriais.

Supondo que os fatores são não correlacionados e que os erros de amostragem na estimação de $A$ e $\Psi$ são desprezíveis. Sejam:

$\underset{\sim}{x^{\prime}}=\left(x_{1}, x_{2}, \cdots, x_{p}\right):$ vetor das observações

$\underset{\sim i}{f}=\left(f_{i 1}, f_{i 2}, \ldots, f_{i m}\right):$ vetor dos escores fatoriais para a $i-\underline{e}$ sima unidade amostral.

$\mathrm{e}^{\prime}=\left(\mathrm{e}_{1}, \mathrm{e}_{2}, \ldots, \mathrm{e}_{\mathrm{p}}\right)$ : vetor dos resíduos específicos. 
e as pressuposições:

$$
\begin{aligned}
& E\left(\underset{\sim}{f f} f^{\prime}\right)=I_{m} \\
& E\left(\underset{\sim}{x} f_{\sim}^{\prime}\right)=A \\
& E\left(\underset{\sim}{(x} x^{\prime}\right)=A^{\prime}+\Psi
\end{aligned}
$$

o método devido a THOMSON (1951) consiste em obter m re gressões lineares de $\underset{\sim}{f}$ sobre $\underset{\sim}{x}$.

$$
\text { Sejam } \overrightarrow{\mathrm{I}}_{\mathrm{r}}=\underset{\sim \mathrm{r}}{\mathrm{c}} \underset{\sim}{\mathrm{x}}=\underset{\sim}{\mathrm{x}} \underset{\sim}{\mathrm{c}} \underset{\mathrm{r}}{ }(\mathrm{r}=1,2, \ldots, \mathrm{m}) \text {. Onde: } \underset{\sim \mathrm{r}}{\mathrm{c}} \overline{\mathrm{e}}
$$

um vetor de ordem $\mathrm{p}$ e definido tal que a variância de $\overrightarrow{\mathbf{f}}_{\mathrm{r}}-\mathrm{f}_{\mathrm{r}} \overline{\mathrm{e}}$ minimizada.

$$
E\left(\hat{\mathrm{f}}_{\mathrm{r}}-\mathrm{f}_{\mathrm{r}}\right)^{2}=E\left(\underset{\sim}{\mathrm{x}^{\prime}} \underset{\sim r}{\mathrm{r}}-\mathrm{f}_{\mathrm{r}}\right)^{2}
$$

Diferenciando e igualando a zero as derivadas parciais com relação ao vetor $\stackrel{\sim}{c}_{r}$, resulta:

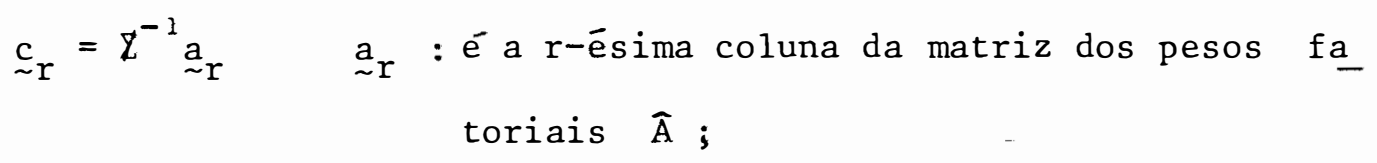

e assim:

$$
\hat{\mathrm{f}}_{\mathrm{r}}=\underset{\sim \mathrm{r}}{\mathrm{a}^{\prime}} z^{-1} \mathrm{x}
$$




$$
\begin{aligned}
& \text { No entanto, se } \underline{\sim}^{\prime}=\left(f_{1}, f_{2}, \ldots, f_{m}\right) \text {, então: } \\
& \underset{\sim}{\underline{\underline{f}}}=\mathrm{A}^{\prime} \underline{Z}^{-1} \underset{\sim}{x}=\mathrm{A}^{\prime}\left(\mathrm{AA}^{\prime}+\Psi\right)^{-1} \underset{\sim}{\mathrm{x}} \quad 4.3 .5 .1 \text {. } \\
& \text { HARMAN (1976) sugere a fórmula } \underset{\sim}{\hat{x}}=A^{\prime} \mathrm{S}^{-1} \underset{\sim}{x} \text {. } \\
& \text { Entretanto, usando a identidade } 4.3 .9 \text { resulta: } \\
& \underline{\underline{\underline{I}}}=(I+\Delta)^{-1} \mathrm{~A}^{\prime} \Psi^{-1} \underset{\sim}{\mathrm{x}}
\end{aligned}
$$

Generalizando para a matriz $\mathrm{F}$ de ordem $\mathrm{N} \times \mathrm{m}$ dos escores fatoriais:

$$
F=X \Psi^{-1} A(I+\Delta)^{-1}
$$

4.3.6. Metodologia dos indices normalizados

Como critério de pós-estratificação envolvendo todas as variāveis respostas, utilizar-se-ā um índice que caracterize a importância da subunidade conglomerada. Este índice é definido como o módulo da resultante da soma vetorial dos escores fatoriais ponderados pela contribuição em percentagem do respectivo fator à comunalidade total. Esses in dices serão divididos pelo de maior magnitude, implicando numa normalização entre 0 e 1 . 
A justificativa da aplicação desses índices prende-se ao fato dos fatores serem ortogonais. A seguinte expressão sintetiza o expos to:

$$
I_{i}=\sqrt{\sum_{J=1}^{m} P_{j} f_{i j}^{2}} \quad i=1,2, \ldots, N
$$

$\mathrm{N}$ : número de subunidades conglomeradas.

m : número de fatores

$f_{i j}$ : valor do escore fatorial do j-ésimo fator correspondente à i-ésima subunidade conglomerada.

$\mathrm{p}_{\mathrm{j}}$ : contribuição em percentagem do j-ésimo fator à comunalidade total. 
5.1. Matriz das correlações das variāveis respostas

A matriz das correlações das variáveis resposta está apresentada na Tabela 1. Verifica-se que a variável VOLT correlaciona-se $\underline{i}$ gualmente com as variáveis VOL1, VOL2 e VOL3, as quais, basicamente são independentes entre si.

5.2. Estimativas de máxima verossimithança dos pesos fatoriais $\bar{A}=\left[\begin{array}{l}\hat{a}_{j} \\ j\end{array}\right]$ e variāncias específicas $(\widehat{\Psi})$

Os resultados concernentes às estimativas de máxima verossimilhança dos pesos fatoriais e variâncias específicas estão incluídos na Tabela 2. 
Destacam-se que soluções impróprias foram detectadas, as quais foram obtidas minimizando a função $\mathrm{f}_{\mathrm{m}}(\Psi)$ dentro da região $\mathrm{R}_{\varepsilon}$ tal que $\varepsilon \geq 0,005$. Calculou-se a cada ocorrencia de solução imprópria a matriz de dispersão $S_{22,1}=S_{22} \quad S_{21} S_{11}^{-1} S_{12}$ visando obter os pesos fato rials dos fatores subsequentes.

Estão apresentados na Tabela 3 , os resultados das deriva das parciais de primeira ordem e os valores da função $f_{m}(\Psi)$ calculados respectivamente pelas expressões 4.3.19 e 4.3.17 apos 30 iterações, onde constatam-se convergências satisfatórias. Os valores absolutos das derivadas correspondentes ao quarto e último fator são praticamente nulos, sendo a maior magnitude atingida de 0,000244 assegurando a convergência da função $\mathrm{f}^{\mathrm{m}}(\Psi)$ para o valor mínimo.

Os pesos fatoriais (Tabela 2) correspondentes ao primeiro fator $\left({\underset{\sim}{a}}_{1}\right)$, são praticamente iguais aos valores dos coeficientes de correlação associados à variável VOLT. Depreendendo-se que os pesos fato riais relativos ao primeiro fator $\left.(\underset{\sim}{a})_{1}\right)$, simplesmente correspondem aos ete mentos da segunda coluna da matriz de correlações. Assim, resulta como so lução final de máxima verossimilhança para $\widehat{A} e-\Psi$ os valores contidos na Tabela 4 .

No referente a verificação da suficiência do numero de fatores para a reprodução do modelo, salienta-se que, pela utilização da expressao 4.3.4.2., resulta $\mathrm{U}_{4}=0,1314$ concluindo-se pela não rejeição da hipótese de que os quatro fatores computados são adequados para ex primir a matriz de correlações original. 
O número de graus de liberdade ao aplicar a expressão 4.3.4.4., é igual a 1 (um), ressaltando-se que foram subtraídos o número de soluções impróprias ocorridas dos valores de $\mathrm{N}, \mathrm{p}$ e m. Verifica-se a rejeição da hipótese da nulidade para $U_{3}$.

\subsection{Estimativas dos escores fatoriais}

Os escores fatoriais foram calculados através da expressão 4.3.5.1. Na Tabela 5 estão inseridos os coeficientes dos escores fa toriais, isto é, os valores correspondentes a matriz $(\widehat{A} \hat{A}+\widehat{\Psi})^{-1} \widehat{A}$. Esses valores foram computados de modo que $\widehat{A}$ e $\widehat{\psi}$ reproduzissem a matriz das covariâncias .

Os valores dos pesos fatoriais associados à matriz de co variâncias foram computados pela multiplicação daqueles relativos à matriz de correlações pelo fator $S_{i}$ (desvio padrão da i-ésima variável res posta, $\mathrm{i}=1,2, \ldots, \mathrm{p})$ e, no que se refere às variâncias específicas pe lo fator $S_{i}^{2}$. 0 motivo dessa transformação foi dar condições para aplicação da metodologia concernente aos índices normalizados, a qual não fun ciona para dados estandartizados (matriz X).

Os resultados dos escores fatoriais obtidos pelo método de regressão devido a THOMSON (1951) estão expostos no Apêndice III. Em decorrência da variável vOLT estar $100 \%$ correlacionada com o fator 1 , tem-se que, os valores dos escores fatoriais concernentes a esse fator serão 
proporcionais aos valores assumidos pela variável VOLT, onde o fator multiplicativo é igual ao inverso do desvio padrão da variável vOLT ( $\left.\frac{1}{35.0316}\right)$. 35.0316

Por outro lado, se a matriz de correlações fosse utiliza da, então os valores dos escores do fator 1 seriam exatamente os valores estandartizados associados à variável VOLT.

\subsection{Interpretação dos fatores}

Quando a matriz de correlações é utilizada na análise de fatores os pesos fatoriais são os coeficientes de correlação entre as va riāveis respostas e os fatores. Assim, conclusões importantes poderão sur gir dessa interpretação em relação à magnitude dos pesos fatoriais.

Fator 1: explica totalmente a variável VOLT e está igualmente cor relacionado com as variáveis VOL1 $(0,5728)$, VOL2 $(0,5711)$ e VOL3 $(0,5920)$. O fator 1 explica a densidade florestal no que se refere ao volume total sem casca congregando todas as espécies indistintamente. 0 mapeamento com referência à partição pelo fator 1, corresponderá à estratificação da floresta com respeito à variāvel VOLT. A contribuição do fator 1 à comuna lidade total é de $70,08 \%$.

A Tabela 6 e a Figura 4 condensam os resultados e representam respectivamente os seguintes critérios de estratificação pelo fator 1 , onde os valores 6,678910 e 1,089360 correspondem ao maior e menor escores fatoriais respectivamente. 


$$
\begin{aligned}
& \text { Estrato I : }(4,815727 ; 6,678910) \\
& \text { Estrato II : }(2,952544 ; 4,815727] \\
& \text { Estrato III: }(1,089360 ; 2,952544]
\end{aligned}
$$

Fator 2: é bem correlacionado positivamente com a variável vol3 $(0,8018)$ apresentando as seguintes correlações negativas com as variáveis VOL1 $(-0,3388)$ e VOL2 $(-0,4362)$.

Do exposto, se for efetuado o mapeamento baseado no. fator 2, ter-se-á una estratificação da floresta com respeito a un contraste linear da variável VOL3 contra as variáveis VOL1 e VOL2. Observa-se que o fator 2 independe da variável VOLT. A contribuição do fator 2 à comunalidade total è de $15,42 \%$.

A tabela 7 e a Figura 5 comprovam os resultados e caracterizam respectivamente os seguintes critérios de estratificação do fator 2 , onde os valores 3,796392 e $-2,724250$ correspondem ao maior e menor escores fatoriais respectivamente.

$$
\begin{aligned}
& \text { Estrato I : }(1,622845 ; 3,796392) \\
& \text { Estrato II : }(-0,550703 ; 1,622845] \\
& \text { Estrato III: }(-2,724250 ;-0,550703]
\end{aligned}
$$

Fator 3: 0 fator em questão encontra-se positivamente correlacionado com a variável vol2 $(0,6903)$ e negativamente correlacionado com a va riāve1 VOL1 $(-0,5565)$. 
No contexto de um inventário florestal, implica que estruturando-se um mapa com respeito ao fator 3, resultará na estratificação da floresta concernente a um contraste linear da variável vol2 versus VOLl. Note-se que, o fator 3 independe das variáveis VOLT e VOL2, e, sua contribuição a comunalidade total é $11,62 \%$.

A Tabela 8 e a Figura 6 decorrem dos seguintes critérios de estratificação pelo fator 3 , onde os valores 3,274426 e -3,080471 correspondem ao maior e menor escores fatoriais respectivamente.

$$
\begin{aligned}
& \text { Estrato I : }(+1,156127 ; 3,274426) \\
& \text { Estrato II : }(-0,962172 ;+1,156127] \\
& \text { Estrato III : }(-3,080471 ;-0,962172]
\end{aligned}
$$

Fator 4: é relativamente correlacionado com a variável voll $(0,4935)$. Assim, produzindo-se um mapa com relação ao fator 4 , ter-se-á uma estratificação da floresta com referência à variável voll. 0 fator 4 independe das variáveis VOLT, VOL2 e VOL3 e sua contribuição à comunalidade to tal è de $2,87 \%$.

Na Tabela 9 e Figura 7 constam os resultados decorrentes dos seguintes critérios de estratificação pelo fator 4 , onde os valores 1,153570 e -4,706075 correspondem ao maior e menor escores fatoriais res pectivamente.

$$
\begin{aligned}
& \text { Estrato I : }(-0,799645 ; 1,153570) \\
& \text { Estrato II : }(-2,752860 ;-0,799645] \\
& \text { Estrato IF : }(-4,706075 ;-2,752860]
\end{aligned}
$$


5.5. Mapeamento com respeito aos indices normalizados

0 apêndice IV apresenta os indices normalizados resultantes dainclusão dos quatro fatores.

A estratificação reunindo todos os fatores corresponde a exatamente estratificar a floresta univariadamente com relação à variável VOLT, confirmando o que realmente deve acontecer: "Nas extensões mais den sas da floresta provavelmente tem-se maior ocorrência volumétrica das es pécies desejáveis", o que é lógico.

Na Tabela 10 e Figura 8 mostram os resultados decorrentes dos seguintes critérios de partição dos índices normalizados.

$$
\begin{aligned}
& \text { Estrato I : }[0,7 ; 1,0) \\
& \text { Estrato II : }[0,4 ; 0,7) \\
& \text { Estrato III: } \quad<0,4
\end{aligned}
$$

Confrontando as Tabelas 10 e Figura 8 com Tabela 6 e Fi gura 4 respectivamente, percebe-se similaridades. No apêndice III apresen tam-se os valores dos escores fatoriais.

Apresentam-se as correlações entre o indice normalizado e as variáveis respostas. A importância da variável vOLT na construção do indice normalizado é confirmada pela correlação existente $(0,9987)$. 


$$
\begin{aligned}
& \text { CORR (Indice, VOLT) }=0,9987 \\
& \text { CORR (Indice, ALT) }=0,3353 \\
& \text { CORR (Indice, DAP) }=0,5078 \\
& \operatorname{CORR} \text { (Indice, VOL1) }=0,5622 \\
& \operatorname{CORR}(\text { Indice, VOL2) }=0,5710 \\
& \operatorname{CORR}(\text { Indice, VOL3) }=0,5951
\end{aligned}
$$

Reune-se alguns resultados que despertaram atenção:

a) Os coeficientes de correlação entre o fator 1 e as variáveis $\operatorname{VOL1}(0,5739), \operatorname{VOL} 2(0,5720)$ e VOL3 $(0,5934)$ são próximos.

b) Os coeficientes de correlação das variāveis DAP e ALT são basicamente nulos com relação aos fatores 2,3 e 4 .

De conformidade com os itens a e b e devido à variável VOLT independer dos fatores 2, 3 e 4, poder-se-ia pensar em computar um indice normalizado abrangendo os fatores 2, 3 e 4 e obter um mapa estrutu rado sob uma estratificação multidimensional reunindo as variáveis VOL1, VOL2 e VOL3. No entanto, essas variáveis são independentes entre si como mostra a Tabela 1 , tornando sem interesse tal procedimento. 
A Tabela 11 comprova o exposto para os seguintes critérios de estratificação pelo índice normalizado reunindo os fatores 2 , 3 e 4.

$$
\begin{aligned}
& \text { Estrato I : }[0,7 ; 1,0) \\
& \text { Estrato II : }[0,4 ; 0,7) \\
& \text { Estrato III: } \quad<0,4
\end{aligned}
$$

5.6. Experiēncias com outros procedimentos iterativos.

Elaborou-se um programa baseado no procedimento devido a LAWLEY (1942), citado em HARMAN (1976), o qual mostrou-se ineficiente e desvantajoso em alguns testes.

Posteriormente elaborou-se um programa que apresentou boa eficiência, mas convergência lenta baseado no algoritmo:

1. Cálculo das variâncias específicas iniciais.

$$
\Psi_{i}=\frac{2 p-m}{2 p}\left(1 / s^{i i}\right) \quad I=1, \ldots, p
$$

$\mathrm{S}^{\mathrm{i} i}$ : é o i-ésimo elemento diagonal da matriz $\mathrm{S}$.

2. Obter as $m$ maiores raízes características e vetores prōprios associados à matriz $\Psi^{-1 / 2} \mathrm{~S}^{-1 / 2}$. 
59.

3. Calcular $\mathrm{A}_{0}=\Psi^{1 / 2} W(\Theta-I)^{1 / 2}$

W : matriz formada em colunas pelos vetores próprios associados às m maiores raizes características $\theta=\left(\theta_{1}, \ldots, \theta_{\mathrm{m}}\right) \mathrm{da}$ matriz $S^{*}=\Psi^{-1 / 2} \mathrm{~S}^{-1 / 2}$.

4. Obter as novas aproximações das variâncias específicas através da expressão

$$
\Psi_{i}=\operatorname{diag}\left(S-A_{0} A_{0}^{\prime}\right) \quad i=1,2, \ldots, P
$$

e retornar ao item 2 e prosseguir até atingir-se a convergência desejada. 
60.

6. CONCLUSOES

Baseando-se na experiência adquirida e no significado dos resultados do presente trabalho, as principais conclusões extraídas foram as seguintes:

a) Os resultados refletiram uma adequação aos objetivos propostos, isto é, demonstraram haver flexibilidade e eficiência da aplica ção do método da máxima verossimilhança da anālise de fatores na descrição da estrutura florestal tropical, pois pela observa ção detalhada da matriz dos pesos fatoriais, pode um pesquisador florestal com alguma experiência em anālise estatística mul tivariada, interpretar o significado das variáveis envolvidas e suas interrelações. 
b) Apesar do exemplo florestal exposto nesta pesquisa não envolver todas as variáveis necessárias para descrever de forma completa a estrutura da floresta tropical estudada, destaquem-se que re sultados importantes foram obtidos, principalmente no que se re fere à orientação ao planejamento de explorações madeireiras; tais resultados podem ser observados nas estratificações isoladas dos fatores 2,3 e 4, onde as seguintes conclusões foram e videnciadas.

b.1) A partição pelo fator 2 evidencia a estratificação volumé trica das espécies da classe III, onde verifica-se que quanto maior è a sua ocorrência, menores corresponderão às classes I e II, embora o decréscimo na classe II seja menos acentuado. b.2) A partição pelo fator 3 evidencia a estratificação volumétrica das espécies da classe II, onde verifica-se que quanto maior é a sua ocorrência menor corresponderā à classe I. b.3) A partição pelo fator 4 evidencia a estratificação volumétrica das espécies da classe I.

c) No referente a utilização da metodologia dos índices normalizados, o qual correspondeu nesta pesquisa na estratificação univa riada da variável VOLT, vindo a confirmar o que ocorre na floresta tropical em termos das variáveis envolvidas, demonstrou perfeita adequação e operacionalidade. 
Devido aos aspéctos envolvidos na construção dos índices normalizados e nas experiências adquiridas dos resultados deste trabalho, conclui-se que em inventärios florestais direcionados a descrever completamente a estrutura florestal tropical, a obtenção de mapas baseados nos Índices normalizados possibilitarā a identificação precisa das unidades tipológicas existentes, considerando-se os efeitos das características en volvidas e suas interdependências. Assim, terão os silvicultores tropicais a oportunidade de estabelecer e aplicar corretamente o tratamento si 1 vicultural específico a cada tipo florestal.

d) Considerando o alto custo da confecção de mapas florestais atra vés de fotografias aéreas em escala operacionalmente adequada (1:10.000 a 1:5000), técnica que exige também levantamento de campo para comprovar as respectivas interpretações fotogrä́icas, recomenda-se descartar o levantamento aerofotogramétrico em be nefício de uma maior intensidade de amostragem de campo.

Outro aspecto importante, é que nos levantamentos de cam po podem ser qualificadas e quantificadas todas as características importantes na descrição da estrutura florestal tropical, e logicamente, se as sociadas a uma anālise estatística adequada dos seus efeitos e interrelações, obviamente resultarão conclusões importantes e fundamentais para de finição do plano de manejo específico. 
e) Relativamente ao processo de amostragem visando estudar multidi mensionalmente as características florestais tropicais e depois descrevê-las em forma de mapas, recomenda-se a utilização de $\underline{u}$ nidades amostrais conglomeradas distribuídas sistematicamente em faixas equidistantes. Contudo, observando-se os resultados desta pesquisa e os respectivos mapas, conclui-se ser mais pre ciso e eficiente, estabelecer uma estrutura espacial conglomera da com maior número de subunidades.

Por outro lado, as dimensões da subunidade devem estar $\underline{a}$ dequadas para absorver as variações das características dentro dos conglo merados e por razões inerentes às peculiaridades das características florestais, aspéctos de subamostragem devem ser considerados.

f) Concernente ao objetivo delineado de apresentar os fundamentos teóricos sobre o método da máxima verossimilhança da análise de fatores associado ao desenvolvimento de um programa FORTRAN para computador, conclui-se que o referido objetivo foi atingido eficientemente.

g) Finalmente, pelos resultados apresentados nos testes, eficiência e rāpica convergência, conclui-se ser vantajosa a adaptação 
64.

do método de minimização de funções de NEWTON-RAPHSON na estima ção de máxima verossimilhança dos pesos fatoriais e variâncias específicas na anālise de fatores. 


\section{LITERATURA CITADA}

ANDERSON, T.W., 1958. An Introduction to Multivariate Statistical Analysis. New York, Wiley.

ANDERSON, T.W. e N. RUBIN, 1956. Statistical Inference in Factor Analysis. Proceedings Third Berkeley Symp. Math. Statist. Probab., 5: 111-150 .

BARTLETT, M.S., 1937. The Statistical Conception of Mental Factors . Britsh Journal of Psychology, 28: 97-104.

BARTLETT, M.S., 1938. Methods of Estimating Mental Factors. Nature, 141: 609-610.

BARTLETT, M.S., 1962. Factor Analysis in Psychology as a Statistician See it, In Essays on Probability and Statistics. New York, Wiley. 
BRASIL, 1977. Departamento Nacional de Produção Mineral. Projeto RADAM-BRASIL. Folha SA-21 - Santarém. 522 p. Rio de Janeiro.

CARVALHO, J.O.P., 1982. Anālise Estrutural da Regeneração Natural em Flo resta Tropical Densa na Região do Tapajós no Estado do Pará. Curitiba, 123 p. (Dissertação de Mestrado - U.F.P.)

DEPIZZOLATTI, A.L.V., 1983. Pontos Críticos de Superfícies de Resposta com Raiz Quadrada em Função das Doses de Nutrientes Usadas nos Experimentos de Adubação. Piracicaba, ESALQ/USP, 110 p. (Tese de Doutorado)

FACHEL, J.H.G., 1976. Anālise Fatorial. São Paulo, IME/USP, 81 p. (Dissertação de Mestrado)

HARMAN, H.H., 1976. Modern Factor Analysis. 3. ed. Chicago. University of Chicago Press.

JÖRESKOG, K.G., 1963. Estatístical Estimation in Factor Analysis. Almquist and Wikseel, Stockholm.

JÖRESKOG, K.G., 1966. UMFLA - A Computer Program for Restricted Maximum Likelihood Factor Analysis. Research Memorandum, 66-20. Princeton, N. J., Educational Testing Service.

LAWLEY, D.N., 1940. The Estimation of Factor Looding by The Method of Ma ximum Likelihood. Proceedings of The Royal Society of Edinburger, 60: 64-82.

LAWLEY, D.N., 1942. Further Investigations in Factor Estimation. Proceedings of The Royal Society of Edinburger, Section B, 61: 176-185. 
LAWLEY, D.N., 1943. The Application of Maximum Likelihood Method to Factor Analysis. Britsh Journal of Psychology, 33: 172-175.

LAWLEY, D.N. e A.E. MAXWELL, 1971. Factor Analysis as Statistical Method. Butterwortbs . London.

LIMA, A.A. e P. SANTOS, 1976. Pesquisas Bibliogrāficas Polo XI - Tapajós. Serviço Nacional de Levantamento e Conservação do Solo. EMBRAPA.

MAXWELL, A.E., 1964. Calculating Maximum Likelihood Factor Loading. Journal of The Royal Statistical Society, Series A, 127: 238-241.

MORRISON, D.F., 1976. Multivariate Statistical Methods. 2. ed. New York. McGraw-Hil1.

MULAIK, S.A., 1972. The Foundations of Factor Analysis. New York, McGraw-Hil1.

NOBLE, B., 1969. Applied Linear Algebra. New York, Prentice Hall.

QUEIROZ, W.T., 1977. Efeitos da Variação Estrututal em Unidades Amostrais na Aplicação do Processo de Amostragem em Conglomerados nas Florestas do Planalto do Tapajós. Curitiba, U.F.P, 109 p. (Dissertação de Mestrado)

RAO, C.R., 1955. Estimation and Tests of Significance in Factor Analysis. Psychometrika, 20: 93-111. 
SPEARMAN, C., 1904. General Intelligence Objectivelly Determined and Mea sured. Amer. J. Psychol., 15: 201-293.

THOMSON, G.H., 1951. The Factorial Analysis of Human Ability. Loridon, University of London. 
69.

TABELAS E FIGURAS 
TABELA 1. Matriz de correlações das variāveis respostas.

\begin{tabular}{lcccccc}
\hline & ALT & VOLT & DAP & VOL1 & VOL2 & VOL3 \\
\hline ALT & 1,0000 & 0,3362 & 0,1797 & 0,1370 & 0,2723 & 0,1404 \\
VOLT & 0,3362 & 1,0000 & 0,5067 & 0,5739 & 0,5720 & 0,5934 \\
DAP & 0,1797 & 0,5067 & 1,0000 & 0,2980 & 0,3799 & 0,2676 \\
VOL1 & 0,1370 & 0,5739 & 0,2980 & 1,0000 & 0,0927 & 0,0670 \\
VOL2 & 0,2723 & 0,5720 & 0,3799 & 0,0927 & 1,0000 & $-0,0126$ \\
VOL3 & 0,1404 & 0,5934 & 0,2676 & 0,0670 & $-0,0126$ & 1,0000 \\
\hline
\end{tabular}

TABELA 2. Estimativas de máxima verossimilhança dos pesos fatoriais $\widehat{A}=\left[\begin{array}{c}\hat{a}_{j} \\ \sim\end{array}\right]$ e variâncias específicas $\hat{\Psi}$ (soluções imprōprias).

\begin{tabular}{lccccc}
\hline VARIĀVEIS & $\underset{\sim}{\mathrm{a}}$ & $\underset{\sim}{\mathrm{a}}$ & $\underset{\sim}{\mathrm{a}}$ & $\underset{\sim}{\mathrm{a}}$ & $\hat{\Psi}$ \\
\hline ALT & 0,3371 & $-0,0735$ & 0,0703 & $-0,0864$ & 0,8694 \\
VOLT & 0,9975 & 0,0000 & 0,0000 & 0,0000 & 0,0050 \\
DAP & 0,5078 & $-0,0415$ & 0,1032 & 0,1027 & 0,7204 \\
VOL1 & 0,5728 & $-0,3388$ & $-0,5565$ & 0,4935 & 0,0050 \\
VOL2 & 0,5711 & $-0,4362$ & 0,6903 & 0,0000 & 0,00550 \\
VOL3 & 0,5920 & 0,8018 & 0,0000 & 0,0000 & 0,0050 \\
\hline
\end{tabular}


TABELA 3. Valores das derivadas parciais de primeira ordem e da função $\mathrm{f}_{\mathrm{m}}(\Psi)$ após 30 iterações.

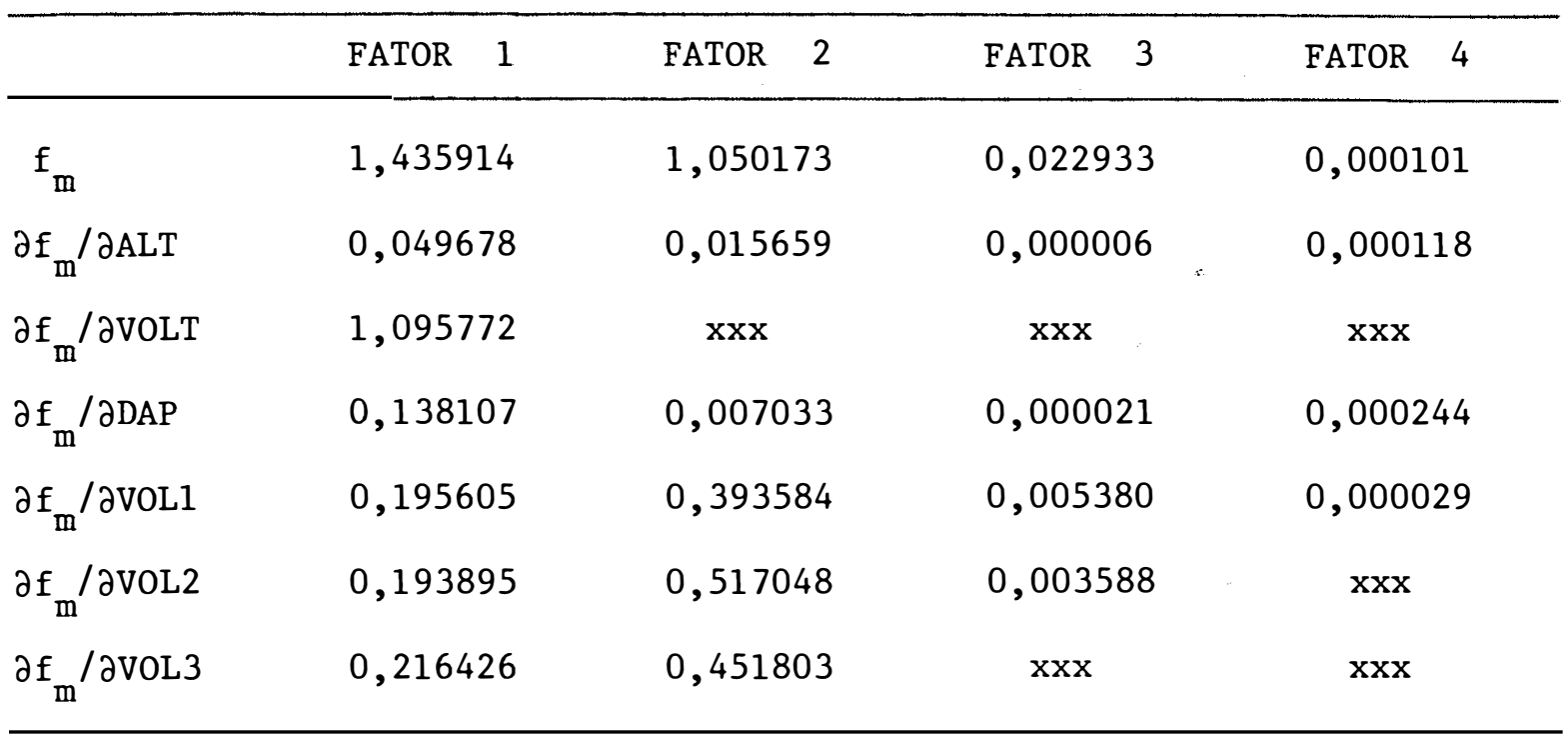

TABELA 4. Estimativas de máxima verossimilhança dos pesos fatoriais $\widehat{A}=\left[\begin{array}{c}\hat{a} \\ -j\end{array}\right]$ e variâncias específicas $\widehat{\Psi}$ (solução final).

\begin{tabular}{lccccc}
\hline VARIÁVEIS & $\hat{\mathrm{a}}_{1}$ & $\hat{\mathrm{a}}_{2}$ & $\mathfrak{\sim}_{\sim_{3}}^{\hat{\mathrm{a}}}$ & ${\underset{\sim}{\sim}}_{4}$ & $\Psi$ \\
\hline ALT & 0,3362 & $-0,0735$ & 0,0703 & $-0,0864$ & 0,8694 \\
VOLT & 1,0000 & 0,0000 & 0,0000 & 0,0000 & 0,0000 \\
DAP & 0,5067 & $-0,0415$ & 0,1032 & 0,1027 & 0,7204 \\
VOL1 & 0,5739 & $-0,3388$ & $-0,5565$ & 0,4935 & 0,0050 \\
VOL2 & 0,5720 & $-0,4362$ & 0,6903 & 0,0000 & 0,0050 \\
VOL3 & 0,5934 & 0,8018 & 0,0000 & 0,0000 & 0,0050 \\
\hline
\end{tabular}


TABELA 5. Coeficientes dos escores fatoriais $\left(\widehat{A}^{\prime}{ }^{\prime}+\widehat{\Psi}\right)^{-1} \widehat{A}$.

\begin{tabular}{|c|c|c|c|c|}
\hline VARIĀVEIS & FATOR 1 & FATOR & FATOR & FATOR 4 \\
\hline ALT & 0,000000 & $-0,001139$ & $-0,000957$ & $-0,003601$ \\
\hline VOLT & 0,028545 & $-0,019866$ & $-0,034847$ & $-0,084375$ \\
\hline DAP & 0,000000 & 0,000467 & 0,001142 & 0,002374 \\
\hline VOL1 & 0,000000 & $-0,001306$ & 0,002248 & 0,118712 \\
\hline VOL2 & 0,000000 & $-0,001234$ & 0,072190 & 0,078890 \\
\hline VOL 3 & 0,000000 & 0,062322 & 0,037956 & 0,083819 \\
\hline
\end{tabular}

TABELA 6. Estimativas das médias (estratificação pelo fator 1).

\begin{tabular}{lcccc}
\hline VARIÁVEIS & ESTRATO I & ESTRATO II & ESTRATO III & POPULAÇÃ̃ \\
\hline ALT & 14,77 & 14,64 & 13,94 & 14,45 \\
VOLT & 185,50 & 130,99 & 82,55 & 122,80 \\
DAP & 52,53 & 50,39 & 47,57 & 49,20 \\
VOL1 & 36,97 & 17,17 & 7,82 & 16,60 \\
VOL2 & 54,32 & 44,55 & 24,87 & 39,91 \\
VOL3 & 65,02 & 44,22 & 29,18 & 42,12 \\
\hline
\end{tabular}


TABELA 7. Estimativas das médias (estratificação pelo fator 2).

\begin{tabular}{lcccc}
\hline VARIAVEIS & ESTRATO I & ESTRATO II & ESTRATO III & POPULAÇÃO. \\
\hline ALT & 14,59 & 14,40 & 14,59 & 14,45 \\
VOLT & 149,15 & 117,46 & 132,87 & 122,80 \\
DAP & 51,24 & 49,36 & 50,87 & 49,20 \\
VOL1 & 13,66 & 13,63 & 27,39 & 16,60 \\
VOL2 & 25,61 & 36,96 & 54,00 & 39,91 \\
VOL3 & 84,96 & 43,51 & 24,81 & 42,12 \\
\hline
\end{tabular}

TABELA 8. Estimativas das médias (estratificação pelo fator 3).

\begin{tabular}{ccccc}
\hline VARIĀVEIS & ESTRATO I & ESTRATO II & ESTRATO III & POPULAÇÃO: \\
\hline ALT & 14,7 & 14,39 & 14,50 & 14,45 \\
VOLT & 138,23 & 117,15 & 140,78 & 122,80 \\
DAP & 51,49 & 49,39 & 50,31 & 49,20 \\
VOL1 & 8,96 & 14,29 & 42,98 & 16,60 \\
VOL2 & 69,40 & 35,72 & 28,64 & 39,91 \\
VOL3 & 40,90 & 43,30 & 35,59 & 42,12 \\
\hline
\end{tabular}


TABELA 9. Estimativa das médias (estratificação pelo fator 4).

\begin{tabular}{lcccc}
\hline VARIATVEIS & ESTRATO I & ESTRATO II & ESTRATO III & POPULAÇÃO \\
\hline ALT & 14,40 & 14,44 & 14,59 & 14,45 \\
VOLT & 135,37 & 117,92 & 130,88 & 122,80 \\
DAP & 51,45 & 49,36 & 49,84 & 49,20 \\
VOL1 & 34,71 & 13,07 & 10,10 & 16,60 \\
VOL2 & 39,76 & 40,22 & 38,50 & 39,91 \\
VOL3 & 45,74 & 41,13 & 42,27 & 42,12 \\
\hline
\end{tabular}

TABELA 10. Estimativas das médias (estratificação pelos índices normaliza dos considerando todos os fatores).

\begin{tabular}{lcccc}
\hline VARIAVVIS & ESTRATO I & ESTRATO II & ESTRATO III & POPULAÇÃO: \\
\hline ALT & 14,82 & 14,56 & 13,90 & 14,45 \\
VOLT & 180,99 & 125,43 & 76,77 & 122,80 \\
DAP & 52,44 & 50,11 & 47,12 & 49,20 \\
VOL1 & 36,50 & 15,98 & 5,58 & 16,60 \\
VOL2 & 54,16 & 41,74 & 24,96 & 39,91 \\
VOL3 & 60,91 & 43,44 & 25,78 & 42,12 \\
\hline
\end{tabular}


TABELA 11. Estimativas das médias (estratificação pelos índices normalizados considerando os fatores 2,3 e 4).

\begin{tabular}{ccccc}
\hline VARIĀVEIS & ESTRATO I & ESTRATO II & ESTRATO III & POPULAÇÃO \\
\hline ALT & 14,85 & 14,60 & 14,35 & 14,45 \\
VOLT & 156,30 & 140,26 & 111,31 & 122,80 \\
DAP & 51,06 & 50,94 & 49,12 & 49,20 \\
VOL1 & 21,98 & 17,28 & 15,87 & 16,60 \\
VOL2 & 44,01 & 46,54 & 36,15 & 39,91 \\
VOL3 & 56,66 & 48,41 & 37,80 & 42,12 \\
\hline
\end{tabular}




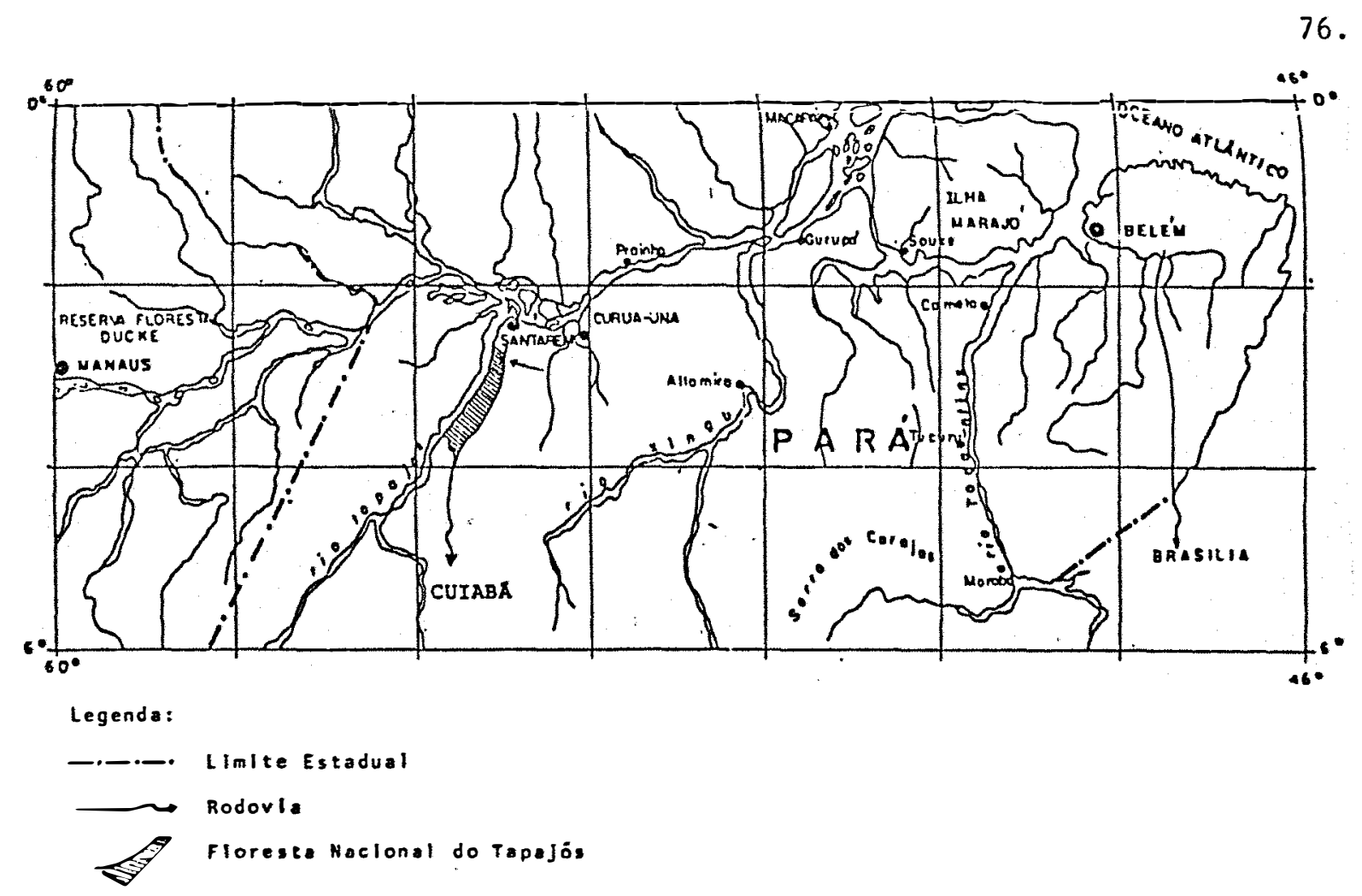

FIGURA 1 - Posição geográfica da floresta estudada.

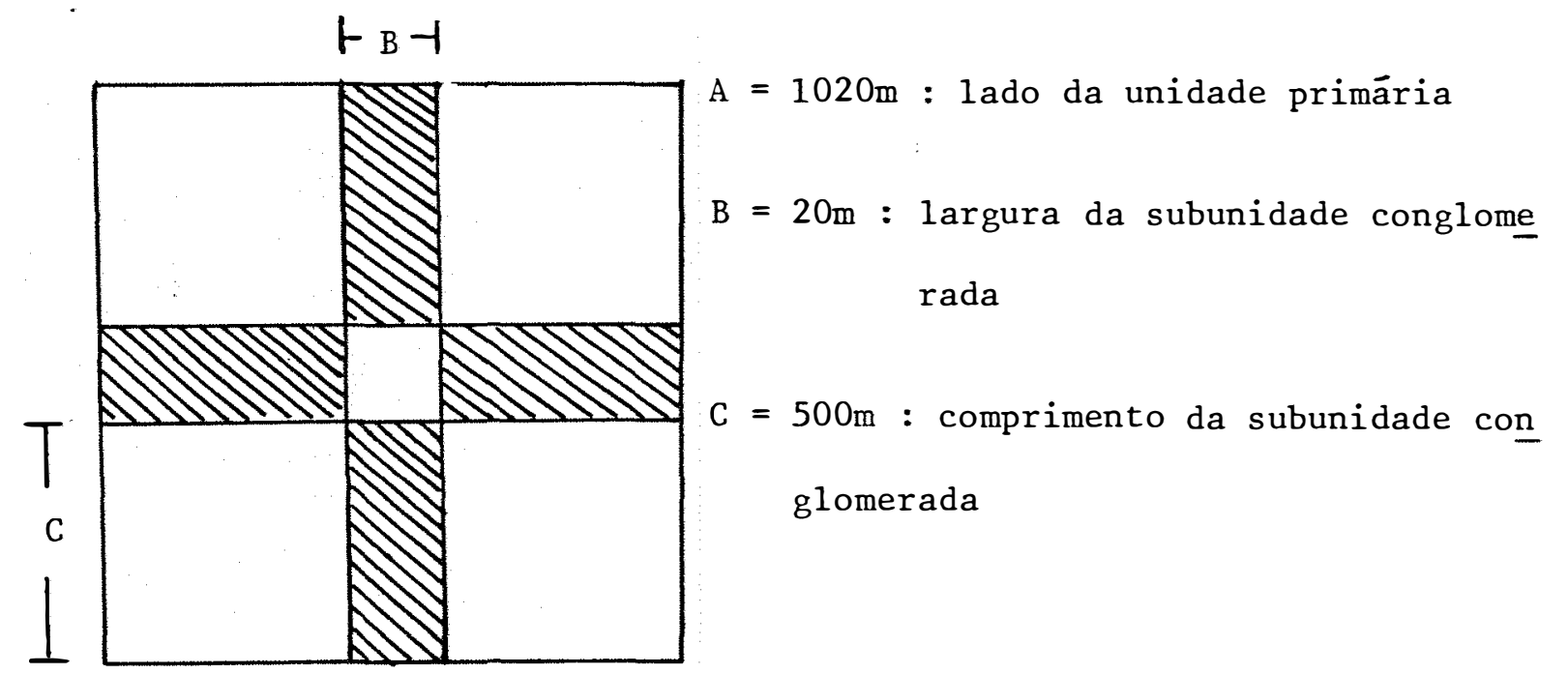

FIGURA 2 - Caracterização espacial da unidade amostral conglome rada. 


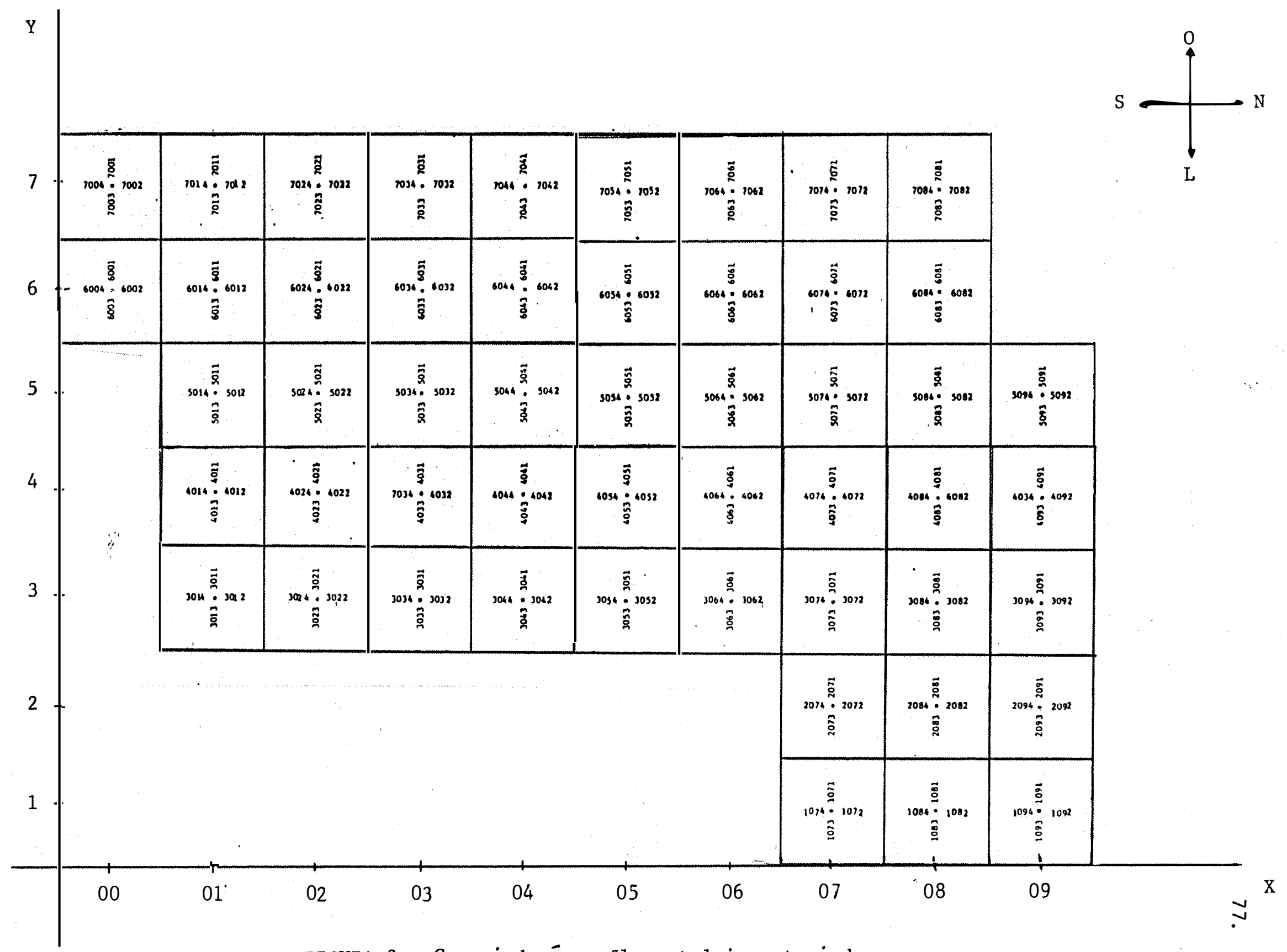

FIGURA 3 - Croqui da área florestal inventariada. 
78.

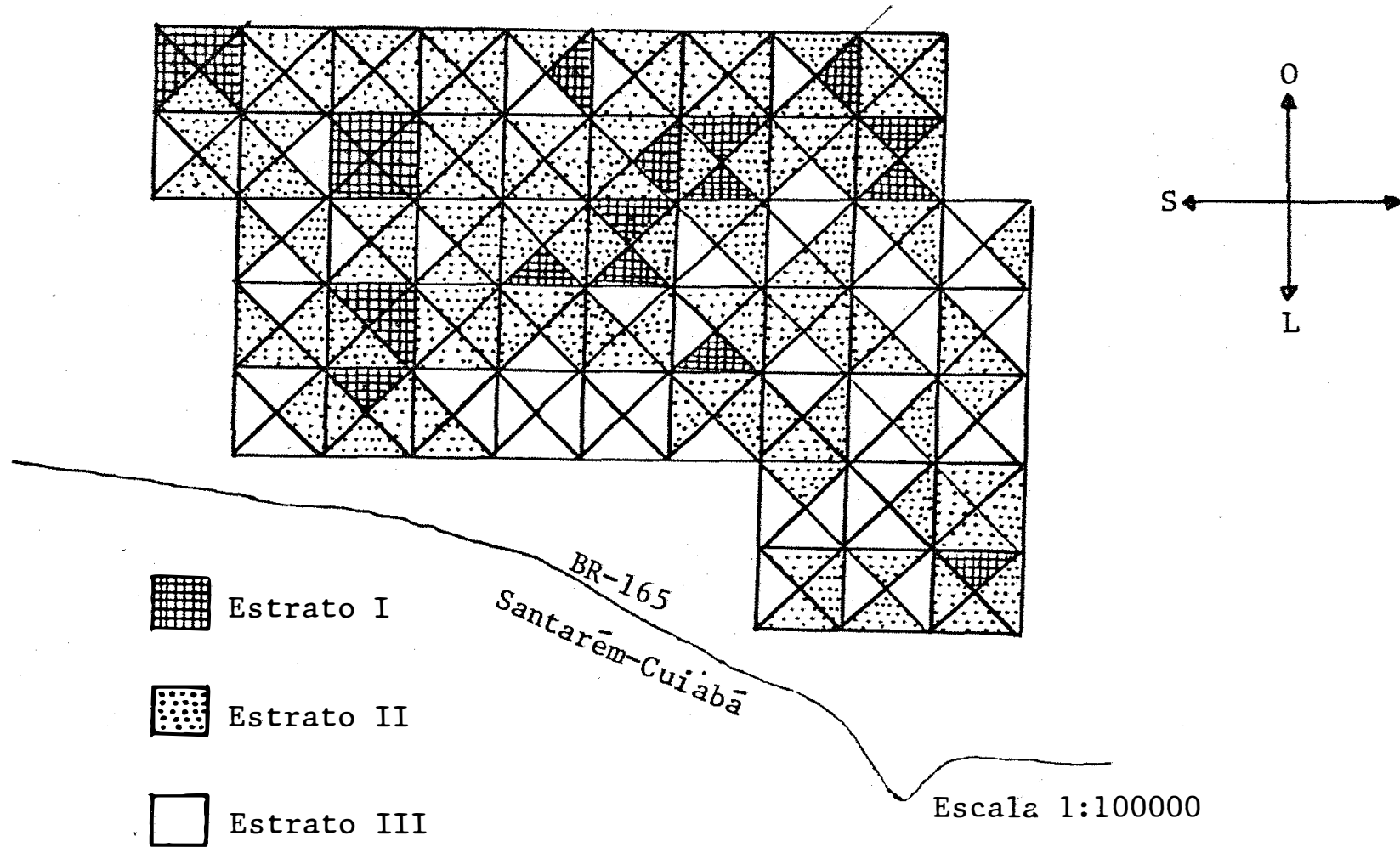

FIGURA 4 - Mapa caracterizando a estratificação pelo fator 1.

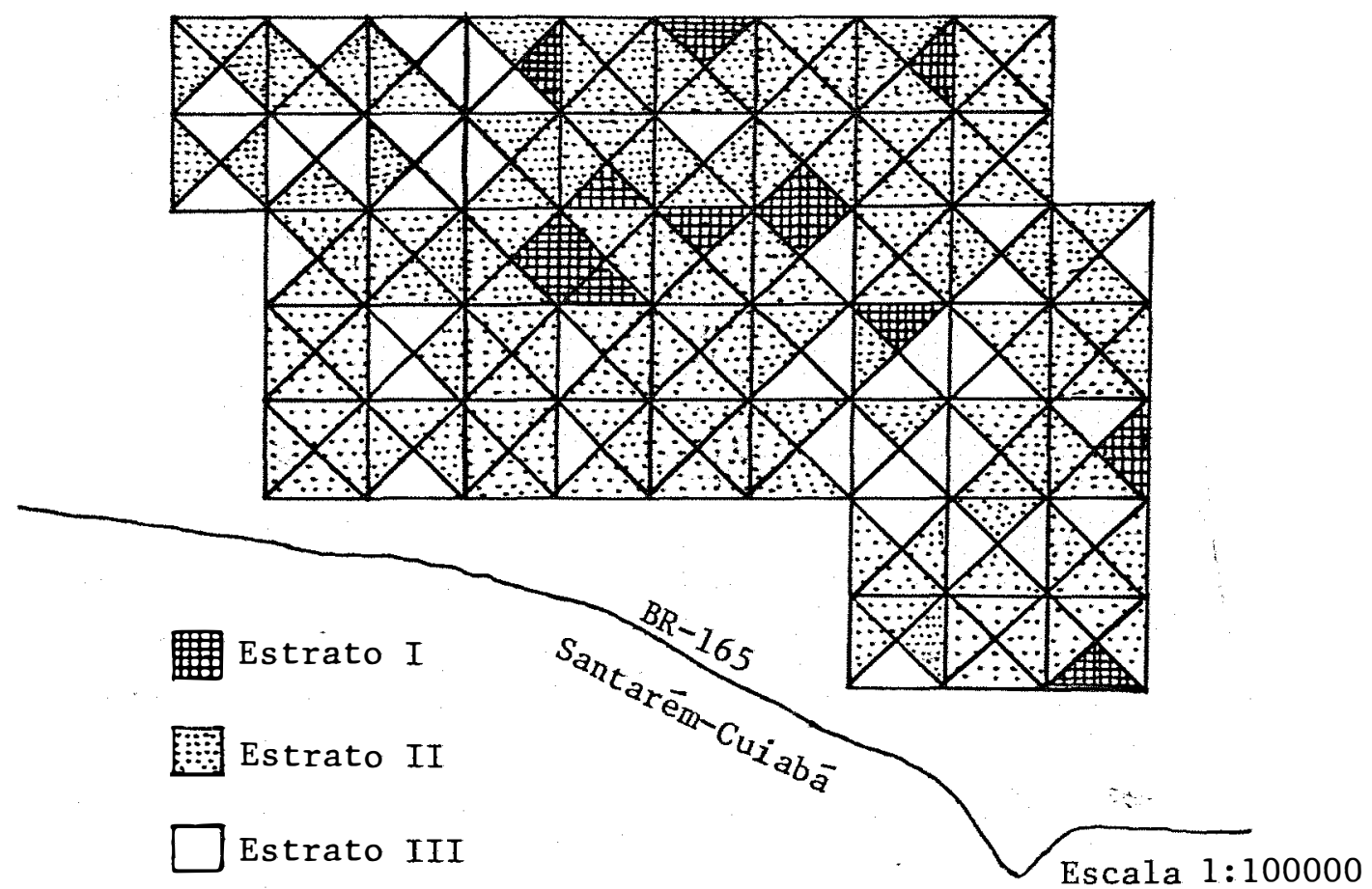

FIGURA 5 - Mapa caracterizando a estratificação pelo fator 2. 


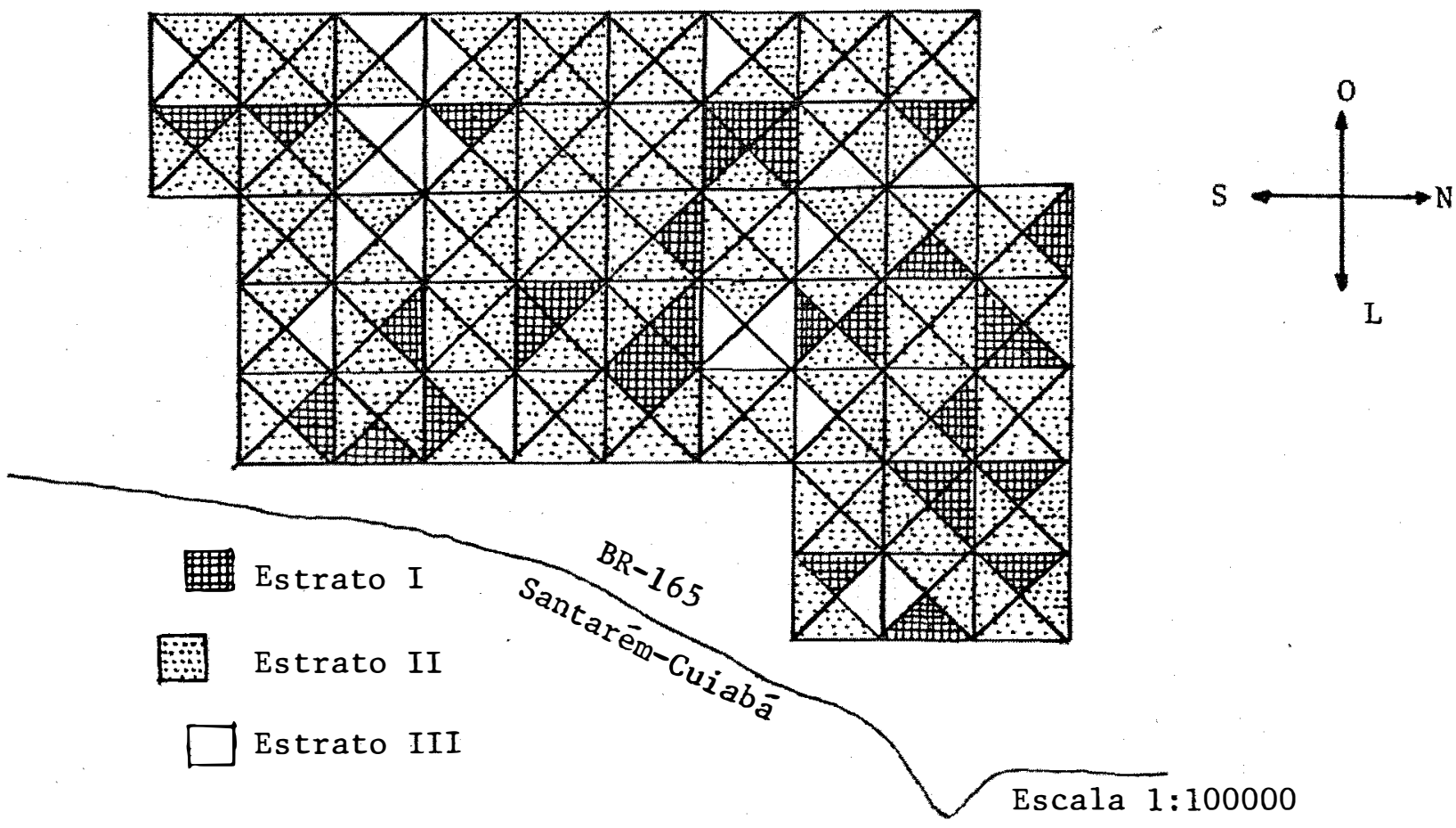

FIGURA 6 - Mapa mostrando a estratificação pelo fator 3 .

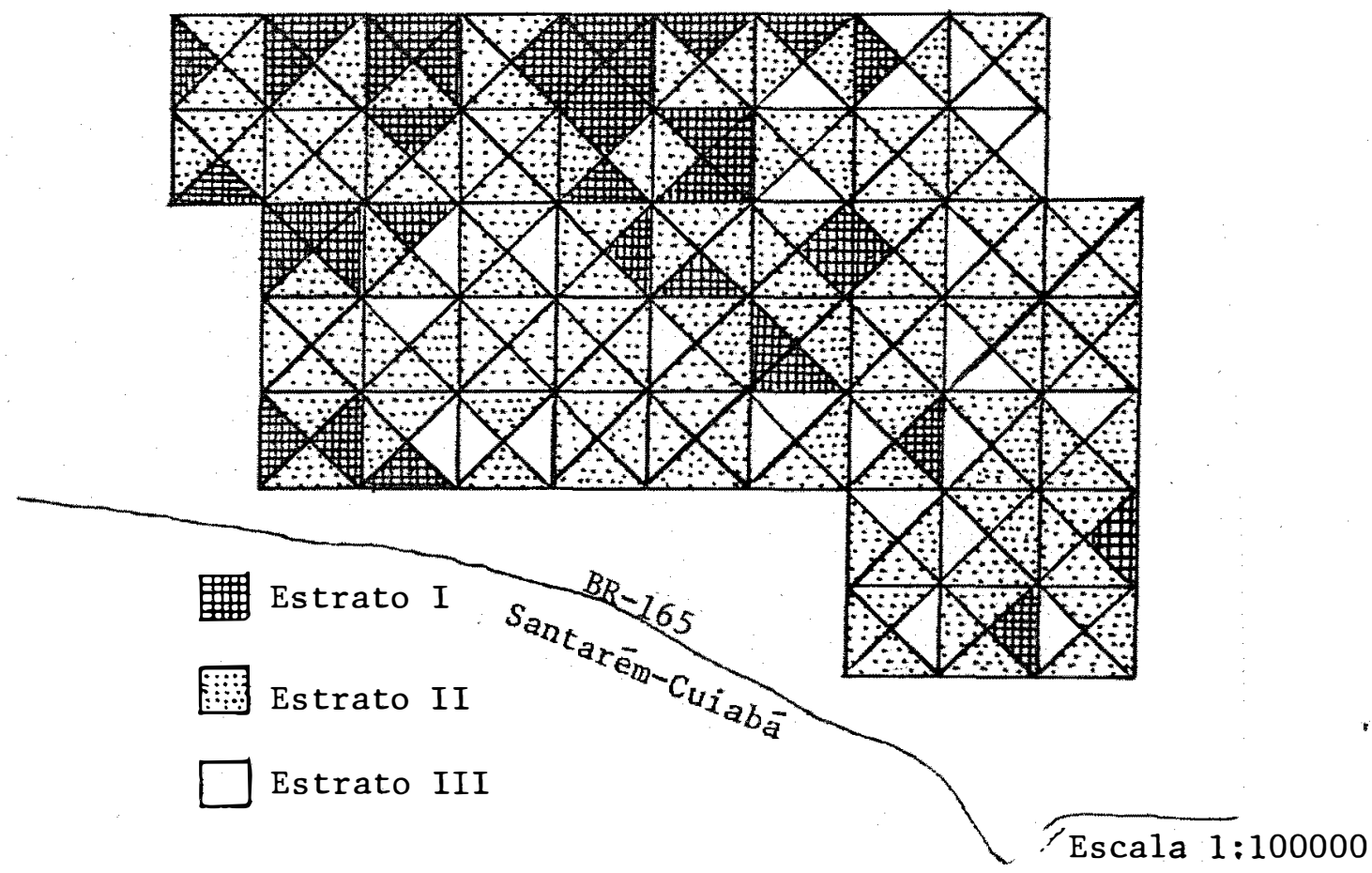

FIGURA 7 - Mapa evidenciando a estratificação pelo f́a tor 4 . 
80.

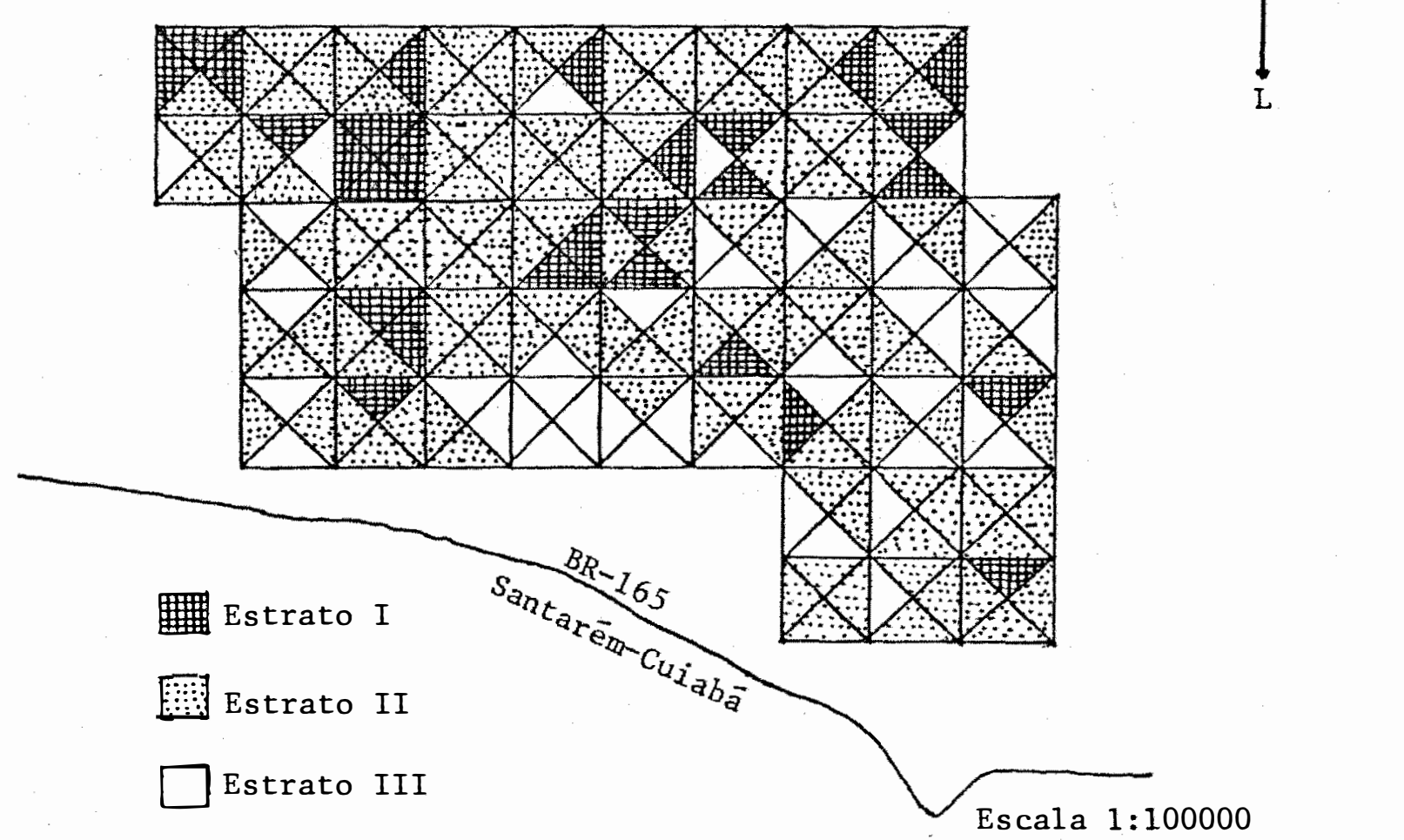

FIGURA 8 - Mapa evidenciando a estratificação pelos ín dices normalizados congregando todos os $\mathrm{fa-}$ tores. 
81.

APENDICE I - Códigos, classes de importāncia, nomes vulgares e cientîficos, famîlia botānica das espécies en contradas. 
82.

\begin{tabular}{|c|c|c|c|c|}
\hline CŌDIGO & CLASSE & NOME CIENTIFICO & N. VULGAR & FAMILIA \\
\hline 001 & & Alexa grandiflora Ducke & Melancieira & Leguminoseae \\
\hline 002 & III & Anacardium spruceanum Engl. & Caju-Açu & Anacardiaceae \\
\hline 003 & II & Aniba burcherllii Kersterm & Louro amarelo & Lauraceae \\
\hline 004 & . & Aniba canelilla Mez. & Preciosa & Lauraceae \\
\hline 005 & & Annonaceae Gr. Envira & Envira Pinaúba & Annonaceae \\
\hline 006 & & Annonaceae Gr. Pimenta & $\begin{array}{l}\text { Pimenta de } \\
\text { Jacu }\end{array}$ & Annonaceae \\
\hline 007 & & Apeiba echinata Ducke & $\begin{array}{l}\text { Pente de Ma } \\
\text { caco }\end{array}$ & Tiliaceae \\
\hline 008 & & Apuleia molaris Benth & Muiratauá & Leguminoseae \\
\hline 009 & III & Aspidosperma sp. & Araracanga & Apocynaceae \\
\hline 010 & II & $\begin{array}{l}\text { Aspidosperma duckei Huber } \\
\text { ex Ducke }\end{array}$ & Bucheira & Apocynaceae \\
\hline 011 & I & Astronium lecointei Ducke & Muiracatiara & Anacardiaceae \\
\hline 012 & II & $\begin{array}{l}\text { Astronium fraxinifolium } \\
\text { Mattick }\end{array}$ & Aroeira & Anacardiaceae \\
\hline 013 & II & Bagasa guianensis Aubl. & Tatajuba & Moraceae \\
\hline 014 & & Bellutia & Muuba da Mata & Melastomataceae \\
\hline 015 & II & Berthollettia excelsa HBK & $\begin{array}{l}\text { Castanha do } \\
\text { Pará }\end{array}$ & Lecythidaceae \\
\hline 016 & III & Bixa arborea Huber. & Urucu da Mata & Bixaceae \\
\hline 017 & III & $\begin{array}{l}\text { Bocageopsis multiflora } \\
\text { R.E. Fries }\end{array}$ & Envira Preta & Annonaceae \\
\hline 018 & III & Bombax sp. & Mamorana & Bombacaceae \\
\hline
\end{tabular}




\begin{tabular}{|c|c|c|c|c|}
\hline cठ̃DIGO & CLASSE & NOME CIENTIFICO & N. VULGAR & FAMILIA \\
\hline 019 & III & Bombax paraense Ducke & Mungubarana & Bombacaceae \\
\hline 020 & I & Bowdichia nitida Spruce & Sucupira & Leguminoseae \\
\hline 021 & III & Brosimum spp. & Janità & Moraceae \\
\hline 022 & III & Brosimum spp. & $\begin{array}{l}\text { Amapá folha } \\
\text { larga }\end{array}$ & Moraceae \\
\hline 023 & III & Brosimum amplicoma Ducke & $\begin{array}{l}\text { Amapā Amar- } \\
\text { goso }\end{array}$ & Moraceae \\
\hline 024 & & Brosimum obovatum Ducke & Mururé & Moraceae \\
\hline 025 & III & Brosimum spp. & $\begin{array}{l}\text { Amapá doce } \\
\text { folha miūda }\end{array}$ & Moraceae \\
\hline 026 & & Brosimum vellutinum Ducke & Caxinguba & Moraceae, \\
\hline 027 & I & Calophyllum brasiliense Camb. & Jacareüba & Guttiferaceae \\
\hline 028 & I & Carapa guianensis Aubl. & Andiroba & Meliaceae \\
\hline 029 & II & Caryocar villosum Wittm. & Piquiā & Cariocaraceae \\
\hline 030 & & Cassia apoucouita Benth. & Irari & Leguminoseae \\
\hline 031 & & Cassia leiandra Sandwith & Mari-mari & Leguminoseae \\
\hline 032 & & Cassia lucens Huber & Cassia & Leguminoseae \\
\hline 033 & & Cassia spruceana D.C. & Fava mari-mari & Leguminoseae \\
\hline 034 & I & Cedrela odorata L. & Cedro vermelho & Meliaceae \\
\hline 035 & I & Ceiba pentandra Bakh & Sumaúma & Bombacaceae \\
\hline 036 & & Chaunochi Kappleri Ducke & Lacrão & Olacaceae \\
\hline 037 & $\mathrm{I}$ & Clarisia racemosa R. Pav. & Guariūba & Moraceae \\
\hline 038 & & Coccoloba sp. & Tinteiro & Poligonaceae \\
\hline
\end{tabular}


84.

\begin{tabular}{|c|c|c|c|c|}
\hline CODIGO & CLASSE & NOME CIENTIFICO & N. VULGAR & FAMILIA \\
\hline 039 & & $\begin{array}{l}\text { Connarus angustifolius } \\
\text { Schellenb }\end{array}$ & Connarua & Connaraceae \\
\hline 040 & II & Copaifera duckei Dwyer & Copaíba & Leguminoseae \\
\hline 041 & I & Cordia goeldiana Huber & $\begin{array}{l}\text { Freijó verda } \\
\text { deiro }\end{array}$ & Borraginaceae \\
\hline 042 & II & Cordia bicolor A.DC. & Freijó branco & Borraginaceae \\
\hline 043 & & Conceveiba guianensis Ducke & Maravuvia & Euphorbiaceae \\
\hline 044 & & Couepia bracteosa Ducke & Pajurá da mata & Rosaceae \\
\hline 045 & & Couma spp. & Marfim preto & Apocynaceae \\
\hline 046 & II & Couma guianensis Aub1. & Sorva & Apocynaceae \\
\hline 047 & III & Crudia glaberrima Macbr. & Fava-Ipê & Leguminoseae \\
\hline 048 & & Dialium guianensis Aubl. & Jutai-pororoca & Leguminoseae \\
\hline 049 & II & $\begin{array}{l}\text { Didymopanax morototoni Mar } \\
\text { chal }\end{array}$ & Morototó & Araliaceae \\
\hline 050 & II & Dinizzia excelsa Ducke & Angelim pedra & Leguminoseae \\
\hline 051 & III & Diospyros guianensis Ducke & Caqui & Ebenaceae \\
\hline 052 & III & $\begin{array}{l}\text { Diospyros praetermissa San } \\
\text { dwith }\end{array}$ & Caqui & Ebenaceae \\
\hline 053 & II & Dipteryx odorata Ducke & Cumaru & Leguminoseae \\
\hline 054 & $\mathrm{I}$ & Diplotropis spp. & Sucupira & Leguminoseae \\
\hline 055 & III & Endopleura uchi Cuatr. & Uchi 1 iso & Humiriaceae \\
\hline 056 & III & Enterolobium maximum Ducke & Fava timbaúba & Leguminoseae \\
\hline 057 & II & $\begin{array}{l}\text { Enterolobium schomburgkii } \\
\text { Benth }\end{array}$ & Fava de rosca & Leguminoseae \\
\hline
\end{tabular}




\begin{tabular}{|c|c|c|c|c|}
\hline CODIGO & CLASSE & NOME CIENTIFICO & N. VULGAR & FAMILIA \\
\hline 058 & III & Erisma uncinatum Warm. & Quarubarana & Vochysiaceae \\
\hline 059 & & Eschweilera amara Ndz. & $\begin{array}{l}\text { Matā-matá ver } \\
\text { melho }\end{array}$ & Lecytidaceae \\
\hline 060 & & $\begin{array}{l}\text { Eschweilera amazonica R. } \\
\text { Knuth }\end{array}$ & Matā-matáa & Lecythidaceae \\
\hline 061 & & Eschweilera odora Warm. & $\begin{array}{l}\text { Matā-matā } \\
\text { branco }\end{array}$ & Lecythidaceae \\
\hline 062 & & Eschweilera spp. & $\begin{array}{l}\text { Matā-matá } \\
\text { preto }\end{array}$ & Lecuthidaceae \\
\hline 063 & & Eugania spp. & Goiabinha & Mirtaceae \\
\hline 064 & III & Fagara spp. & Tamanqueira & Rutaceae \\
\hline 065 & & Fusaea longifolia Safford & $\begin{array}{l}\text { Envira suru- } \\
\text { cucu }\end{array}$ & Annonaceae \\
\hline 066 & III & $\begin{array}{l}\text { Glycydendron amazonicum } \\
\text { Ducke }\end{array}$ & $\begin{array}{l}\text { Mirindiba do } \\
\text { ce }\end{array}$ & Euphorbiaceae \\
\hline 067 & & Guarea costata C. DC. & Jatuauba preta & Meliaceae \\
\hline 068 & & $\begin{array}{l}\text { Guatteria amazonica R.E. } \\
\text { Fries }\end{array}$ & Envira branca & Annonaceae \\
\hline 069 & II & Goupia glabra Aubl. & Cupiūba & Celastraceae \\
\hline 070 & & Heisteria flexuosa Engl. & $\begin{array}{l}\text { Não encontra } \\
\text { da }\end{array}$ & Olacaceae \\
\hline 071 & III & Hevea spp. & $\begin{array}{l}\text { Seringa fraca } \\
\text { da mata }\end{array}$ & Euphorbiaceae \\
\hline 072 & III & Hevea spp. & Seringueira & Euphorbiaceae \\
\hline 073 & III & Hevea spruceana Ducke & $\begin{array}{l}\text { Seringa barri } \\
\text { guda }\end{array}$ & Euphorbiaceae \\
\hline
\end{tabular}




\begin{tabular}{|c|c|c|c|c|}
\hline CODIGO & CLASSE & NOME CIENTIFICO & N. VULGAR & FAMILIA \\
\hline 074 & & Hippecratea volubitis Ubr. & Fava de arara & Hippocrateace \\
\hline 075 & II & Holopyxidium jarana Ducke & Jarana & Lecythidaceae \\
\hline 076 & & Hymattanthus sucuuba Warm & Sucuuba & Apocynaceae \\
\hline 077 & II & Hymenacea courbaril L. & Jutai-açu & Leguminoseae \\
\hline 078 & II & Hymenaea parvifolia Huber & Jutai mirim & Leguminoseae \\
\hline 079 & III & Hymenolobium spp. & $\begin{array}{l}\text { Angelim da } \\
\text { mata }\end{array}$ & Leguminoseae \\
\hline 080 & & Inga alba Wille & Ingā-chichi & Leguminoseae \\
\hline 081 & & Inga gracilifolia Ducke & Ingā & Leguminoseae \\
\hline 082 & III & Jacaranda copaia Bur. & Parapará & Bignoniaceae \\
\hline 083 & & $\begin{array}{l}\text { Laetia procera (Poepp) } \\
\text { Eich1 }\end{array}$ & Pau Jacaré & Flacourtiaceae \\
\hline 084 & III & Não identificado Nọ 1 & & \\
\hline 085 & II & $\begin{array}{l}\text { Lecythis usitata var. paraen } \\
\text { sis R. Knuth }\end{array}$ & $\begin{array}{l}\text { Castanha sa- } \\
\text { pucaia }\end{array}$ & Lecythidaceae \\
\hline 086 & & Licania heterophylla Aubl. & Macucu & Rosaceae \\
\hline 087 & & Licania incana Aubl. & Caraipe & Rosaceae \\
\hline 088 & & Licania micrantha & Caraiperana & Rosaceae \\
\hline 089 & & Luhea procera Mart. & Açoita cavalo & Tiliaceae \\
\hline 090 & II & Manilkara huberi Ducke & Maçaranduba & Sapotaceae \\
\hline 091 & II & Manilkara paraensis & Maparajuba & Sapotaceae \\
\hline 092 & III & Maquira sclerophylla Aub1. & $\begin{array}{l}\text { Muiratinga } \mathrm{Fo} \\
\text { lha larga }\end{array}$ & Moraceae \\
\hline 093 & & Maytenus guianensis & Chichuá & Celastraceae \\
\hline
\end{tabular}




\begin{tabular}{|c|c|c|c|c|}
\hline CठDIGO & CLASSE & NOME CIENTIFICO & N. VULGAR & FAMILIA \\
\hline 094 & II & $\begin{array}{l}\text { Mezilaurus itauba Taubert } \\
\text { ex Mez. }\end{array}$ & Itauba & Lauraceae \\
\hline 095 & II & Mezilaurus lindaviana Mez & Itauba amarela & Lauraceae \\
\hline 096 & & Micropholis spp. & Abiurana & Sapotaceae \\
\hline 097 & & Micropholis guyanensis & Rosadinha & Sapotaceae \\
\hline 098 & & Myrcia falax & Murta & Myrtaceae \\
\hline 099 & & Neea spp. & João mole & Nyctaginaceae \\
\hline 100 & III & Nectandra spp. & Louro & Lauraceae \\
\hline 101 & & Não identificado Nọ 2 & & \\
\hline 102 & III & Ocotea guianensis Kosterm & Louro branco & Lauraceae \\
\hline 103 & III & Ocotea spp. & Louro preto & Lauraceae \\
\hline 104 & I & Ocotea rubra Mez. & $\begin{array}{l}\text { Louro verme- } \\
\text { lho }\end{array}$ & Lauraceae \\
\hline 105 & & Ormosia coccinea Rudd. & Tento & Leguminoseae \\
\hline 106 & III & Brosimum spp. & Amapá doce & Apocynaceae \\
\hline 107 & II & Hymenolobium excelsum Benth & $\begin{array}{l}\text { Angelim da } \\
\text { mata }\end{array}$ & Leguminoseae \\
\hline 108 & III & Parkia pendula $R$. Benoist & Visgueiro & Leguminoseae \\
\hline 109 & III & Parkia multijuga Benth. & $\begin{array}{l}\text { Paracá Grd.da } \\
\text { Terra firme }\end{array}$ & Leguminoseae \\
\hline 110 & III & Vataireopsis Ducke & Fava amargosa & Leguminoseae \\
\hline 111 & III & Peltogyne spp. & Coatá-quiçaua & Leguminoseae \\
\hline 112 & III & Perebea spp. & $\begin{array}{l}\text { Muiratinga pe } \\
\text { luda }\end{array}$ & Moraceae \\
\hline 113 & & Piptadenia spp. & $\begin{array}{l}\text { Fava folha } \\
\text { fina }\end{array}$ & Leguminoseae \\
\hline
\end{tabular}




\begin{tabular}{|c|c|c|c|c|}
\hline cठDIGO & CLASSE & NOME CIENTIFICO & N. VULGAR & FAMILIA \\
\hline 114 & & $\begin{array}{l}\text { Pithecelobium cauliflorum } \\
\text { Lindm. }\end{array}$ & Ingarana & Leguminoseae \\
\hline 115 & I & $\begin{array}{l}\text { Pithecelobium recemosum } \\
\text { Ducke }\end{array}$ & $\begin{array}{l}\text { Angelim raja } \\
\text { do }\end{array}$ & Leguminoseae \\
\hline 116 & I & Platymiscium filipes Benth & Macacaūba & Leguminoseae \\
\hline 117 & & Phyllanthus sp. & Ginja & Euphorbiaceae \\
\hline 118 & & $\begin{array}{l}\text { Pogonophora schomburgkiana } \\
\text { Benth }\end{array}$ & Amarelinho & Euphorbiaceae \\
\hline 119 & & Pouteria spp. & Abiurana & Sapotaceae \\
\hline 120 & & Pouteria spp. & Abiurana & Sapotaceae \\
\hline 121 & & Pouteria spp. & $\begin{array}{l}\text { Abiurana fru } \\
\text { tão }\end{array}$ & Sapotaceae \\
\hline 122 & & Pouteria spp. & $\begin{array}{l}\text { Abiurana pelu } \\
\text { da }\end{array}$ & Sapotaceae \\
\hline 123 & & Pouteria spp. & Abiu pitomba & Sapotaceae \\
\hline 124 & & Pouteria spp. & $\begin{array}{l}\text { Abiurana cas } \\
\text { ca fina }\end{array}$ & Sapotaceae \\
\hline .125 & & Pouteria engleri Eyma & $\begin{array}{l}\text { Abiurana } C . \\
\text { grossa }\end{array}$ & Sapotaceae \\
\hline 126 & & Pouteria laurifolia Ducke & Abiu seco & Sapotaceae \\
\hline 127 & & Pouteria macrophylla Eyma & $\begin{array}{l}\text { Abiurana cu- } \\
\text { tite }\end{array}$ & Sapotaceae \\
\hline 128 & & Protium spp. & Breu & Burseraceae \\
\hline 129 & & Protium giganteum Engl. & Breu vermelho & Burseraceae \\
\hline
\end{tabular}




\begin{tabular}{|c|c|c|c|c|}
\hline CరDDIGO & CLASSE & NOME CIENTIFICO & N. VULGAR & FAMILIA \\
\hline 130 & & Protium pallidum Cuatr. & Breu branco & Burseraceae \\
\hline 131 & II & Qualea alboflora Warm. & Mandioqueira & Vochysiaceae \\
\hline 132 & & Rollinia exsucca R.E.Fries & Envira preta & Annonaceae \\
\hline 133 & III & Roupala spp. & Faiera & Proteaceae \\
\hline 134 & III & $\begin{array}{l}\text { Saccoglottis guianensis } \\
\text { Ducke }\end{array}$ & Achua & Humiriaceae \\
\hline 135 & & $\begin{array}{l}\text { Sclerolobium guianensis } \\
\text { Dwyer }\end{array}$ & Tachi & Leguminoseae \\
\hline 136 & & $\begin{array}{l}\text { Sclerolobium aff. chryso- } \\
\text { phyllum, Poepp. \& Endl. }\end{array}$ & $\begin{array}{l}\text { Tachi verme } \\
\text { lho }\end{array}$ & Leguminoseae \\
\hline 137 & III & Tachigalia alba Ducke & Tachi branco & Leguminoseae \\
\hline 138 & II & Simaruba amara Engl. & Marupá & Simarubaceae \\
\hline 139 & & Symplocos spp. & $\begin{array}{l}\text { Não encon- } \\
\text { trado }\end{array}$ & Symplocaceae \\
\hline 140 & & Symplocos spp. & $\begin{array}{l}\text { Não encon- } \\
\text { trado }\end{array}$ & Sumplocaceae \\
\hline 141 & & Simaruba guianensis A.Dc. & Capitu & Monimiaceae \\
\hline 142 & & Sloanea grandiflora L. & Urucurana & Tiliaceae \\
\hline 143 & & Sterculia spp. & Achichā & Sterculiaceae \\
\hline 144 & & Stryphnodendrom pulcherrimum & $\begin{array}{l}\text { Fava barbati } \\
\text { mão }\end{array}$ & Leguminoseae \\
\hline 145 & & Swartzia spp. & $\begin{array}{l}\text { Não encontra } \\
\text { do }\end{array}$ & Leguminoseae \\
\hline 146 & III & Swartizia spp. & $\begin{array}{l}\text { Não encontra } \\
\text { do }\end{array}$ & Leguminoseae \\
\hline 147 & & Swartizia spp. & $\begin{array}{l}\text { Não encontra } \\
\text { do }\end{array}$ & Leguminoseae \\
\hline
\end{tabular}




\begin{tabular}{|c|c|c|c|c|}
\hline CODIGO & CLASSE & NOME CIENTIFICO & N. VULGAR & FAMILIA \\
\hline 148 & & Swartizia spp. & $\begin{array}{l}\text { Não encontra } \\
\text { do }\end{array}$ & Leguminoseae \\
\hline 149 & III & Symphonia globulifera Ducke & Anani & Guttiferaceae \\
\hline 150 & II & Tabebuia serratifolia Rolfe. & $\begin{array}{l}\text { Pau d'arco a } \\
\text { marelo }\end{array}$ & Bignoniaceae \\
\hline 151 & " & Sclerolobium spp. & $\begin{array}{l}\text { Tachi preto } \\
\text { folha miúda }\end{array}$ & Leguminoseae \\
\hline 152 & III & Tachigalia myrmecophila Ducke & $\begin{array}{l}\text { Tachi preto } \\
\text { folha grande }\end{array}$ & Leguminoseae \\
\hline 153 & & Talisia spp. & Pitomba & Sapindaceae \\
\hline 154 & & Talisia spp. & $\begin{array}{l}\text { Pitomba de } \\
\text { leite }\end{array}$ & Sapindaceae \\
\hline 155 & III & Terminalia spp. & Cuiarana & Combretaceae \\
\hline 156 & & Tapirira guianensis Engler & Tatapiririca & Anacardiaceae \\
\hline 157 & III & Trattinickia rhoifolia Engler & Breu Sucuruba & Burseraceae \\
\hline 158 & & Trichilia hirsuta Benth & Chachuā & Meliaceae \\
\hline 159 & & Trichilia spp. & Não encontrado & Meliaceae \\
\hline 160 & III & Vantanea spp. & Uchirana & Humiriaceae \\
\hline 161 & III & Vatairea guianensis Aubl. & $\begin{array}{l}\text { Fava Grd. do } \\
\text { Igapó }\end{array}$ & Leguminoseae \\
\hline 162 & III & Virola spp. & $\begin{array}{l}\text { Ucuuba terra } \\
\text { firme }\end{array}$ & Myristicaceae \\
\hline 163 & III & Virola spp. & $\begin{array}{l}\text { Ucuuba folha } \\
\text { peluda }\end{array}$ & Myristicaceae \\
\hline 164 & III & Virola sebifera Aubl. & $\begin{array}{l}\text { Ucuuba verme } \\
\text { lha }\end{array}$ & Myristicaceae \\
\hline 165 & & Vitex spp. & Taruma & Verbenaceae \\
\hline 166 & I & Vochysia maxima Ducke & $\begin{array}{l}\text { Quaruba ver- } \\
\text { dadeira }\end{array}$ & Vochysiaceae \\
\hline 167 & III & Byrsonima crispa Juss & Muruci da mata & Malpighyaceae \\
\hline
\end{tabular}


APENDICE III - Matriz dos dados. 


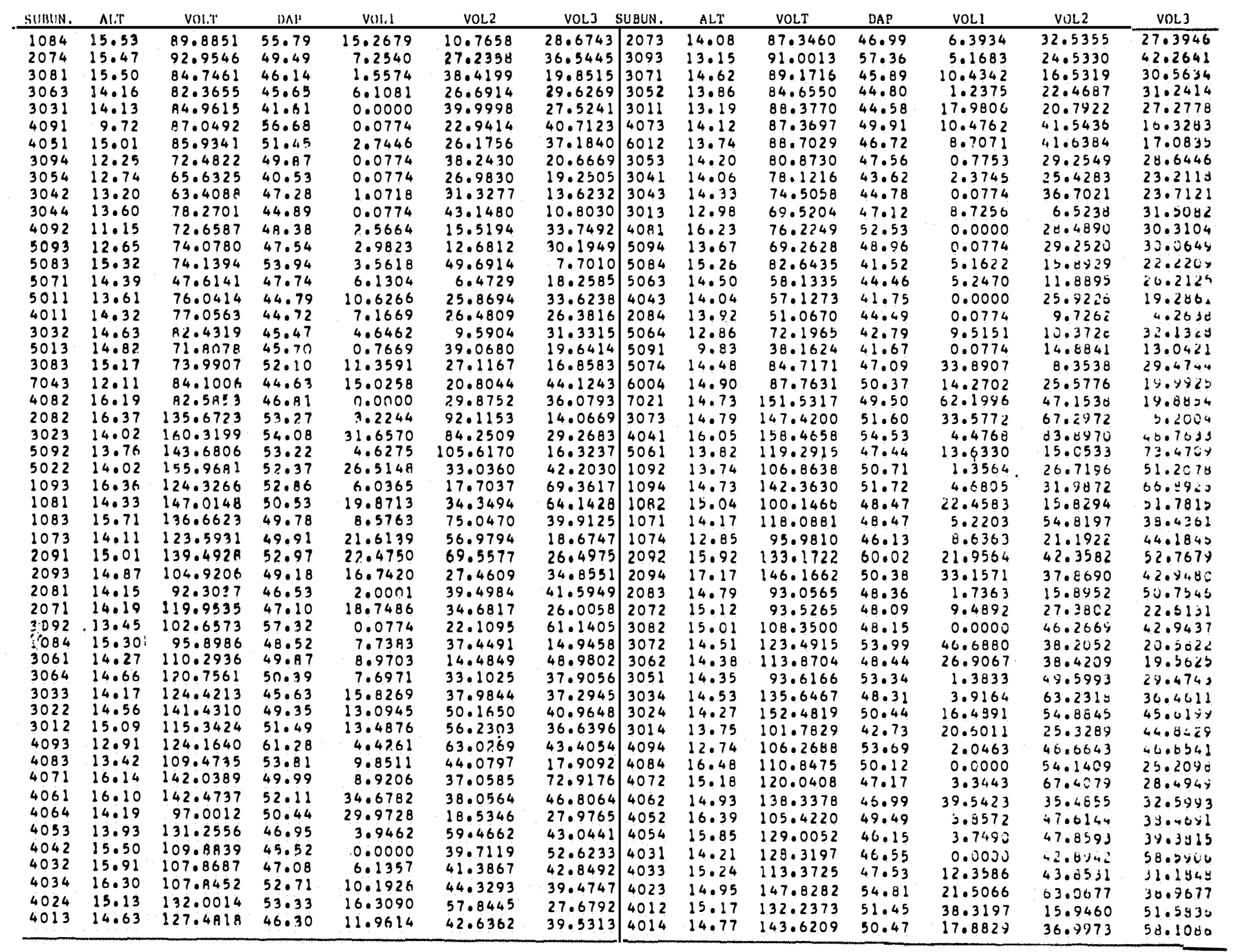




\begin{tabular}{|c|c|c|c|c|c|c|c|c|c|c|c|c|c|}
\hline & Alil & Volit & DAP & VULL & VOL2 & $\mathrm{VOL} 3$ & SUBUN. & ALT & VOLT & DAP & vol. 1 & v०L. 2 & VOLS \\
\hline $\begin{array}{l}5081 \\
5072\end{array}$ & $\begin{array}{l}16.12 \\
14.87\end{array}$ & $\begin{array}{l}145.2978 \\
114.2653\end{array}$ & $\begin{array}{l}50.15 \\
47.18\end{array}$ & $\begin{array}{l}29.2437 \\
12.4699\end{array}$ & $\begin{array}{l}53.2640 \\
38.6020\end{array}$ & $\begin{array}{l}35.4701 \\
43.7271\end{array}$ & \begin{tabular}{|l|}
5082 \\
5073
\end{tabular} & $\begin{array}{l}16.12 \\
15.86\end{array}$ & $\begin{array}{l}118.0885 \\
140.1567\end{array}$ & $\begin{array}{l}51.52 \\
50.87\end{array}$ & $\begin{array}{l}22.2611 \\
24.0284\end{array}$ & $\begin{array}{l}36.7247 \\
30.1754\end{array}$ & $\begin{array}{l}35.5321 \\
40.5542\end{array}$ \\
\hline $\begin{array}{l}5062 \\
5054 \\
5031\end{array}$ & $\begin{array}{l}14.55 \\
13.65 \\
16.12\end{array}$ & $\begin{array}{l}103.8129 \\
108.1405 \\
152.2186\end{array}$ & $\begin{array}{l}53.05 \\
48.49 \\
48.19\end{array}$ & $\begin{array}{r}31.4390 \\
7.0833 \\
8.1464\end{array}$ & $\begin{array}{l}4401253 \\
38.2959 \\
4400537\end{array}$ & $\begin{array}{l}15.6844 \\
42.2432 \\
71.4139\end{array}$ & $\begin{array}{l}5052 . \\
5041 \\
5033\end{array}$ & $\begin{array}{l}15.25 \\
16.02 \\
14.23\end{array}$ & $\begin{array}{l}146.4219 \\
147.3414 \\
122.3332\end{array}$ & $\begin{array}{l}54.91 \\
48.86 \\
48.20\end{array}$ & $\begin{array}{r}14.3301 \\
26.7645 \\
6.6462\end{array}$ & $\begin{array}{l}69.1130 \\
31.3972 \\
21.6540\end{array}$ & $\begin{array}{l}48.4436 \\
66.3101 \\
04.6900\end{array}$ \\
\hline $\begin{array}{l}5034 \\
5023 \\
5012\end{array}$ & $\begin{array}{l}13.83 \\
14055 \\
14006\end{array}$ & $\begin{array}{r}94.4741 \\
123.4919 \\
129.9865\end{array}$ & $\begin{array}{l}45.93 \\
48.67 \\
48.81\end{array}$ & $\begin{array}{r}3.1607 \\
10.3392 \\
25.1385\end{array}$ & $\begin{array}{l}26.3829 \\
55.6053 \\
53.3690\end{array}$ & $\begin{array}{l}37.6851 \\
36.3155 \\
35.2665\end{array}$ & $\begin{array}{l}5021 \\
5024 \\
5014\end{array}$ & $\begin{array}{l}14.54 \\
13.95 \\
15.79\end{array}$ & $\begin{array}{l}142.6302 \\
103.2139 \\
125.1054\end{array}$ & $\begin{array}{l}49.56 \\
46.76 \\
50.10\end{array}$ & $\begin{array}{l}22.2449 \\
26.6664 \\
3405274\end{array}$ & $\begin{array}{l}53.4365 \\
10.1832 \\
50.2045\end{array}$ & $\begin{array}{l}5400429 \\
33.6457 \\
21.6430\end{array}$ \\
\hline $\begin{array}{l}6084 \\
6072 \\
6073\end{array}$ & $\begin{array}{l}15.42 \\
13.88 \\
13.58\end{array}$ & $\begin{array}{r}104.9161 \\
111.3443 \\
98.1044\end{array}$ & $\begin{array}{l}47.95 \\
48.49 \\
51.72\end{array}$ & $\begin{array}{r}2.3083 \\
19.8017 \\
27.8618\end{array}$ & $\begin{array}{l}31.7143 \\
13.3325 \\
19.9010\end{array}$ & $\begin{array}{l}45.4582 \\
55.3935 \\
26.7871\end{array}$ & $\begin{array}{l}6071 \\
6074 \\
6062\end{array}$ & $\begin{array}{l}13.88 \\
15.48 \\
12.63\end{array}$ & $\begin{array}{l}128.1377 \\
118.7605 \\
135.9918\end{array}$ & $\begin{array}{l}55.34 \\
50.33 \\
48.49\end{array}$ & $\begin{array}{r}1.2829 \\
27.3882 \\
6.2778\end{array}$ & $\begin{array}{l}40.9985 \\
31.9830 \\
66.0183\end{array}$ & $\begin{array}{l}64.8180 \\
37.3767 \\
46.0725\end{array}$ \\
\hline $\begin{array}{l}6051 \\
6054 \\
6042\end{array}$ & $\begin{array}{l}14051 \\
13.68 \\
13059\end{array}$ & $\begin{array}{l}117.7313 \\
128.01096 \\
15508163\end{array}$ & $\begin{array}{l}49.29 \\
51.86 \\
49.74\end{array}$ & $\begin{array}{l}32.6333 \\
11.8591 \\
29.3602\end{array}$ & $\begin{array}{l}51.1232 \\
36.3472 \\
47.6030\end{array}$ & $\begin{array}{l}19.0515 \\
53.8252 \\
56.9500\end{array}$ & $\begin{array}{l}6053 \\
6041 \\
6044\end{array}$ & $\begin{array}{l}14.59 \\
15.82 \\
15.21\end{array}$ & $\begin{array}{l}122.0495 \\
139.2592 \\
130.9545\end{array}$ & $\begin{array}{l}51.90 \\
52.82 \\
50.58\end{array}$ & $\begin{array}{l}13.5464 \\
19.8206 \\
30.6801\end{array}$ & $\begin{array}{l}41.2633 \\
36.0940 \\
32.8031\end{array}$ & $\begin{array}{l}5406440 \\
60.4254 \\
46.0130\end{array}$ \\
\hline $\begin{array}{l}6032 \\
6013 \\
6002\end{array}$ & $\begin{array}{l}13.80 \\
14.67 \\
14.23\end{array}$ & $\begin{array}{l}110.9276 \\
149.9336 \\
117.1640\end{array}$ & $\begin{array}{l}46.58 \\
47.21 \\
51.59\end{array}$ & $\begin{array}{r}23.7692 \\
8.0299 \\
14.2765\end{array}$ & $\begin{array}{l}21.6373 \\
57.8774 \\
42.7034\end{array}$ & $\begin{array}{l}44.0845 \\
55.6765 \\
42.9534\end{array}$ & $\begin{array}{l}6033 \\
6014 \\
7081\end{array}$ & & $\begin{array}{l}107.4037 \\
104.3351 \\
139.2249\end{array}$ & $\begin{array}{l}48.15 \\
49.18 \\
50.08\end{array}$ & $\begin{array}{l}14.9123 \\
15.8469 \\
1.7760\end{array}$ & $\begin{array}{l}35.7552 \\
53.0706 \\
46.4421\end{array}$ & $\begin{array}{l}23.2100 \\
20.0345 \\
64.4704\end{array}$ \\
\hline $\begin{array}{l}7083 \\
7071 \\
7074 \\
7062 \\
7052 \\
7054\end{array}$ & $\begin{array}{l}14.20 \\
13.83 \\
14.119 \\
12.69 \\
13.95 \\
13.81\end{array}$ & $\begin{array}{r}110.2373 \\
1340900 \\
97.6840 \\
126.5169 \\
120.3177 \\
98.6302\end{array}$ & $\begin{array}{l}47.27 \\
49.69 \\
52.63 \\
48.81 \\
51.04 \\
47.18\end{array}$ & $\begin{array}{r}0.0774 \\
6.8716 \\
19.8348 \\
1.4659 \\
7.0017 \\
19.2651\end{array}$ & $\begin{array}{l}34.4876 \\
23.8618 \\
21.3725 \\
41.8506 \\
38.9577 \\
20.2532\end{array}$ & $\begin{array}{l}37.5018 \\
68.9984 \\
48.5455 \\
63.2533 \\
41.5474 \\
36.5241\end{array}$ & $\begin{array}{l}7084 \\
7073 \\
7061 \\
7063 \\
7053 \\
7041\end{array}$ & $\begin{array}{l}15.94 \\
12.74 \\
14.07 \\
12.38 \\
14.86 \\
12.27\end{array}$ & $\begin{array}{l}152.5922 \\
114.0076 \\
154.1652 \\
104.8449 \\
141.0435 \\
138.3084\end{array}$ & $\begin{array}{l}53.07 \\
50.86 \\
56.70 \\
50.48 \\
49.66 \\
52.28\end{array}$ & $\begin{array}{r}3.3674 \\
0.6479 \\
36.4179 \\
7.2708 \\
7.5205 \\
39.8827\end{array}$ & $\begin{array}{l}46.7469 \\
18.7070 \\
32.1698 \\
24.4101 \\
39.9944 \\
44.7659\end{array}$ & $\begin{array}{l}64.0060 \\
59.1425 \\
63.3242 \\
35.9701 \\
62.0401 \\
39.1772\end{array}$ \\
\hline $\begin{array}{l}7044 \\
7033 \\
7024\end{array}$ & $\begin{array}{l}12.40 \\
14.87 \\
14.90\end{array}$ & $\begin{array}{r}99.3037 \\
120.2857 \\
147.9737\end{array}$ & $\begin{array}{l}46.11 \\
49.07 \\
55.38\end{array}$ & $\begin{array}{l}20.6760 \\
22.5298 \\
45.5158\end{array}$ & $\begin{array}{l}22.9849 \\
46.0195 \\
37.4199\end{array}$ & $\begin{array}{l}40.6504 \\
30.3399 \\
54.3350\end{array}$ & $\begin{array}{l}7031 \\
7023 \\
7011\end{array}$ & & & $\begin{array}{l}46.51 \\
45.44 \\
56.60\end{array}$ & $\begin{array}{r}12.3465 \\
9.1042 \\
40.8214\end{array}$ & $\begin{array}{l}37.0931 \\
33.2062 \\
46.5548\end{array}$ & $\begin{array}{l}36.1671 \\
6.0514 \\
23.7270\end{array}$ \\
\hline $\begin{array}{l}7012 \\
7014\end{array}$ & $\begin{array}{l}13.45 \\
14.22\end{array}$ & $\begin{array}{l}103.4606 \\
139.0050\end{array}$ & $\begin{array}{l}45.81 \\
55.20\end{array}$ & $\begin{array}{r}4.6785 \\
26.8539\end{array}$ & $\begin{array}{l}29.3462 \\
60.5616\end{array}$ & $\begin{array}{l}47.8953 \\
38.2223\end{array}$ & $\begin{array}{l}7013 \\
7003\end{array}$ & $\begin{array}{l}14.18 \\
14.39\end{array}$ & $\begin{array}{l}104.5969 \\
103.8877\end{array}$ & $\begin{array}{l}51.97 \\
47.71\end{array}$ & $\begin{array}{r}8.5792 \\
16.2607\end{array}$ & $\begin{array}{l}45.3514 \\
50.1108\end{array}$ & $\begin{array}{l}33.170: \\
13.6910\end{array}$ \\
\hline $\begin{array}{l}7014 \\
7032\end{array}$ & 14.30 & 127.4943 & 47.73 & 16.3781 & $\begin{array}{r}00.5616 \\
8.4507\end{array}$ & 87.3599 & 7034 & & 107.4352 & 46.96 & 37.2648 & 24.2413 & $1 \% .2600$ \\
\hline $\begin{array}{l}4044 \\
6034 \\
5044\end{array}$ & $\begin{array}{l}14.94 \\
14.45 \\
13.85\end{array}$ & $\begin{array}{l}137.4869 \\
161.5088 \\
156.5022\end{array}$ & $\begin{array}{l}51.82 \\
47.39 \\
52.37\end{array}$ & $\begin{array}{r}3.3673 \\
41.8210 \\
21.0401\end{array}$ & $\begin{array}{l}74.1001 \\
47.3613 \\
20.5239\end{array}$ & $\begin{array}{l}31.0338 \\
29.0165 \\
87.4305\end{array}$ & $\begin{array}{l}6064 \\
7051 \\
6003\end{array}$ & $\begin{array}{l}14.23 \\
15.05 \\
12.59\end{array}$ & $\begin{array}{l}162.4811 \\
134.8249 \\
114.2937\end{array}$ & $\begin{array}{l}49.06 \\
49.47 \\
49.83\end{array}$ & $\begin{array}{l}23.4058 \\
17.0811 \\
25.2443\end{array}$ & $\begin{array}{l}76.5185 \\
23.2726 \\
48.2047\end{array}$ & $\begin{array}{l}47.8821 \\
84.2227 \\
23.5037\end{array}$ \\
\hline $\begin{array}{l}1072 \\
7064 \\
6082\end{array}$ & $\begin{array}{l}13.75 \\
12.34 \\
15.76\end{array}$ & $\begin{array}{l}104.0773 \\
124.5726 \\
158.7056\end{array}$ & $\begin{array}{l}48.97 \\
48.43 \\
33.45\end{array}$ & $\begin{array}{r}1.6883 \\
39.6629 \\
1.0171\end{array}$ & $\begin{array}{l}21.5769 \\
10.6375 \\
49.3309\end{array}$ & $\begin{array}{l}25.1269 \\
47.7221 \\
66.2350\end{array}$ & $\begin{array}{l}4074 \\
5032 \\
6031\end{array}$ & $\begin{array}{l}15.81 \\
15.58 \\
14060\end{array}$ & $\begin{array}{l}155.5606 \\
157.4042 \\
161.1587\end{array}$ & $\begin{array}{l}50.63 \\
47.69 \\
47.14\end{array}$ & $\begin{array}{r}2.0195 \\
10.0500 \\
8.7907\end{array}$ & $\begin{array}{l}74.1240 \\
19.6607 \\
59.1 .864\end{array}$ & $\begin{array}{l}51.9000 \\
89.5121 \\
69.2818\end{array}$ \\
\hline $\begin{array}{l}6001 \\
3021\end{array}$ & $\begin{array}{l}13.53 \\
14.73\end{array}$ & $\begin{array}{l}147.5419 \\
174.5112\end{array}$ & $\begin{array}{l}30.32 \\
49.88\end{array}$ & $\begin{array}{l}13.4533 \\
35.8678\end{array}$ & $\begin{array}{l}84.0116 \\
40.2023\end{array}$ & $\begin{array}{l}31.8273 \\
60.4328\end{array}$ & $\begin{array}{l}6043 \\
3091\end{array}$ & $\begin{array}{l}15.32 \\
13.56\end{array}$ & $\begin{array}{l}134.9714 \\
168.3202\end{array}$ & $\begin{array}{l}52.84 \\
57.93\end{array}$ & $\begin{array}{l}26.0673 \\
25.3648\end{array}$ & $\begin{array}{l}21.3607 \\
68.2460\end{array}$ & $\begin{array}{l}72.4747 \\
32.9853\end{array}$ \\
\hline $\begin{array}{l}4022 \\
4021\end{array}$ & $\begin{array}{l}15.15 \\
14086\end{array}$ & $\begin{array}{l}1 A 8.3988 \\
203.7609\end{array}$ & $\begin{array}{l}52.21 \\
53.92\end{array}$ & $\begin{array}{l}240 \\
27.0\end{array}$ & $\begin{array}{l}89.0981 \\
89.1957\end{array}$ & $\begin{array}{l}53.4130 \\
43.7629\end{array}$ & $\begin{array}{l}7042 \\
6011\end{array}$ & $\begin{array}{l}12.83 \\
14.83\end{array}$ & $\begin{array}{l}168.8829 \\
165.1668\end{array}$ & $\begin{array}{l}53.28 \\
51.02\end{array}$ & $\begin{array}{r}59.9964 \\
19.6487\end{array}$ & $\begin{array}{r}48.9424 \\
89.5267\end{array}$ & $\begin{array}{l}51.7712 \\
42.7502\end{array}$ \\
\hline & $\begin{array}{l}15.20 \\
13.76\end{array}$ & & $\begin{array}{l}55.49 \\
53.59\end{array}$ & & $\begin{array}{l}73.9206 \\
62.9655\end{array}$ & $\begin{array}{l}61.1076 \\
76.4975\end{array}$ & & $\begin{array}{l}14.03 \\
14.02 \\
15.11\end{array}$ & $\begin{array}{l}177.5481 \\
172.2741\end{array}$ & $\begin{array}{l}51002 \\
53.08 \\
49.12\end{array}$ & $\begin{array}{l}10.4463 \\
55.9260\end{array}$ & $\begin{array}{l}46.4134 \\
38.6973\end{array}$ & $\begin{array}{l}87.7188 \\
39.1881\end{array}$ \\
\hline $\begin{array}{l}6023 \\
7022 \\
7002 \\
4063 \\
6083 \\
6063\end{array}$ & $\begin{array}{l}13.01 \\
140.96 \\
150.25 \\
15014 \\
15.98 \\
14.30\end{array}$ & $\begin{array}{l}180.1233 \\
163.0658 \\
170.6683 \\
187.0222 \\
174.4017 \\
201.02051\end{array}$ & $\begin{array}{l}50.25 \\
51.07 \\
52.16 \\
61.57 \\
52.87 \\
50.91\end{array}$ & $\begin{array}{l}56.4178 \\
71.8191 \\
33.7601 \\
71.4591 \\
56.7322 \\
20.3709\end{array}$ & $\begin{array}{l}45.9902 \\
36.7770 \\
55.5909 \\
42.1592 \\
13.5527 \\
49.5092\end{array}$ & $\begin{array}{l}41.7042 \\
35.8166 \\
60.5571 \\
40.0595 \\
55.3577 \\
91.7233\end{array}$ & $\begin{array}{l}6024 \\
7001 \\
3074 \\
5043 \\
6061 \\
6021\end{array}$ & $\begin{array}{l}16.05 \\
13.96 \\
15.31 \\
13.57 \\
16.07 \\
15.86\end{array}$ & $\begin{array}{l}203.7940 \\
173.8114 \\
159.9600 \\
174.5297 \\
198.99112 \\
233.9733\end{array}$ & $\begin{array}{l}50.28 \\
50.41 \\
48.73 \\
53.13 \\
53.41 \\
54.39\end{array}$ & $\begin{array}{l}41.9683 \\
22.1655 \\
45.7654 \\
10.0110 \\
13.9154 \\
92.3114\end{array}$ & $\begin{array}{l}60.9771 \\
59.1912 \\
37.5979 \\
22.7086 \\
94.8083 \\
67.9557\end{array}$ & $\begin{array}{r}64.6345 \\
50.1290 \\
13.0127 \\
117.0375 \\
78.6493 \\
48.9120\end{array}$ \\
\hline $\begin{array}{l}7072 \\
7082\end{array}$ & & $\begin{array}{l}186.0994 \\
163.8518\end{array}$ & 51.30 & $\begin{array}{r}17.4207 \\
5.8497\end{array}$ & 29.1065 & 110.0468 & 7004 & 14.23 & 195.2550 & & 69.7999 & 34.6837 & 62.6225 \\
\hline & & 176.7127 & & 8.1713 & 76.7397 & 55.8455 & 5042 & & 166.2186 & 50.69 & $\begin{array}{l}36.4609 \\
40.3640\end{array}$ & & $\begin{array}{l}71.1386 \\
71.2320\end{array}$ \\
\hline
\end{tabular}


94.

APENDICE III - Valores dos escores fatoriais. 


\begin{tabular}{|c|c|c|c|c|c|c|c|c|c|c|}
\hline SUBLS. & & EAIOR 1 & FATOR 2 & FATOR 3 & EATOB_4. & SUBUN. & EATOR 1 & FATOR 2 & INTO3 3 & FATOR 4 \\
\hline $\begin{array}{l}1034 \\
2074\end{array}$ & & $\begin{array}{l}2.56532 \\
? .65=44\end{array}$ & $\begin{array}{r}-0.02350 \\
0.39327\end{array}$ & $\begin{array}{r}-1.25216 \\
0.13944\end{array}$ & $\begin{array}{l}-2.44229 \\
-1.70838\end{array}$ & $\begin{array}{l}2073 \\
30\end{array} 093$ & $\begin{array}{l}2.49334 \\
2.59763\end{array}$ & $\begin{array}{r}-0.07054 \\
0.80091\end{array}$ & $\begin{array}{l}2.37558 \\
0.24539\end{array}$ & $\begin{array}{l}-1.68709 \\
-1.49794\end{array}$ \\
\hline $\begin{array}{l}308 ! \\
2953 \\
303 ! \\
4091\end{array}$ & & $\begin{array}{l}2.41913 \\
2.35117 \\
2.42527 \\
2.43497\end{array}$ & $\begin{array}{r}-0.49195 \\
0.17438 \\
-0.01353 \\
0.79492\end{array}$ & $\begin{array}{l}0.60821 \\
0.20602 \\
1.00562 \\
0.22326\end{array}$ & $\begin{array}{l}-2.21698 \\
-1.57813 \\
-1.65811 \\
-2.01373\end{array}$ & $\begin{array}{llll}3 & 0 & 71 \\
3 & 0 & 5 & 2 \\
3 & 0 & 1 & 1 \\
4 & 0 & 7 & 3\end{array}$ & $\begin{array}{l}2.54545 \\
2.41653 \\
2.52277 \\
2.49402\end{array}$ & $\begin{array}{r}0.10401 \\
0.24103 \\
-0.09906 \\
-0.77582\end{array}$ & $\begin{array}{r}-0.73=11 \\
-0 .:=05 \\
-0.54=7 \\
0.59-14\end{array}$ & $\begin{array}{l}-2.36291 \\
-2.54925 \\
-1.33727 \\
-1.01453\end{array}$ \\
\hline 4051 & & 2.45304 & 0.58123 & 0.34464 & -1.67307 & 6012 & 2.53208 & -0.75410 & 0.56358 & -1.67246 \\
\hline $\begin{array}{l}3094 \\
3054\end{array}$ & & 2.06905 & -0.18990 & 1.06446 & -1.28295 & 3053 & 2.30857 & 0.14746 & $0 . \div 1974$ & -1.96093 \\
\hline $\begin{array}{l}3054 \\
3042\end{array}$ & & $\begin{array}{l}.37352 \\
.31004\end{array}$ & $\begin{array}{l}-0.13312 \\
-0.44368\end{array}$ & $\begin{array}{l}0.142539 \\
0.60797\end{array}$ & $\begin{array}{l}-1.73597 \\
-1.54485\end{array}$ & $\begin{array}{l}3041 \\
3043\end{array}$ & $\begin{array}{l}2.23003 \\
2.12681\end{array}$ & $\begin{array}{l}-0.13530 \\
-0.04316\end{array}$ & $\begin{array}{l}0.025-0 \\
0.79 C-8\end{array}$ & $\begin{array}{l}-2.30509 \\
-1.33959\end{array}$ \\
\hline 3044 & & $? .23423$ & -0.92954 & 0.83548 & -2.22782 & 3013 & 1.98450 & 0.57032 & -0.73373 & -1.60928 \\
\hline $\begin{array}{l}4092 \\
5093\end{array}$ & & $\begin{array}{l}2.07408 \\
2.11450\end{array}$ & $\begin{array}{l}0.64725 \\
0.39840\end{array}$ & $\begin{array}{l}-0.09179 \\
-0.48438\end{array}$ & $\begin{array}{l}-1.69807 \\
-2.29767\end{array}$ & $\begin{array}{l}4081 \\
5094\end{array}$ & $\begin{array}{l}2.17588 \\
1.97715\end{array}$ & $\begin{array}{l}0.34559 \\
0.46331\end{array}$ & $\begin{array}{l}0.59533 \\
0.351 \geqslant 0\end{array}$ & $\begin{array}{l}-1.57714 \\
-0.94016\end{array}$ \\
\hline $\begin{array}{l}5093 \\
5083\end{array}$ & & 2.11635 & -1.05116 & 1.33491 & -1.19415 & 5084 & 2.35911 & -0.28131 & $-0.867 ? 6$ & -3.20030 \\
\hline 5071 & & 1.35917 & 0.18190 & -0.47194 & -1.18712 & 5063 & 1.05945 & 0.46144 & $-0.1+7-5$ & -1.09373 \\
\hline 5011 & & 2.17064 & 0.54445 & 0.50815 & -0.23802 & 4043 & 1.63073 & 0.03355 & 0.64690 & -1.10909 \\
\hline 4011 & & 2.19962 & 0.07586 & 0.24906 & -1.29588 & 2084 & 1.45773 & -0.75596 & -0.07325 & -3.11942 \\
\hline 3032 & & $\begin{array}{l}2.35307 \\
2.04979\end{array}$ & $\begin{array}{r}0.30169 \\
-0.24721\end{array}$ & -0.96348 & -2.96562 & 5064 & 2.06089 & 0.54841 & -0.53222 & -1.39510 \\
\hline 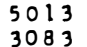 & & $\begin{array}{l}2.04979 \\
2.11211\end{array}$ & $\begin{array}{l}-0.24721 \\
-0.46052\end{array}$ & 1.09982 & -1.18423 & 5091 & 1.08936 & 0.04446 & 0.27767 & -0.87985 \\
\hline $\begin{array}{l}3083 \\
7043\end{array}$ & & $\begin{array}{l}2.112211 \\
2.40070\end{array}$ & $\begin{array}{r}-0.46052 \\
1.04090\end{array}$ & $\begin{array}{l}0.03851 \\
0.25159\end{array}$ & $\begin{array}{r}-1.27316 \\
0.08980\end{array}$ & $\mid \begin{array}{l}5074 \\
6004\end{array}$ & $\begin{array}{l}2.41830 \\
2.50525\end{array}$ & $\begin{array}{r}0.10481 \\
-0.54120\end{array}$ & $\begin{array}{l}-1.25663 \\
-0.44163\end{array}$ & $\begin{array}{r}0.06442 \\
-1.95148\end{array}$ \\
\hline $403 ?$ & & 2.35744 & 0.57442 & 0.68622 & -1.53433 & 7021 & 4.32556 & -1.90417 & $-1.217 C_{0}$ & 0.04956 \\
\hline 2082 & & 3.87285 & -1.93028 & 2.49385 & -2.55103 & 3073 & 4.20819 & -2.72425 & -0.11232 & -2.63334 \\
\hline 3023 & & 4.57643 & -1.49693 & 1.58345 & -0.59123 & 4041 & 4.52350 & -0.21129 & $2.4<213$ & -2.06154 \\
\hline 5092 & & 4.10145 & -1.96427 & 3.27442 & -1.79657 & 5061 & 3.40525 & 2.17901 & -0.27127 & -1.03816 \\
\hline 5022 & & 4.45220 & -0.53524 & -1.46155 & -3.79474 & 1092 & 3.05049 & 1.04167 & $0.1703=$ & -2.33462 \\
\hline 1093 & & 2.54898 & 1.82917 & -0.39055 & -2.49642 & 1094 & 4.06384 & 1.30246 & $-0.0783 \equiv$ & -3.25617 \\
\hline 1081 & & 4.19663 & 1.01580 & -0.20944 & -1.89086 & 1082 & 2.85874 & 1.19422 & -0.39123 & -0.13384 \\
\hline 1083 & & 3.90111 & -0.32600 & 2.19281 & -1.18529 & 1071 & 3.37089 & -0.01352 & $1.3 \geq 13$ & -1.73354 \\
\hline 1073 & & 3.52804 & -1.38280 & 0.51019 & -1.73427 & 1074 & 2.73983 & 0.81636 & -0.11675 & -1.63457 \\
\hline $\begin{array}{l}2091 \\
2093\end{array}$ & & $\begin{array}{l}3.98191 \\
2.99502\end{array}$ & $\begin{array}{r}-1.22738 \\
0.03813\end{array}$ & $\begin{array}{r}1.16178 \\
-0.34652\end{array}$ & $\begin{array}{l}-1.32156 \\
-1.71409\end{array}$ & $\begin{array}{l}2092 \\
2094\end{array}$ & $\begin{array}{l}3.80148 \\
4.17240\end{array}$ & $\begin{array}{r}0.57191 \\
-0.31324\end{array}$ & $\begin{array}{r}0.42390 \\
-0.76302\end{array}$ & $\begin{array}{l}-0.78017 \\
-1.75152\end{array}$ \\
\hline 2081 & & 2.63486 & 0.71280 & 1.24875 & -0.88872 & 2083 & 2.65635 & 1.29830 & -0.13165 & -2.07582 \\
\hline 2071 & & 3.42414 & -0.82375 & -0.69124 & -2.91887 & 2072 & 2.66977 & -0.43967 & -0.40513 & -2.64968 \\
\hline 3092 & & 2.93041 & 1.75505 & 0.39185 & -1.69594 & 3082 & 3.09291 & 0.47212 & 1.23492 & -1.83229 \\
\hline 3084 & & 2.73748 & -1.02478 & -0.04769 & -2.90563 & 3072 & 3.52514 & -1.27003 & -0.32127 & -0.06205 \\
\hline 3061 & & 3.14840 & $\begin{array}{r}0.83886 \\
-0.08069\end{array}$ & $\begin{array}{l}-0.91553 \\
-0.35338\end{array}$ & $\begin{array}{l}-2.92597 \\
-3.4\end{array}$ & 3062 & 3.25050 & -1.11932 & $-0.470 a a$ & -1.67972 \\
\hline 3064 & & $\begin{array}{r}3.44705 \\
3.55168\end{array}$ & $\begin{array}{l}-0.08069 \\
-0.20989\end{array}$ & $\begin{array}{l}-0.35338 \\
-0.17512\end{array}$ & $\begin{array}{l}-3.41958 \\
-2.43934\end{array}$ & & & -0.07736 & 1.48111 & -1.27634 \\
\hline 3033 & 1 & $\begin{array}{l}3.55168 \\
4.03723\end{array}$ & $\begin{array}{l}-0.20989 \\
-0.32924\end{array}$ & $\begin{array}{r}-0.17512 \\
0.26078\end{array}$ & $\begin{array}{l}-2.43934 \\
-2.92291\end{array}$ & 3034 & 3.87212 & -0.49960 & 1.25413 & -2.87343 \\
\hline 3022 & ! & $\begin{array}{l}4.03723 \\
3.29252\end{array}$ & $\begin{array}{l}-0.32924 \\
-0.08811\end{array}$ & $\begin{array}{l}0.26078 \\
1.44465\end{array}$ & $\begin{array}{l}-2.92291 \\
-0.55588\end{array}$ & 3024 & 4.35269 & -0.26809 & $0.3 \varepsilon 597$ & -2.68621 \\
\hline 3012 & & $\begin{array}{l}3.29252 \\
3.54433\end{array}$ & -0.08811 & $\begin{array}{l}1.44465 \\
1.91833\end{array}$ & $\begin{array}{l}-0.55588 \\
-1.24153\end{array}$ & 3014 & 2.90545 & 0.71878 & $-0 . \approx 2696$ & -0.33352 \\
\hline 4093 & & $\begin{array}{r}3.54433 \\
3.12499\end{array}$ & 0.16879 & 1.91833 & -1.24153 & 4094 & 3.03351 & 0.75918 & 1.43346 & -1.03332 \\
\hline 4061 & & 4.06700 & 0.00038 & -0.47479 & -0.91323 & 4062 & 3.94893 & -0.80710 & -1.07117 & -1.33862 \\
\hline 4064 & & 2.76896 & -0.23812 & -1.00368 & -0.75054 & 4052 & 3.00933 & 0.24377 & 1.25593 & -1.39739 \\
\hline 4053 & & 3.74677 & 0.00255 & 1.38418 & -2.24575 & 4054 & 3.68253 & -0.16898 & 0.43336 & -3.31076 \\
\hline 4042 & & 3.13670 & 1.05120 & 1.07219 & $-1.675 \equiv 2$ & 4031 & 3.60296 & 1.05487 & 0.83339 & -2.47273 \\
\hline 4032 & & 3.07918 & 0.47227 & 0.87992 & -1.46200 & 4033 & 3.23628 & -0.37421 & 0.41060 & -1.96729 \\
\hline 4034 & & 3.01850 & 0.25569 & 0.96202 & -1.01716 & 4023 & 4.21984 & -0.60560 & 0.83245 & -1.60199 \\
\hline 4024 & & 3.76806 & -0.98235 & 0.63627 & -2.24604 & 4012 & 3.77479 & 0.52475 & -1.54096 & -0.95933 \\
\hline 4013 & & 3.63904 & -0.13220 & 0.14795 & -2.60205 & 4014 & 4.09974 & 0.70596 & -0.12507 & -2.13916 \\
\hline 5081 & & 4.14761 & -0.77483 & 0.10431 & -1.55186 & 5022 & 3.37091 & $-0.200 \leq 4$ & -0.12137 & -1.33132 \\
\hline 5072 & & 3.26177 & 0.39630 & 0.47618 & -1.39188 & 5073 & 4.00006 & -0.32915 & -0.59963 & -2.4979 \\
\hline 5062 & & 2.96340 & -1.17220 & 0.13911 & -0.15778 & 5052 & 4.17970 & 0.04564 & 1.76053 & -1.02300 \\
\hline 5054 & & 3.08693 & 0.43492 & 0.62597 & -1.65533 & 5041 & 4.20595 & 1.13668 & -0.3725. & -1.15850 \\
\hline 5031 & & 4.34517 & 1.36577 & 0.60773 & -2.35880 & 5033 & 3.49207 & 1.58472 & -0.21027 & -2.32235 \\
\hline 5034 & & 2.69682 & 0.44077 & 0.07492 & -2.29674 & 5021 & 4.07146 & 0.44610 & $0.93: 27$ & -0.58295 \\
\hline 5023 & & 3.52515 & -0.26603 & 1.10761 & -1.69847 & 5024 & 2.94630 & 0.00519 & -1.60423 & -1.85844 \\
\hline
\end{tabular}




\begin{tabular}{|c|c|c|c|c|c|c|c|c|c|}
\hline SUBUN. & FATOR 1 & FATOR 2 & EATOR 3 & FATOR 4 & SUBUN. & FATOR 1 & EATOR 2 & FATOK 3 & EATOR 4 \\
\hline 5012 & 3.73054 & -0.47635 & 0.64743 & -0.75422 & 5014 & 3.57121 & -1.24806 & 0.62817 & 0.01097 \\
\hline 6084 & 2.99489 & 0.71143 & 0.39365 & -2.20778 & 6071 & 3.65777 & 1.45177 & 1.00174 & -1.91054 \\
\hline 6072 & 3.17839 & 1.20476 & -0.81746 & -1.28402 & 6074 & 3.39009 & -0.09917 & -0.42977 & $-1.0491 ?$ \\
\hline 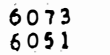 & $\begin{array}{l}2.80045 \\
3.36071\end{array}$ & $\begin{array}{l}-0.33180 \\
-1.25077\end{array}$ & $\begin{array}{r}-0.98184 \\
0.28013\end{array}$ & $\begin{array}{l}-1.08089 \\
-0.36486\end{array}$ & $\begin{array}{l}60622 \\
6053\end{array}$ & $\begin{array}{l}3.88197 \\
3.48398\end{array}$ & $\begin{array}{l}0.08826 \\
0.91986\end{array}$ & $\begin{array}{l}1.80484 \\
0.81465\end{array}$ & $\begin{array}{l}-1.58950 \\
-0.70367\end{array}$ \\
\hline $\begin{array}{l}6054 \\
6042\end{array}$ & $\begin{array}{l}3.65696 \\
4.44787\end{array}$ & $\begin{array}{l}0.75772 \\
0.36440\end{array}$ & $\begin{array}{l}0.22211 \\
0.14609\end{array}$ & $\begin{array}{l}-1.94858 \\
-1.06356\end{array}$ & $\begin{array}{l}6041 \\
6044\end{array}$ & $\begin{array}{l}3.97524 \\
3.73817\end{array}$ & $\begin{array}{l}1.43593 \\
0.19165\end{array}$ & $\begin{array}{r}0.35176 \\
-0.47500\end{array}$ & $\begin{array}{l}-0.74331 \\
-0.87338\end{array}$ \\
\hline 6032 & 3.16649 & 0.49200 & -0.64369 & -1.07486 & 6033 & 3.06590 & -0.44022 & -0.09485 & $-1.4 \div 251$ \\
\hline $\begin{array}{l}6013 \\
6002 \\
7083\end{array}$ & $\begin{array}{l}4.27994 \\
3.34452 \\
3.14679\end{array}$ & $\begin{array}{l}0.41467 \\
0.28587 \\
0.11042\end{array}$ & $\begin{array}{l}1.08849 \\
0.64347 \\
0.11184\end{array}$ & $\begin{array}{l}-2.4054 a \\
-1.15051 \\
-3.36693\end{array}$ & $\begin{array}{l}6014 \\
7081 \\
7084\end{array}$ & $\begin{array}{l}2.97831 \\
3.97426 \\
4.35584\end{array}$ & $\begin{array}{r}-0.90310 \\
1.22992 \\
0.95197\end{array}$ & $\begin{array}{l}0.96314 \\
1.00597 \\
0.55483\end{array}$ & $\begin{array}{l}-0.98899 \\
-2.36177 \\
-3.28677\end{array}$ \\
\hline $\begin{array}{l}7083 \\
7071\end{array}$ & $\begin{array}{l}3.14679 \\
3.82768\end{array}$ & $\begin{array}{l}0.11042 \\
1.60528\end{array}$ & $\begin{array}{r}0.11184 \\
-0.30310\end{array}$ & $\begin{array}{l}-3.36693 \\
-2.76413\end{array}$ & $\begin{array}{l}7084 \\
7073\end{array}$ & $\begin{array}{l}4.35584 \\
3.25441\end{array}$ & $\begin{array}{l}0.95197 \\
1.40616\end{array}$ & $\begin{array}{r}0.53483 \\
-0.33320\end{array}$ & $\begin{array}{l}-3.28677 \\
-3.03474\end{array}$ \\
\hline 7074 & 2.78845 & 1.04097 & -0.01659 & -0.05850 & 7061 & 4.40074 & 0.80699 & -0.67693 & $\begin{array}{l}-3.03474 \\
-0.75486\end{array}$ \\
\hline 7062 & 3.61150 & 1.38343 & 1.05359 & -1.82726 & 7063 & $2: 99286$ & 0.12920 & -0.49634 & -2.96655 \\
\hline 7052 & 3.43454 & 0.14977 & 0.22579 & $-2.6938 ?$ & 7053 & 4002617 & 0.94922 & 0.31465 & -2.67193 \\
\hline 7054 & 2.81546 & 0.27311 & -0.59845 & -1.32135 & 7041 & 3.94810 & -0.46529 & -0.18065 & -0.12372 \\
\hline 7044 & 2.83468 & 0.51266 & -0.26393 & -0.63889 & 7031 & 3.27504 & 0.04459 & 0.14155 & -2.02693 \\
\hline 7033 & 3.43363 & -0.57902 & 0.27327 & -1.23807 & 7023 & 3.03041 & 0.86798 & 0.55758 & -1.13379 \\
\hline 7024 & 4.22400 & 0.34984 & -0.44612 & 0.50217 & 7011 & 3.73562 & -1.22156 & -0.33959 & -0.45080 \\
\hline 7012 & 2.95334 & 0.89330 & 0.36004 & -1.78413 & 7013 & 2.98578 & -0.06940 & 0.91474 & -1.37604 \\
\hline 7014 & 3.96798 & -0.47971 & 0.96780 & -0.47945 & 7003 & 2.96554 & -1.29037 & 0.51664 & -1.43546 \\
\hline 7032 & 3.63940 & 2.88579 & -0.51291 & -0.76215 & 7034 & 3.06680 & -1.06736 & -1.34309 & -1.13297 \\
\hline 4044 & 3.92465 & -0.88592 & 1.77349 & -2.68453 & 6064 & 4.63812 & -0.36208 & 1.66907 & -0.81560 \\
\hline 6034 & 4.61037 & -1.50761 & -1.16151 & -2.43372 & 7051 & 3.84866 & 2.52540 & 0.18225 & -0.38943 \\
\hline 5044 & 4.46745 & 2.29560 & -0.65426 & -1.68526 & 6003 & 3.26258 & -0.88443 & 0.38610 & -0.78783 \\
\hline 1072 & 2.97095 & -0.52329 & -1.07648 & -4.70607 & 4074 & 4.44057 & 0.05617 & 1.93063 & -2.62380 \\
\hline 7064 & 3.55500 & 0.44297 & -1.80741 & -0.89260 & 5032 & 4.49320 & 2.41867 & -0.65130 & -2.97699 \\
\hline 6082 & 4.53035 & 0.91981 & 0.58844 & -3.75647 & 6031 & 4.60037 & 1.03615 & 1.35704 & -1.96332 \\
\hline 6001 & 4.21167 & -1.06072 & 2.14569 & -1.48564 & 6043 & 3.85284 & 1.78221 & -0.42340 & -0.46354 \\
\hline 3021 & 4.98153 & 0.20899 & -0.92415 & -2.16648 & 3091 & 4.80480 & -1.39393 & 0.30933 & -2.95351 \\
\hline 4022 & 5.37796 & -0.54912 & 1.88367 & -1.38356 & 7042 & 4.82086 & $-0.2570 B$ & -0.47322 & 1.15357 \\
\hline 4021 & 3.81647 & -1.45789 & 0.98587 & -3.18709 & 6011 & 4.71479 & -0.74610 & 2.32986 & -0.88960 \\
\hline 1091 & 4.91148 & 0.29640 & 1.68960 & -2.47065 & 5051 & 5.06822 & 1.87749 & 0.51671 & -2.65096 \\
\hline 5053 & 5.56999 & 0.77106 & 0.60859 & -0.31302 & 6022 & 4.91767 & -1.09524 & -1.80639 & -1.49680 \\
\hline $\begin{array}{l}6023 \\
7022\end{array}$ & 5.14173 & -1.10200 & -1.45651 & -1.30710 & 5024 & 5.81742 & -0.14410 & -0.29798 & -1.92166 \\
\hline $\begin{array}{l}7022 \\
7002\end{array}$ & 4.65481 & -1.13973 & -1.78546 & 0.73794 & 7001 & 4.96155 & 0.07542 & 0.41692 & -2.42266 \\
\hline 7002 & 4.87193 & 0.27778 & 0.33338 & -0.86210 & 3074 & 4.56615 & -2.34305 & -2.35205 & -3.77873 \\
\hline 4063 & 5.33866 & -1.35270 & -2.05806 & -0.52160 & 5043 & 4.98206 & 3.79639 & 0.02577 & -1.55699 \\
\hline 6083 & 4.97840 & -0.09911 & -3.08047 & -2.19725 & 0061 & 5.68032 & 0.81932 & 2.90949 & -0.99732 \\
\hline 6063 & 5.74352 & 1.63896 & 0.04274 & -2.89513 & 6021 & 6.67891 & -1.79694 & -1.55167 & 0.74984 \\
\hline 7072 & 5.31232 & 3.11062 & -0.20083 & -2.04237 & 7004 & 5.57367 & -0.10326 & -2.03732 & -0.13698 \\
\hline $\begin{array}{l}7082 \\
6001\end{array}$ & $\begin{array}{l}4.67725 \\
5.04437\end{array}$ & $\begin{array}{r}1.49304 \\
-0.12877\end{array}$ & $\begin{array}{l}1.00223 \\
1.52915\end{array}$ & $\begin{array}{l}-2.49093 \\
-3.13549\end{array}$ & $\begin{array}{l}6052 \\
5042\end{array}$ & $\begin{array}{l}4.90712 \\
4.74481\end{array}$ & $\begin{array}{l}0.91299 \\
1.04385\end{array}$ & $\begin{array}{r}0.47200 \\
-0.44804\end{array}$ & 0.00780 \\
\hline & & & 1.52915 & -3.13549 & 5042 & 4.74481 & 1.04385 & & -0.26164 \\
\hline
\end{tabular}


97.

APENDICE IV - Valores dos indices normalizados condensando todos os fatores. 


\begin{tabular}{|c|c|c|c|c|c|c|c|c|c|c|c|}
\hline $\begin{array}{l}\text { SUBUN. } \\
1084 \\
3063 \\
4051\end{array}$ & $\begin{array}{c}\text { INDICE } \\
0.393649 \\
0.351263 \\
0.368949\end{array}$ & $\begin{array}{l}\text { SUBUN. } \\
2073 \\
3052 \\
6012\end{array}$ & $\begin{array}{c}\text { INDICE } \\
0.372806 \\
0.365793 \\
0.382944\end{array}$ & $\begin{array}{l}\text { SUBUN. } \\
2074 \\
3031 \\
3094\end{array}$ & $\begin{array}{c}\text { INDICE } \\
0.396682 \\
0.367048 \\
0.315194\end{array}$ & $\begin{array}{l}\text { SUBUN. } \\
3093 \\
3011 \\
3053\end{array}$ & $\begin{array}{c}\text { INDICE } \\
0.390948 \\
0.376654 \\
0.347424\end{array}$ & $\begin{array}{l}\text { SUBUN. } \\
3021 \\
4091 \\
3054\end{array}$ & $\begin{array}{c}\text { PNDICE } \\
0.367220 \\
0.370621 \\
0.233159\end{array}$ & $\begin{array}{l}\text { SUBUN. } \\
3071 \\
4073 \\
3041\end{array}$ & $\begin{array}{c}\text { INDICE } \\
0.383399 \\
0.376760 \\
0.337004\end{array}$ \\
\hline $\begin{array}{l}3042 \\
5093\end{array}$ & $\begin{array}{l}0.275774 \\
0.322647\end{array}$ & $\begin{array}{l}3043 \\
5094\end{array}$ & $\begin{array}{l}0.322589 \\
0.300219\end{array}$ & $\begin{array}{l}3044 \\
5083\end{array}$ & $\begin{array}{l}0.346798 \\
0.333128\end{array}$ & $\begin{array}{l}3013 \\
5084\end{array}$ & $\begin{array}{l}0.303210 \\
0.366003\end{array}$ & $\begin{array}{l}4092 \\
5071\end{array}$ & $\begin{array}{l}0.314129 \\
0.206437\end{array}$ & $\begin{array}{l}4031 \\
5063\end{array}$ & $\begin{array}{l}0.325015 \\
0.249758\end{array}$ \\
\hline 5011 & 0.324687 & 4043 & 0.246508 & 4011 & 0.327923 & 2084 & 0.246413 & 3032 & 0.364323 & 5064 & $0.311: 05$ \\
\hline 5013 & 0.312720 & 5091 & 0.164094 & 3083 & 0.316236 & 5074 & 0.365688 & 7043 & 0.362560 & 6004 & 0.371812 \\
\hline 4082 & 0.356237 & 7021 & 0.657183 & 2082 & 0.611732 & 3073 & 0.655090 & 3023 & 0.69142 .1 & 4041 & 0.687489 \\
\hline 5092 & 0.654288 & $506 !$ & 0.526863 & 5022 & 0.674818 & 1092 & 0.462477 & 1093 & 0.545521 & 1094 & 0.015412 \\
\hline 1081 & 0.627182 & $108 ?$ & 0.431393 & 1083 & 0.593227 & 1071 & 0.507484 & 1073 & 0.533815 & 1074 & 0.412023 \\
\hline $\begin{array}{l}2091 \\
2071\end{array}$ & $\begin{array}{l}0.600288 \\
0.518612\end{array}$ & $\begin{array}{l}2092 \\
2072\end{array}$ & $\begin{array}{l}0.364543 \\
0.404802\end{array}$ & $\begin{array}{l}2093 \\
3092\end{array}$ & $\begin{array}{l}0.446298 \\
0.453331\end{array}$ & $\begin{array}{l}2094 \\
3032\end{array}$ & $\begin{array}{l}0.621233 \\
0.467703\end{array}$ & & $\begin{array}{l}0.400131 \\
0.420066\end{array}$ & $\begin{array}{l}2083 \\
3072\end{array}$ & $\begin{array}{l}0.407795 \\
0.530927\end{array}$ \\
\hline $306 i$ & 0.480418 & 3062 & 0.490255 & 3064 & 0.520318 & 3051 & 0.406902 & 3033 & 0.530503 & 3034 & 0.384882 \\
\hline $\begin{array}{l}3022 \\
4083\end{array}$ & $\begin{array}{l}0.603954 \\
0.477098\end{array}$ & $\begin{array}{l}3024 \\
4084\end{array}$ & $\begin{array}{l}0.649271 \\
0.482424\end{array}$ & $\begin{array}{l}3012 \\
4071\end{array}$ & $\begin{array}{l}0.494857 \\
0.613831\end{array}$ & $\begin{array}{l}3014 \\
4072\end{array}$ & $\begin{array}{l}0.432599 \\
0.523618\end{array}$ & $\begin{array}{l}4093 \\
4061\end{array}$ & $\begin{array}{l}0.533054 \\
0.602642\end{array}$ & $\begin{array}{l}4094 \\
4062\end{array}$ & $\begin{array}{l}0.461457 \\
0.591566\end{array}$ \\
\hline 4064 & 0.414790 & 4052 & $\begin{array}{l}0.482424 \\
0.453588\end{array}$ & $\begin{array}{l}4071 \\
4053\end{array}$ & $\begin{array}{l}0.613831 \\
0.564246\end{array}$ & 4054 & $\begin{array}{l}0.523618 \\
0.554327\end{array}$ & $\begin{array}{l}4061 \\
4042\end{array}$ & $\begin{array}{l}0.602642 \\
0.476550\end{array}$ & $\begin{array}{l}4062 \\
4031\end{array}$ & 0.554098 \\
\hline 4032 & 0.461604 & 4033 & 0.483454 & 4034 & 0.460207 & 4023 & 0.629427 & 4024 & 0.560601 & 4012 & 0.367094 \\
\hline 4013 & 0.543823 & 4014 & 0.611566 & 5081 & 0.617394 & 5082 & 0.500378 & 5072 & 0.485705 & 5073 & 0.597797 \\
\hline 5062 & 0.445749 & 5052 & 0.627788 & 5054 & 0.461644 & $504 \mathrm{~J}$ & 0.628220 & 5031 & 0.654270 & 5033 & 0.532612 \\
\hline 5034 & 0.405809 & 5021 & 0.605652 & 5023 & 0.528251 & 5024 & 0.449673 & 5012 & 0.551475 & 5014 & 0.536420 \\
\hline 6084 & & 6071 & 0.556372 & 6072 & 0.4 & 6074 & 0.302931 & 6073 & $0.4201: 1$ & 6062 & 0.586148 \\
\hline $605 !$ & 0.504828 & 6053 & 0.521914 & 6054 & 0.540549 & 6041 & 0.596045 & 6042 & 0.658972 & 6044 & 0.554239 \\
\hline $\begin{array}{l}6032 \\
7083\end{array}$ & $\begin{array}{l}0.472132 \\
0.476177\end{array}$ & $\begin{array}{l}6033 \\
7084\end{array}$ & $\begin{array}{l}0.456460 \\
0.655708\end{array}$ & $\begin{array}{l}6013 \\
7071\end{array}$ & $\begin{array}{l}0.640920 \\
0.582994\end{array}$ & $\begin{array}{l}6014 \\
7073\end{array}$ & $\begin{array}{l}0.449543 \\
0.499733\end{array}$ & $\begin{array}{l}6002 \\
7074\end{array}$ & $\begin{array}{l}0.497622 \\
0.418577\end{array}$ & $\begin{array}{l}7081 \\
7061\end{array}$ & $\begin{array}{l}0.601043 \\
0.654753\end{array}$ \\
\hline 7062 & 0.548974 & 7063 & 0.452417 & 7052 & 0.514473 & 7053 & 0.604548 & 7054 & 0.420142 & 7041 & 0.584766 \\
\hline 7044 & 0.421374 & 7031 & 0.488114 & 7033 & 0.510890 & 7023 & 0.454614 & 7024 & 0.625785 & 7011 & 0.559343 \\
\hline 7012 & 0.444802 & 7013 & 0.446826 & 7014 & & 7003 & 0.450655 & 7032 & 0.5731 .23 & 7034 & 0.461732 \\
\hline 4044 & 0.598646 & 6064 & 0.693998 & 6034 & 0.697012 & 7051 & 0.505024 & 5044 & 0.682481 & 6003 & 0.487413 \\
\hline 1072 & 0.467253 & 4074 & 0.671494 & & 0.538474 & 5032 & 0.692095 & 6082 & $0.683: 31$ & 6031 & 0.691358 \\
\hline 6001 & 0.641779 & 6043 & 0.583658 & 3021 & 0.741645 & 3091 & 0.722651 & & 0.805197 & 7042 & 0.714436 \\
\hline 4021 & 0.873201 & 6011 & 0.713478 & 1091 & 0.737305 & 5051 & 0.765373 & 5053 & $0.826: 73$ & 6022 & 0.140483 \\
\hline 6023 & 0.770095 & 6024 & 0.862324 & 7022 & 0.701422 & 7001 & 0.7376 & 7002 & 0.721343 & 3074 & 0.1171 .94 \\
\hline 4063 & 0.804679 & 3043 & 0.784266 & 6083 & 0.761986 & 6061 & 0.860365 & 6063 & 0.861181 & 6021 & 1.000000 \\
\hline 7072 & 0.816049 & 7004 & 0.833240 & 7082 & 0.705832 & 6052 & 0.728875 & 6081 & 0.757 .07 & 5042 & 0.105049 \\
\hline
\end{tabular}


99.

APENDICE V - Listagens do programa computacional e subrotinas utilizadas. 


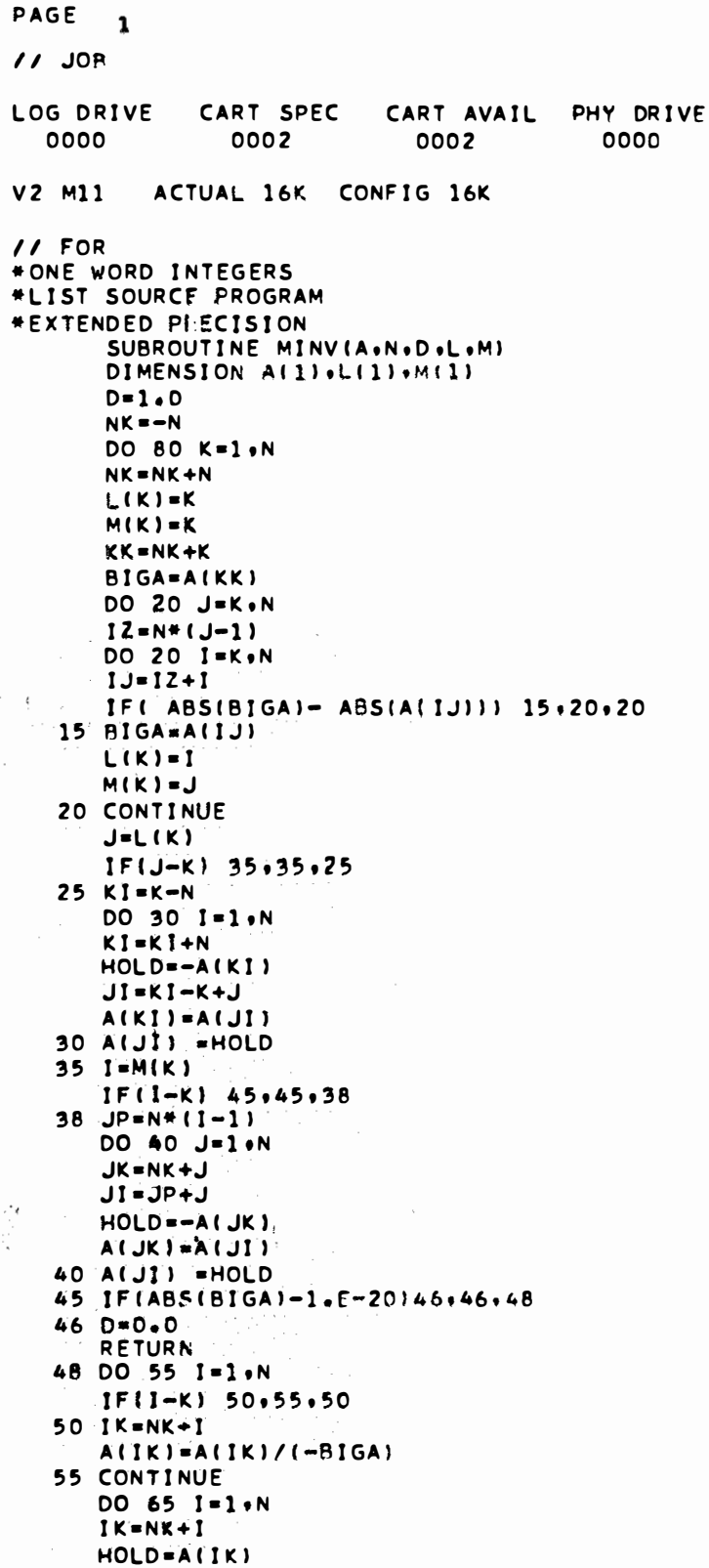

RELATIVE ENTRY POINT ADDRESS IS DO24 (HEX)

END OF COMPILATION 
PAGE I

I/ JOR

$\begin{array}{cccc}\text { LOG DRIVE } & \text { CART SPEC } & \text { CART AVAIL PHY DRIVE } \\ 0000 & 0002 & 0002 & 0000\end{array}$

V2 M11 ACTUAL $16 \mathrm{~K}$ CONFIG $16 \mathrm{~K}$

$1 /$ FOR

LIST SOURCE PROGRAM

- ExTFENOE PRECISION

ONE WORD INTEGERS

SUBROUTINE AUVALIA,AA,C,NR,N I

DIMENSION A

OIMENSION AII1,11, IAA 131,11

DIMENSION BIII,III OABII1,1II

DIMENSION CIIIOIII

EPS=1.E-20

GB CONTINUE

$X N O R=O$.

DO $331.1 . \mathrm{N}$

DO $33 \mathrm{~J}=1 . \mathrm{N}$

C(1,0)=A(1, J)

IF(1-J) $37,53,57$

$37 \quad X N O R=X N O R+A A S(A)(1, J)$

$X N N R=X N O R=1, E-24$

$N R=0$

DO $311=1, \mathrm{~N}$

DO 31 J $J=1 . N$

IF(1-J)51.52,51

32 AA $(1, J)=10$

GO TO 31

31 $A A(1, J)=0$

31 CONTINUE

$26 \quad M A X=0$

$\mathrm{NN}=\mathrm{N}-1$

DO $21.1 . N N$

$\mathrm{Jj}=1+1$

DO 2 JeJJPN

IFIMAX-ABS(AII,J)) $13,13,2$

MAX $=A B S(A)(1, J)$

$N I=!$

nje

2 CONTINUE

IFIMAX-EPS I $13,13,16$

16 IFIABSIAINIONI)-AINJ,NJI)-XNNR)19,19,18

9 CONTINUE

$Y=0$.

$X=A(N), N J) / A B S(A(N), N J)$

$X$ IN=X*SORT1O.S

(O)

TO 20

Ia ALFA=12*AINI, NJ)I/IAINI,NI)-A(NJ,NJI)

$R R=S O R T(1+A L F A * A L F A)$

SI -ALFA/ABS (ALFA)

$X=A L F A / R R$

$X \operatorname{COS}=\operatorname{SORT}(0.5 \times(1 .+Y) 1$

DACE 2

$X S I N=S I * S O R T(0.5 *(1 .-Y))$

20 AUX $=x \cos * x \operatorname{Cns}$

$N R=N R+1$

BU $x=x \cos * x \sin$

CUXXXSINAXSIN

$A(N), N)$ ( $=A(N), N\{) * A U X+2 * A(N), N J) * B U X+A(N J, N J) * C U X$

$P(N), N J)=A(N), N(): C U X-2 * A(N), N J)=A U X+A(N J) N J)=A U x$

G(N)

$A(N), N I)=B(N I, N I)$

$\operatorname{ar}(N), N J)=R(N), N J)$

$A(N ! \cap N J)=B(N ! \circ N J)$

AINJ, NIII:AINI, NJI

DO $24 \quad K=1, N$

$\mid F(K-N \mid) 22,26,22$

22. $\quad[F(X-N) \mid 23,26,23$

3 $A(N !, K)=A(N), K) * \times \operatorname{COS}+A(N J, K) * \times S ! N$

$A(N J, K)=-A(N), K) * x S[N+A(N J, K) * x \cos$

$A(N), K)=P(N), K)$

$A(N J, K)=R(N J, K)$

$A(K, N)=A(N), K)$

$A(K, N J)=A(N J, K)$

2. CONTINUE

DO $23 K=1, N$

RB $(N), K)=A A(N), K) * \times \operatorname{COS}+A A(N), K) \cup \times S I N$

$A B(N), K)=-A A(N), K) \times X S(N+A A(N), K) * x C O S$

$A A(N), K)=B B(N), K)$

AA (NJOK) =RA (NJ,K)

23 CONTINUE

15 CONTINUE

$N I=N-1$

$33 \quad K=0$

$0099 \mathrm{~J}=1 . \mathrm{N} 1$

$21 K=1$

$M=l=A(J, J)$

$A(J \cdot J)=A(J+1 \cdot J+1)$

$A(J+1, J+1)=A B R$

$k K=J$

DO $10 \quad 1=9, n$

$A A V=A A(K K, !)$

AAIKK +1)=AA $(K K+1,1$

$A A(K K+1,1) \cdot A A^{\prime}$

10 CONTINUE

IF(K) 55.50 .55

30 RETURN

FEATURES SUPPORTED

ONF WORD INTEGERS

COMMAN O VARIABLES T9G PROGRAM 1010

RELATIVE ENTRY DOINT ADDRESS IS 0331 (HEX)

END DF COMPILATION 


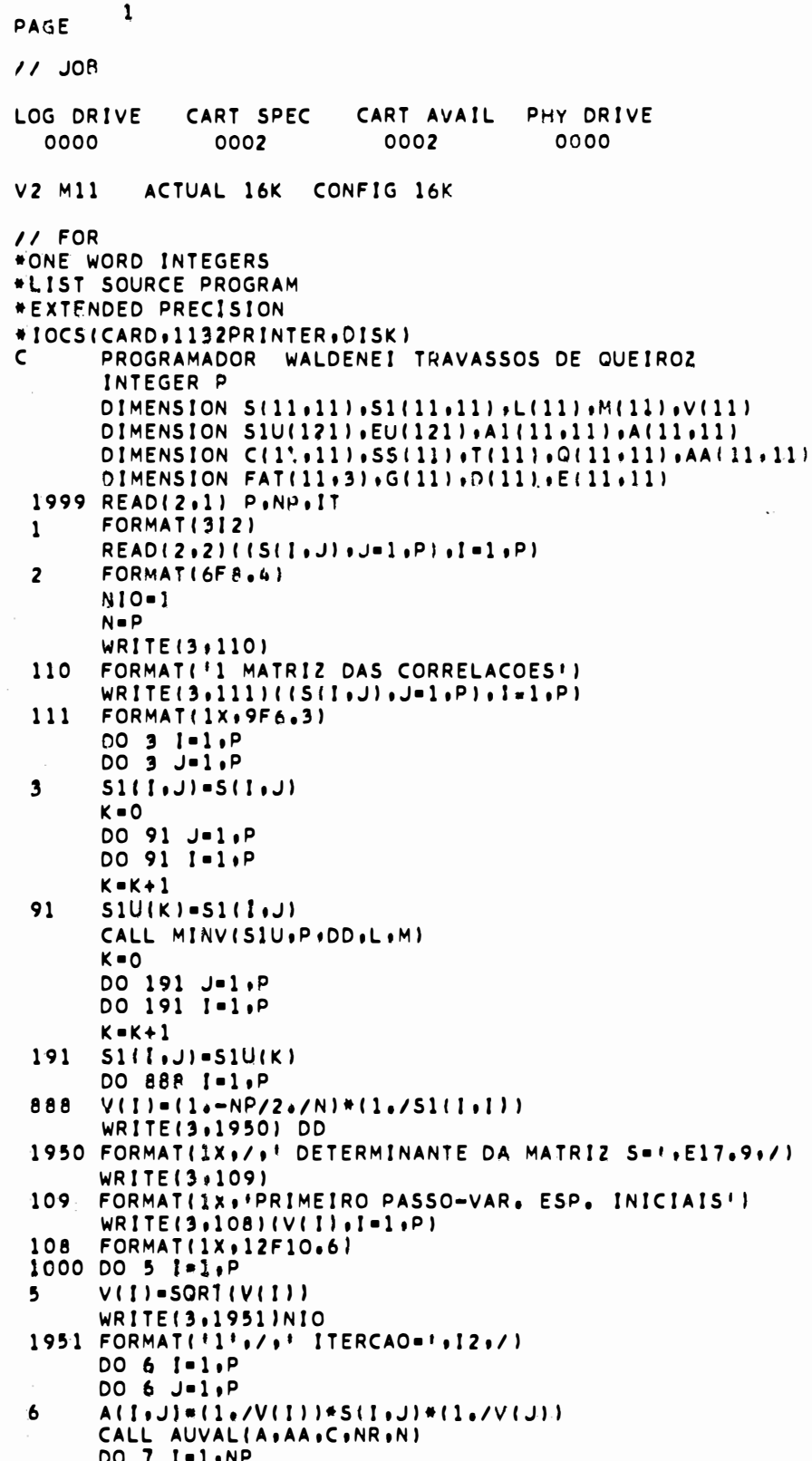

$21 \quad$ C $(1, J)=11, P(1)) *(1, J) *(1, / V(J)$ DO $221-1.0$ 


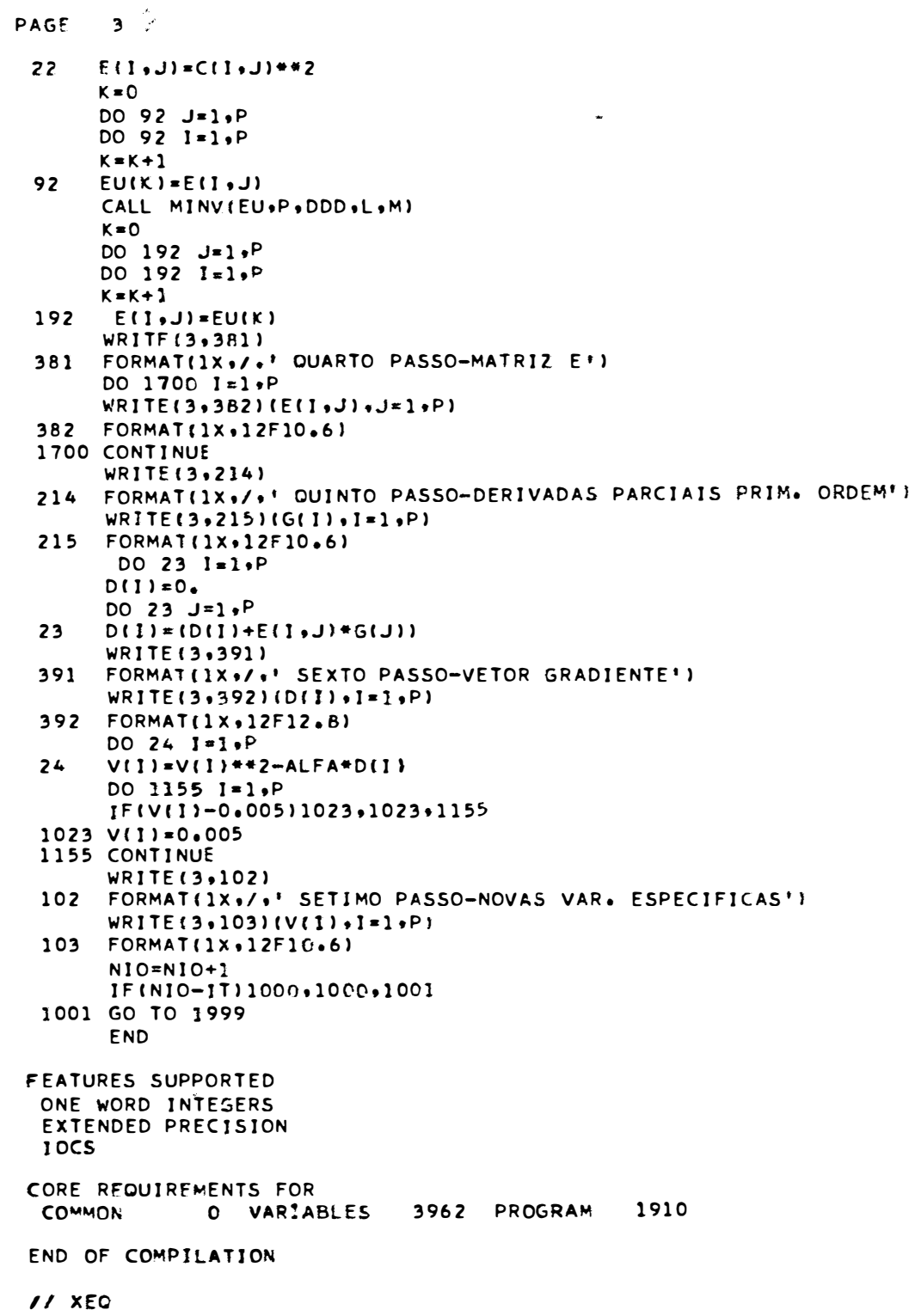

\section{EXEMPLO ILUSTRATIVO}

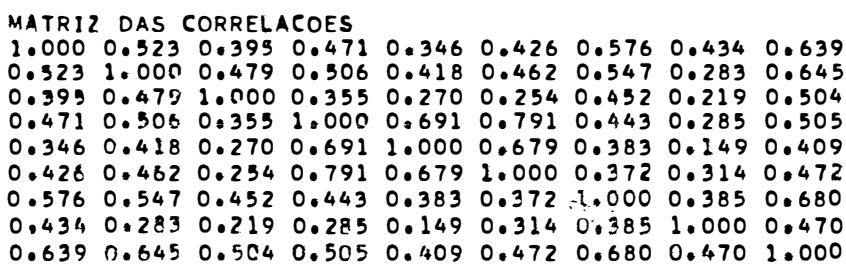


104.

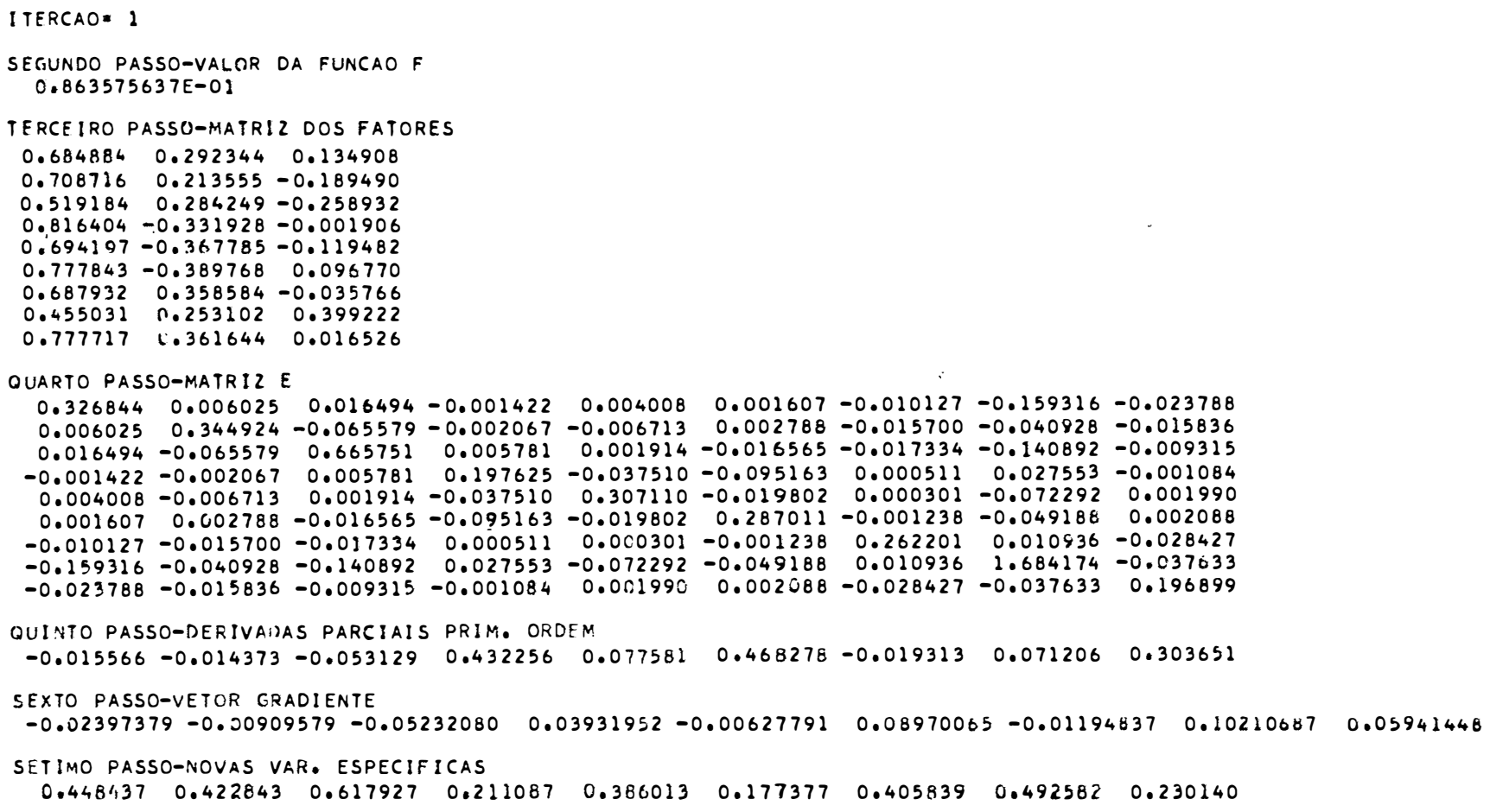

ITERCAO $=2$

SEGUNDO PASSO-VALOR DA FUNCAO $F$

$0.354005098 E-01$

TERCEIRO PASSO-MATRIL DOS FATORES

$\begin{array}{llll}0.663929 & 0.322431 & 0.084375\end{array}$

$0.6895790 .251191-0.191628$

$0.492778 \quad 0.304788-0.222985$

$0.837948-0.291792-0.038790$

$0.704972-0.311313-0.154257$

$0.818865-0.3764310 .103817$

$0.6605270 .306115-0.068004$

$0.454637 \quad 0.2857530 .471654$

$0.765404 \quad 0.429324-0.000842$

OUARTO PASSO-MATRIZ E

$\begin{array}{lllllllllllll}0.291827 & 0.004492 & 0.006601 & -0.004130 & 0.007557 & 0.009759 & -0.004751 & -0.127215 & -0.018296\end{array}$

$0.004492 \quad 0.310265-0.019564-0.005108-0.001334 \quad 0.006786-0.012010-0.074057-0.018135$

$\begin{array}{lllllllll}0.006601 & -0.019564 & 0.570538 & 0.002122 & 0.004142 & -0.005518 & -0.010667 & -0.0 .104123 & -0.011350\end{array}$

$\begin{array}{lllllllll}-0.004130 & -0.005108 & 0.002122 & 0.150668 & -0.022668 & -0.103679 & 0.002386 & 0.090672 & -0.0003338\end{array}$

$\begin{array}{llllllllll}0.007557 & -0.001334 & 0.004142 & -0.022668 & 0.275006 & -0.002301 & -0.001524 & -0.159356 & 0.006227\end{array}$

$\begin{array}{llllllllll}0.009759 & 0.006786 & -0.005518 & -0.103679 & -0.002301 & 0.254799 & -0.005759 & -0.215413 & 0.007852\end{array}$

$\begin{array}{llllllllll}-0.004751 & -0.012010 & -0.010667 & 0.002386 & -0.001524 & -0.005759 & 0.267194 & 0.029901 & -0.033265\end{array}$

$\begin{array}{lllllllll}-0.127215 & -0.074057 & -0.104123 & 0.090672 & -0.159356 & -0.215413 & 0.029901 & 2.509953 & -0.0089515\end{array}$

$\begin{array}{llllllllll}-0.018296 & -0.018135 & -0.011350 & -0.003338 & 0.006227 & 0.007852 & -0.033265 & -0.089515 & 0.163511\end{array}$

QUINTO PASSO-DERIVADAS PARCIAIS PRIM. OIRDEM

$\begin{array}{lllllllllll}-0.001603 & -0.010172 & 0.008845 & -0.002416 & 0.024907 & 0.013817 & 0.022266 & 0.013975 & 0.005758\end{array}$

SEXTO PASSO-VETOR GRADIENTE

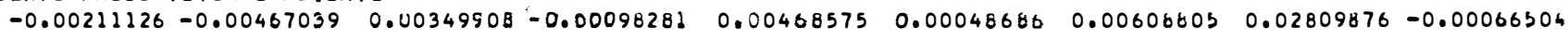

SETIMO PASSO-NOVAS VAR. ESPECIFICRS

$\begin{array}{llllllllll}0.450548 & 0.427513 & 0.614428 & 0.212070 & 0.381327 & 0.176891 & 0.399751 & 0.464483 & 0.230805\end{array}$ 


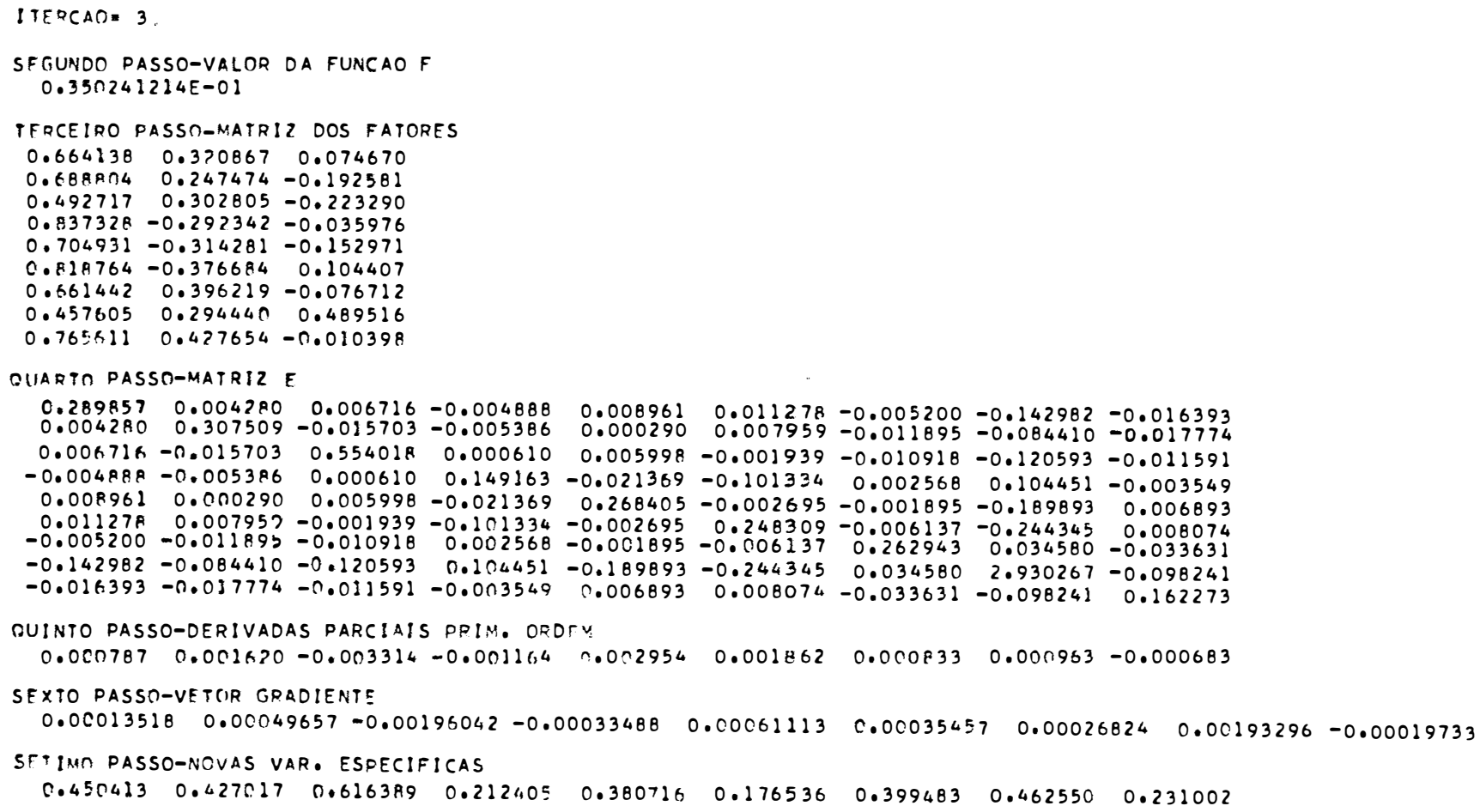

JIEFACAO $=28$

SEGUNDO PASSO-VALOR DA FUNCAO F $0.35017430 B E-01$

TERCEIRO PASSO-MATRIZ DOS FATORES

$0.654136 \quad 0.320530 \quad 0.073430$

$0.588773 \quad 0.247271-0.193307$

$0.4925 ? 80.302259-0.222412$

$0.537242-0.292248-0.035517$

$0.704978-0.314594-0.252821$

$0.016035-0.3766250 .104475$

$0.5514450 .356202-0.077798$

0.4579450 .2956250 .491500

$0.76556=0.427490-0.011733$

QUARTO PASSOMATRIZ E

$\begin{array}{lllllllllll}0.287460 & 0.004349 & 0.006625 & -0.005004 & 0.009163 & 0.011508 & -0.003262 & -0.145423 & -0.010219\end{array}$

$\begin{array}{lllllllll}0.004345 & 0.306984 & -0.015266 & -0.005467 & 0.000537 & 0.008192 & -0.051970 & -0.087318 & -0.017323\end{array}$

$0.004 A 25-0.015266 \quad 0.554480 \quad 0.000455 \quad 0.006122-0.001578-0.01083=-0.120686-0.011627$

$\begin{array}{lllllllll}-0.005004 & -0.005467 & 0.000455 & 0.149076 & -0.021206 & -0.101179 & 0.002596 & 0.106698 & -0.003509\end{array}$

$\begin{array}{llllllllll}0.00516,3 & 0.000537 & 0.006122 & -0.021206 & 0.267697 & -0.002735 & -0.001932 & -0.194444 & 0.006970\end{array}$

$\begin{array}{llllllllll}0.011508 & 0.008192 & -0.001578 & -0.101179 & -0.002735 & 0.247854 & -0.006193 & -0.248938 & 0.008023\end{array}$

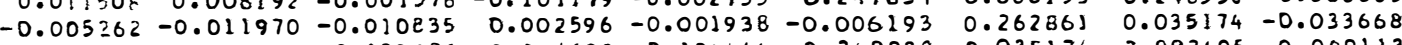

$\begin{array}{lllllllll}-0.1454 .23 & -0.087318 & -0.120686 & 0.106698 & -0.194444 & -0.248938 & 0.035174 & 2.992405 & -0.099113\end{array}$

$\begin{array}{lllllllll}-0.016219 & -0.017823 & -0.011627 & -0.003589 & 0.006970 & 0.008083 & -0.033668 & -0.099113 & 0.162270\end{array}$

QUINTO PASSO-DERIVADAS PARCIAIS PRIM. ORDEM

$0.000002-0.0000=0.0000010 .000018-0.000002-0.0000170 .0000010 .000000-0.000000$

SEXTO PASSO-VETOR GRADIENTE 0.000000 ? : 0.0000011 : $0.000000750 .00000464-0.00000120-0.000000360 .000000230 .00000951-0.00000142$

SETIMO PASSO-NOVAS VAR. ESPECIFICAS $\begin{array}{llllllllll}0.450495 & 0.427040 & 0.616571 & 0.212350 & 0.300601 & 0.176751 & 0.399455 & 0.461: 09 & 0.233017\end{array}$ 


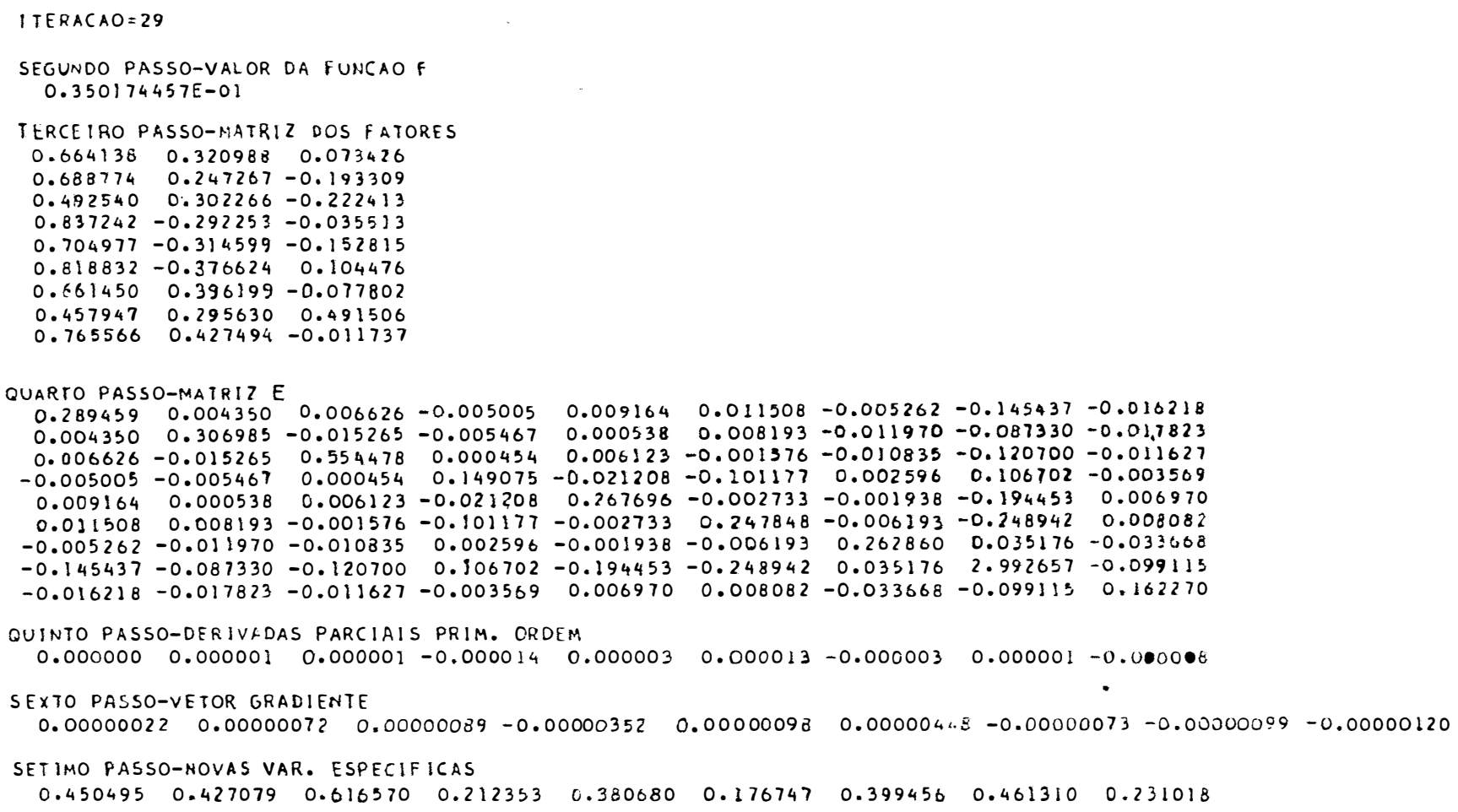

\section{ITERACAO $=30$}

SEGUNDO PASSO-VALOR DA FUNCAO F $0.350174309 E-01$

TERCEIRO PASSOMATRI2 DOS FATORES

$\begin{array}{llll}0.664137 & 0.320990 & 0.073427\end{array}$

$0.688773 \quad 0.247270-0.193308$

$0.492530 \quad 0.302268-0.22241$

$0.837242-0.292249-0.035515$

$0.704978-0.314595-0.157818$

$0.818335-0.3766240 .10 \div 475$

$0.6614490 .396202-0.077701$

$\begin{array}{llll}0.457946 & 0.295629 & 0.491505\end{array}$

$0.7655650 .427497-0.011736$

OUARTO PASSOMATRIL E

$\begin{array}{llllllllllllllll}0.289459 & 0.004350 & 0.006625 & -0.005004 & 0.009164 & 0.011508 & -0.005262 & -0.145432 & -0.016218\end{array}$

$0.004350 \quad 0.306984-0.015265-0.005467 \quad 0.0005380 .008193-0.011970-0.087329-0.017823$

$\begin{array}{lllllllll}0.006625 & -0.015265 & 0.55447 t & 0.000455 & 0.006122 & -0.001577 & -0.010835 & -0.120694 & -0.011627\end{array}$

$\begin{array}{llllllllll}-0.005004 & -0.005467 & 0.000455 & 0.149075 & -0.021206 & -0.0 .101178 & 0.002596 & 0.106701 & -0.003509\end{array}$

$\begin{array}{llllllllll}0.009164 & 0.000538 & 0.006122 & -0.021208 & 0.267696 & -0.002735 & -0.001938 & -0.194452 & 0.006970\end{array}$

$0.011508 \quad 0.008193-0.001577-0.101178-0.0027350 .247851-0.006193-0.2489440 .008083$

$-0.005262-0.011970-0.0108350 .002396-0.001938-0.006193 \quad 0.262861 \quad 0.035175-0.033668$

$\begin{array}{lllllllll}-0.145432 & -0.057375 & -0.120694 & 0.106701 & -0.194452 & -0.248944 & 0.035175 & 2.992974 & -0.094115\end{array}$

$\begin{array}{lllllllll}-0.016218 & -0.017823 & -0.011627 & -0.003369 & 0.006970 & 0.008083 & -0.033668 & -0.099115 & 0.162271\end{array}$

QUINTO PASSO-OERIVADAS PARCIAIS PRIM. ORDEM

$\begin{array}{lllllllll}-0.000001 & 0.000000 & -0.000002 & -0.000003 & 0.000001 & -0.000001 & 0.000001 & -0.000002 & 0.000016\end{array}$

SEXTO PASSO-VETOR GRADIENTE

$\begin{array}{lllllllll}-0.00000037 & -0.00000004 & -0.00000156 & -0.00000060 & 0.00000088 & 0.00000054 & -0.00000030 & -0.00000797 & 0.00000289\end{array}$

SETIMO PASSO-NOVAS VAR. ESPECIFICAS

$\begin{array}{lllllllll}0.450495 & 0.427079 & 0.616571 & 0.212354 & 0.380680 & 0.176746 & 0.399456 & 0.461318 & 0.231016\end{array}$


107.

APENDICE VI - Diferenciação de matrizes. 
Sejam:

$\mathrm{Y}=\left[\mathrm{y}_{\mathrm{ij}}\right]:$ matriz de variáveis de ordem pxp, tal que seus elementos são funcionalmente independentes.

$C=\left[c_{i j}\right]:$ matriz de constantes de ordem pxp •

Seja v uma das possíveis variáveis independentes de

Y. Então:

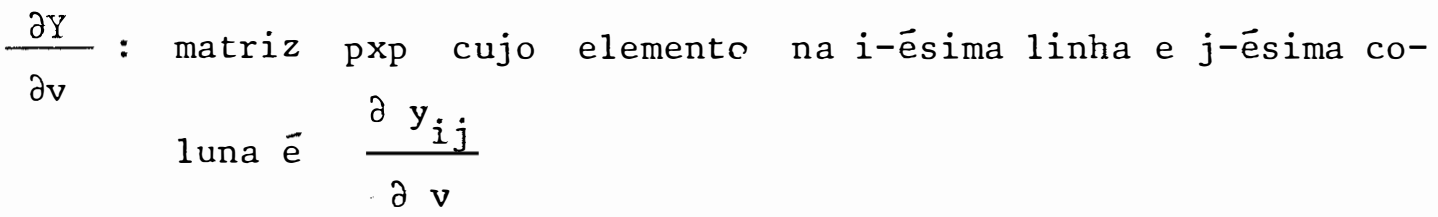

Teorema 1: Se Y é uma matriz não-singular então:

$$
\frac{\partial Y^{-1}}{\partial v}=-Y^{-1}\left(\frac{\partial Y}{\partial v}\right) Y^{-1}
$$


Prova:

$$
\begin{aligned}
& Y Y^{-1}=I \\
& Y\left(\frac{\partial Y^{-1}}{\partial V}\right)+\left(\frac{\partial Y}{\partial V}\right) Y^{-1}=\phi \\
& Y^{-1} Y\left(\frac{\partial Y^{-1}}{\partial V}\right)+Y^{-1}\left(\frac{\partial Y}{\partial V}\right) Y^{-1}=\phi \\
& \frac{\partial Y^{-1}}{\partial V}=-Y^{-1}\left(\frac{\partial Y}{\partial V}\right) Y^{-1}
\end{aligned}
$$

Teorema 2: $\left(\frac{\partial}{\partial Y}\right) \operatorname{tr}(C Y)=C^{\prime}$

Prova:

$$
\begin{aligned}
& \left(\frac{\partial}{\partial y_{i j}}\right) \operatorname{tr}(C Y)=\frac{\partial}{\partial y_{i j}} \sum_{h, k}^{p}\left(c_{h k} y_{h k}\right)=c_{j i} \\
& \text { Daí } \\
& \left(\frac{\partial}{\partial Y}\right) \operatorname{tr}(C Y)=C^{\prime}
\end{aligned}
$$


110.

Se C é simétrica, obviamente,

$$
\left(\underset{\partial Y}{\left(\frac{\partial}{Y}\right)} \operatorname{tr}(C Y)=C\right.
$$

C.Q.D.

Teorema 3: $\frac{\partial|Y|}{\partial y_{i j}}=Y_{i j}$ onde $Y_{i j j}$ é o cofator de $y_{i j} \cdot$

Prova:

$$
\begin{aligned}
& \text { Desde }|Y|=\sum_{k=1}^{p} Y_{i k} Y_{i k} \\
& \text { Então } \frac{\partial|Y|}{\partial y_{i j}}=Y_{i j}
\end{aligned}
$$

Teorema 4: Se $Y^{-1}=\left[y^{i j}\right]$, tem-se $\left(\frac{\partial}{\partial Y}\right) \log _{e}|Y|=\left(Y^{-1}\right)^{\prime}$

\section{Prova:}

$$
\left(\frac{\partial}{\partial y_{i j}}\right) \log _{e}|Y|=|Y|^{-1} \frac{\partial|Y|}{\partial y_{i j}}
$$

Usando o teorema 3:

$$
\left(\frac{\partial}{\partial y_{i j}}\right) \log _{e}|Y|=\frac{Y_{i j}}{|Y|^{-1}}
$$


Daí

$$
\left(\frac{\partial}{\partial Y}\right) \log _{e}|Y|=\left(Y^{-1}\right)^{\prime}
$$

Se C ë simétrica, obviamente,

$$
\left(\frac{\partial}{\partial Y}\right) \log _{e}|Y|=Y^{-1}
$$

Teorema 5: $\left(\frac{\partial}{\partial Y}\right) \operatorname{tr}\left(\mathrm{C} \mathrm{Y}^{-1}\right)=-\left(\mathrm{Y}^{-1} \mathrm{C} \mathrm{Y}^{-1}\right)^{\prime}$

Prova:

$$
\left(\frac{\partial}{\partial y_{i j}}\right) \operatorname{tr}\left(C Y^{-1}\right)=\operatorname{tr}\left[C\left(\frac{\partial Y^{-1}}{\partial y_{i j}}\right)\right]
$$

Usando o teorema 1

$$
\left(\frac{\partial}{\partial y_{i j}}\right) \operatorname{tr}\left(C Y^{-1}\right)=\operatorname{tr}\left[-C Y^{-1}\left(\frac{\partial Y}{\partial y_{i j}}\right) Y^{-1}\right]
$$

Da propriedade de traço de matriz

$$
\begin{aligned}
\left(\frac{\partial}{\partial y_{i j}}\right) \operatorname{tr}\left(C Y^{-1}\right) & =-\operatorname{tr}\left[Y^{-1} C Y^{-1}\left(\partial Y / \partial y_{i j}\right)\right] \\
& =-\left(Y^{-1} C Y^{-1}\right)_{i j}
\end{aligned}
$$




\section{Daí}

$$
\begin{aligned}
& \left(\frac{\partial}{\partial Y}\right) \operatorname{tr}\left(\mathrm{C} \mathrm{Y}^{-1}\right)=-\left(\mathrm{Y}^{-1} \mathrm{C} \mathrm{Y}^{-1}\right)^{\prime} \\
& \text { Se C e Y são simétricas: } \\
& (\underset{\partial Y}{\stackrel{\partial}{\longrightarrow}}) \operatorname{tr}\left(\mathrm{C} \mathrm{Y}^{-1}\right)=-\left(\mathrm{Y}^{-1} \mathrm{C} \mathrm{Y}^{-1}\right) \\
& \text { C.Q.D. }
\end{aligned}
$$

Observação: Se C e Y são simétricas, pode-se demonstrar que as derí vadas parciais com respeito a $y_{i j}(i \neq j)$ são dados por:

$$
\begin{aligned}
& \left(\frac{\partial}{\partial y_{i j}}\right) \operatorname{tr}(C Y)=2 c_{i j} \\
& \frac{\partial|Y|}{\partial y_{i j}}=2 Y_{i j} \\
& \left(\frac{\partial}{\partial y_{i j}}\right) \log |Y|=2 y^{i j} \\
& \left(\frac{\partial}{\partial y_{i j}}\right) \operatorname{tr}\left(C Y^{-1}\right)=-2\left(Y^{-1} C Y^{-1}\right)_{i j}
\end{aligned}
$$

